\title{
The Goddard Cumulus Ensemble model (GCE): Improvements and applications for studying precipitation processes
}

\author{
Wei-Kuo Tao ${ }^{\mathrm{a}, *}$, Stephen Lang a,b , Xiping Zeng ${ }^{\mathrm{a}, \mathrm{c}}$, Xiaowen $\mathrm{Li}^{\mathrm{a}}{ }^{\mathrm{a}, \mathrm{c}}$, Toshi Matsui ${ }^{\mathrm{a}, \mathrm{d}}$, Karen Mohr ${ }^{\mathrm{a}}$, \\ Derek Posselt ${ }^{\mathrm{e}}$, Jiundar Chern ${ }^{\mathrm{a}, \mathrm{c}}$, Christa Peters-Lidard ${ }^{\mathrm{f}}$, Peter M. Norris ${ }^{\mathrm{g}, \mathrm{h}}$, In-Sik Kang ${ }^{\mathrm{i}}$, \\ Ildae Choi ${ }^{\mathrm{i}}$, Arthur Hou ${ }^{\mathrm{j}}$, K.-M. Lau ${ }^{\mathrm{j}}$, Young-Min Yang ${ }^{\mathrm{i}}$ \\ a Mesoscale Atmospheric Processes Laboratory, NASA/Goddard Space Flight Center, Greenbelt, MD 20771, USA \\ b Science Systems and Applications Inc., Lanham, MD 20706, USA \\ c Goddard Earth Sciences Technology and Research, Morgan State University, Baltimore, MD 21250, USA \\ d Earth System Science Interdisciplinary Center, University of Maryland, College Park, MD 20742, USA \\ e Atmospheric, Oceanic and Space Sciences, University of Michigan, Ann Arbor, MI 48109, USA \\ ${ }^{\mathrm{f}}$ Hydrological Sciences Laboratory, NASA Goddard Space Flight Center, Greenbelt, MD, 20771, USA \\ g Global Modeling and Assimilation Office, NASA/Goddard Space Flight Center, Greenbelt, MD 20771, USA \\ ${ }^{\mathrm{h}}$ Goddard Earth Sciences Technology and Research, University Space Research Association, Columbia, MD 21044, USA \\ ${ }^{i}$ School of Earth and Environmental Sciences, Seoul National University, Seoul, Republic of Korea \\ ${ }^{\mathrm{j}}$ Earth Sciences Division, NASA/Goddard Space Flight Center, Greenbelt, MD 20771, USA
}

\section{A R T I C L E I N F O}

\section{Article history:}

Received 1 May 2013

Received in revised form 6 March 2014

Accepted 7 March 2014

Available online 15 March 2014

\section{Keywords:}

Cloud-resolving model

Cloud processes

Microphysics

Diurnal rain

Cloud aerosols

Multiscale modeling framework

\begin{abstract}
A B S T R A C T
Convection is the primary transport process in the Earth's atmosphere. About two-thirds of the Earth's rainfall and severe floods derive from convection. In addition, two-thirds of the global rain falls in the tropics, while the associated latent heat release accounts for three-fourths of the total heat energy for the Earth's atmosphere. Cloud-resolving models (CRMs) have been used to improve our understanding of cloud and precipitation processes and phenomena from micro-scale to cloud-scale and mesoscale as well as their interactions with radiation and surface processes. CRMs use sophisticated and realistic representations of cloud microphysical processes and can reasonably well resolve the time evolution, structure, and life cycles of clouds and cloud systems. CRMs also allow for explicit interaction between clouds, outgoing longwave (cooling) and incoming solar (heating) radiation, and ocean and land surface processes. Observations are required to initialize CRMs and to validate their results.

The Goddard Cumulus Ensemble model (GCE) has been developed and improved at NASA/Goddard Space Flight Center over the past three decades. It is a multi-dimensional non-hydrostatic CRM that can simulate clouds and cloud systems in different environments. Early improvements and testing were presented in Tao and Simpson (1993) and Tao et al. (2003a). A review on the application of the GCE to the understanding of precipitation processes can be found in Simpson and Tao (1993) and Tao (2003). In this paper, recent model improvements (microphysics, radiation and land surface processes) are described along with their impact and performance on cloud and precipitation events in different geographic locations via comparisons with observations. In addition, recent advanced applications of the GCE are presented that include understanding the physical processes responsible for diurnal variation, examining the impact of aerosols (cloud condensation nuclei or CCN and ice nuclei or IN) on precipitation processes, utilizing a satellite simulator to improve the
\end{abstract}

\footnotetext{
* Corresponding author at: Mesoscale Atmospheric Processes Laboratory, NASA/GSFC, Greenbelt, MD 20771, USA.

E-mail address: Wei-Kuo.Tao-1@nasa.gov (W.-K. Tao).
} 
microphysics, providing better simulations for satellite-derived latent heating retrieval, and coupling with a general circulation model to improve the representation of precipitation processes. Future research is also discussed.

Published by Elsevier B.V.

\section{Contents}

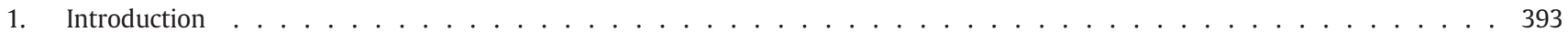

2. Model improvements . . . . . . . . . . . . . . . . . . . . . . . . . . . . . . 394

2.1. Microphysics . . . . . . . . . . . . . . . . . . . . . . . . . . . . . 394

2.1.1. Improved 3ICE bulk microphysics scheme . . . . . . . . . . . . . . . . . . . . . . . . . . 395

2.1.2. Two-moment bulk microphysics scheme . . . . . . . . . . . . . . . . . . . . . . . . . . 396

2.1.3. Improved spectral bin microphysics (SBM) scheme . . . . . . . . . . . . . . . . . . . . . . . . . . . . . . . . . 398

2.2. Radiation . . . . . . . . . . . . . . . . . . . . . . . . . . . . . . 400

2.3. Land surface model $(\mathrm{LSM}) \ldots \ldots \ldots$. . . . . . . . . . . . . . . . . . . . . . . . . 400

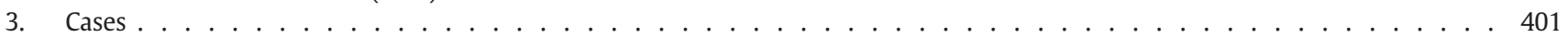

4. Advanced applications . . . . . . . . . . . . . . . . . . . . . . . . . . . . . . . . . . . . . . . 402

4.1. Diurnal variation . . . . . . . . . . . . . . . . . . . . . . . . . . . . . . . . . 402

4.1.1. A midlatitude case . . . . . . . . . . . . . . . . . . . . . . . . . . . 402

4.2. Aerosol effect . . . . . . . . . . . . . . . . . . . . . . . . . . . . . . . . . . . . 402

4.2.1. IN effect . . . . . . . . . . . . . . . . . . . . . . . . . . . . . . . . . . . 404

4.2.2. CCN effect . . . . . . . . . . . . . . . . . . . . . . . . . . . . . . . . 406

4.3. Coupling to satellite simulators . . . . . . . . . . . . . . . . . . . . . 408

4.3.1. Satellite simulator . . . . . . . . . . . . . . . . . . . . . . . . . . 408

4.3.2. Statistical analyses . . . . . . . . . . . . . . . . . . . . . . . . . . 408

4.3.3. A case study . . . . . . . . . . . . . . . . . . . . . . . . . . . . . . . . . . . . . . . . . . . . . . 413

4.4. Role in large-scale modeling . . . . . . . . . . . . . . . . . . . . . . . . . . . . . . . . . . . . . . . . . . . . 413

4.4.1. Application for the development of general circulation model (GCM) cloud parameterizations . . . . . . . 413

4.4.2. Coupling with a GCM . . . . . . . . . . . . . . . . . . . . . . . . . . . . . . . . . . . . . . . . . 413

4.4.3. Multi-scale modeling system with unified physics . . . . . . . . . . . . . . . . . . . . . . . . 415

4.5. Application for development of GCM cloud microphysics scheme . . . . . . . . . . . . . . . . . . . . . . . 417

4.6. TRMM latent heating $(\mathrm{LH})$ retrieval and $\mathrm{LH}$ products . . . . . . . . . . . . . . . . . . . . . . . . . . . . 417

5. Current and future research . . . . . . . . . . . . . . . . . . . . . . . . . . . 419

5.1. Microphysics and aerosols . . . . . . . . . . . . . . . . . . . . . . . . . 419

5.2. GPU empowered GCE model . . . . . . . . . . . . . . . . . . . . . . . . . . . . . . . . . . 420

5.3. Cloud library . . . . . . . . . . . . . . . . . . . . . . . . . . . . . . . . 421

Acknowledgments . . . . . . . . . . . . . . . . . . . . . . . . . . . . . 421

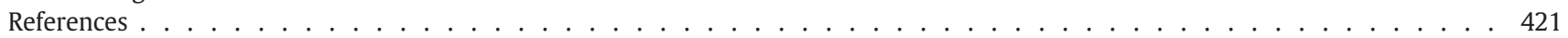

\section{Introduction}

Cloud-resolving models (CRMs) have been developed over the past four decades. They have been used to improve our understanding of cloud and precipitation processes over a range of scales from micro- to cloud- to meso- as well as their interaction with radiation, aerosol and surface processes. The basic characteristic of CRMs is that their governing equations are non-hydrostatic since the vertical and horizontal scales of atmospheric convection are similar. CRMs use sophisticated and physically realistic cloud microphysical processes at very fine spatial and temporal resolution. However, these cloud-microphysical processes (nucleation, diffusion growth and collision among cloud and precipitation particles) must be parameterized in CRMs as does atmospheric turbulence, turbulent processes at oceanic or terrestrial boundaries (latent and sensible heat fluxes into the atmosphere), and radiative transfer processes, which can be complex in the presence of clouds. These processes have to be allowed to interact explicitly with the cloud dynamics (i.e., convective draft/circulation, pressure gradient force, convectively-generated gravity waves, and cool pool). Observations are crucial for verifying model results and improving the initial and boundary conditions as well as the aforementioned physics processes.

Some of the major advantages of using CRMs include their ability to quantify the effects of each physical process upon convective events by means of sensitivity tests (e.g., by eliminating a specific process such as evaporative cooling, melting of precipitating ice particles) and their detailed dynamic and thermodynamic budget calculations. Fig. 1 shows a schematic of the main characteristics of typical CRMs. Reviews of CRMs including their history and applications can be found in Tao $(2003,2007)$ and Tao and Moncrieff (2009).

The Goddard Cumulus Ensemble model (GCE) is a CRM that has been developed and improved at NASA Goddard Space Flight Center (GSFC) over the past three decades. Its development and main features were published in Tao and Simpson 


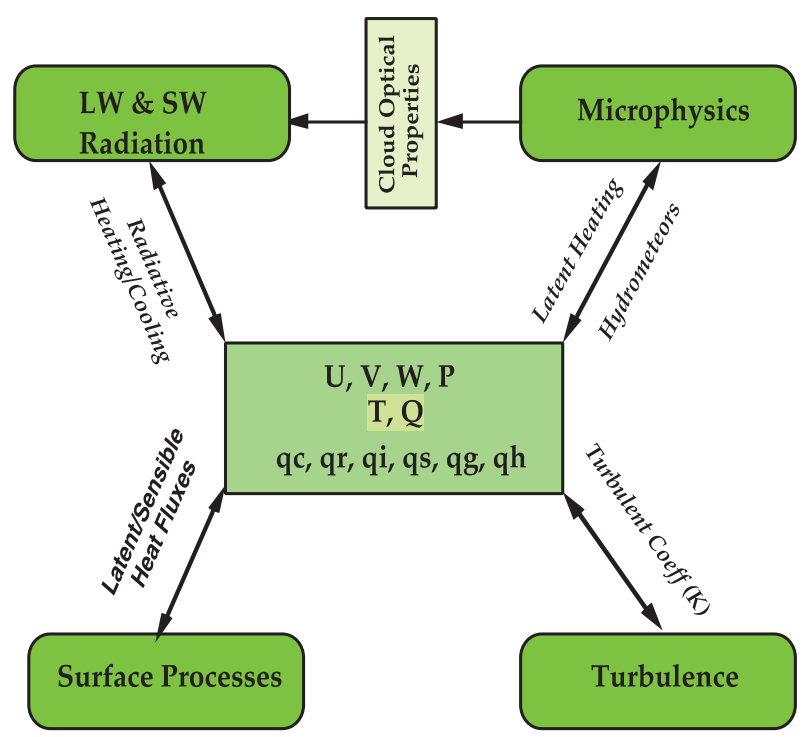

Fig. 1. Schematic diagram showing the characteristics of the cloud-resolving model. Arrows indicate a two-way interaction between different physical processes.

(1993) and Tao et al. (2003a). A review on the application of the GCE to better understand precipitation processes can be found in Simpson and Tao (1993) and Tao (2003). This paper will present the improvements to the model and its application since 2003. Improvements to the model's microphysics, radiation and land surface parameterizations and specific cases are described in Sections 2 and 3, respectively. In Section 4 recent applications of the GCE including the study of diurnal variation, aerosol effects, and satellite physical parameter retrieval as well as coupling with satellite simulators and a global model (i.e., the development of a multi-scale modeling system with unified physics) to study precipitation processes are presented. The summary and future model developments are presented in Section 5.

\section{Model improvements}

The 3D version of the GCE is typically run using $256 \times 256$ up to $1024 \times 1024$ horizontal grid points at $1-2 \mathrm{~km}$ resolution or finer. The model was also recently enhanced to simulate the impact of atmospheric aerosol concentrations on precipitation processes and the impact of land and ocean surface processes on convective systems in different geographic locations (Tao and Simpson, 1984, 1989; Tao and Soong, 1986; Tao et al., 1991, 1993, 1996, 2003b, 2004, 2007; Lang et al., 2003; Johnson et al., 2007; Li et al., 2009a; Zeng et al., 2007, 2009a,b; Shen et al., 2011, 2014; Ping et al., 2013 and many others). The GCE has also been coupled with the Goddard Satellite Data Simulator Unit (G-SDSU), which allows us to scrutinize the performance of the microphysics by analyzing discrepancies between the simulated and observed radiances from remote sensing measurements (Matsui et al., 2009; Li et al., 2010). A message passing interface (MPI) version of the GCE was developed (Juang et al., 2007) and can be run on many different platforms using any number of CPUs. Table 1 shows the main characteristics of the GCE.
Table 1

Characteristics of the Goddard Cumulus Ensemble model.

\begin{tabular}{|c|c|}
\hline $\begin{array}{l}\text { Parameters/ } \\
\text { processes }\end{array}$ & GCE \\
\hline Dynamics & $\begin{array}{l}\text { Anelastic or compressible } \\
\text { 2D (slab- and axis-symmetric) and 3D }\end{array}$ \\
\hline Vertical coordinate & $\mathrm{z}$ \\
\hline Microphysics & $\begin{array}{l}\text { 2-Class water \& 3-class ice (graupel or hail as the } \\
\text { 3rd class) } \\
\text { 2-Class water \& 4-class ice } \\
\text { Two moment 2-class water \& 3-class ice } \\
\text { Two moment 2-class water \& 4-class ice (RAMS) } \\
\text { Spectral bin microphysics }\end{array}$ \\
\hline Numerical methods & $\begin{array}{l}\text { Positive definite advection for scalar variables } \\
4 \text { th-order for dynamic variables }\end{array}$ \\
\hline Initialization & $\begin{array}{l}\text { Initial conditions with forcing from observations/ } \\
\text { large-scale models }\end{array}$ \\
\hline Radiation & $\begin{array}{l}\text { k-Distribution and four-stream discrete-ordinate } \\
\text { scattering ( } 8 \text { bands) } \\
\text { Explicit cloud-radiation interaction }\end{array}$ \\
\hline Sub-grid diffusion & $\begin{array}{l}\text { TKE }(1.5 \text { order }) \\
\text { Dynamic ( } 1 \text { st order })\end{array}$ \\
\hline $\begin{array}{l}\text { Surface energy } \\
\text { budget }\end{array}$ & $\begin{array}{l}\text { Land Information System (LIS) } \\
\text { 7-Layer soil model (PLACE) } \\
\text { TOGA COARE flux module }\end{array}$ \\
\hline Parallelization & OPEN-MP and MPI \\
\hline
\end{tabular}

The GCE has been used to understand the following ${ }^{1}$ :

- The role of the water and energy cycles in the tropical climate system,

- The redistribution of ozone and trace constituents by individual clouds and well-organized convective systems over various spatial scales,

- The relationship between the vertical distribution of latent heating ( $\mathrm{LH}$, phase changes of water), surface rainfall and the large-scale (pre-storm) environment,

- Climate hypotheses of deep convection related to global warming,

- Precipitation processes (i.e., precipitation efficiency),

- The aerosol impact on precipitation and rainfall in different environments,

- The impact of surface process on precipitation and rainfall,

- The assumptions used in the representation of cloud and convective processes in climate and general circulation models, and

- The representation of cloud microphysical processes and their interaction with radiative forcing over tropical and midlatitude regions.

The following sub-sections present the recent improvements in microphysics, radiation and land surface modules.

\subsection{Microphysics}

The GCE model's bulk microphysical schemes are based on Lin et al. (1983) and Rutledge and Hobbs (1984). Modifications have been made to reduce the over-estimated and unrealistic amount of graupel in the stratiform region (Lang et al., 2007), to better address saturation issues (Tao et al., 2003a) and to obtain more realistic ice water contents for longer-term

\footnotetext{
1 More than 150-refereed papers using the GCE have been published in the last three decades.
} 


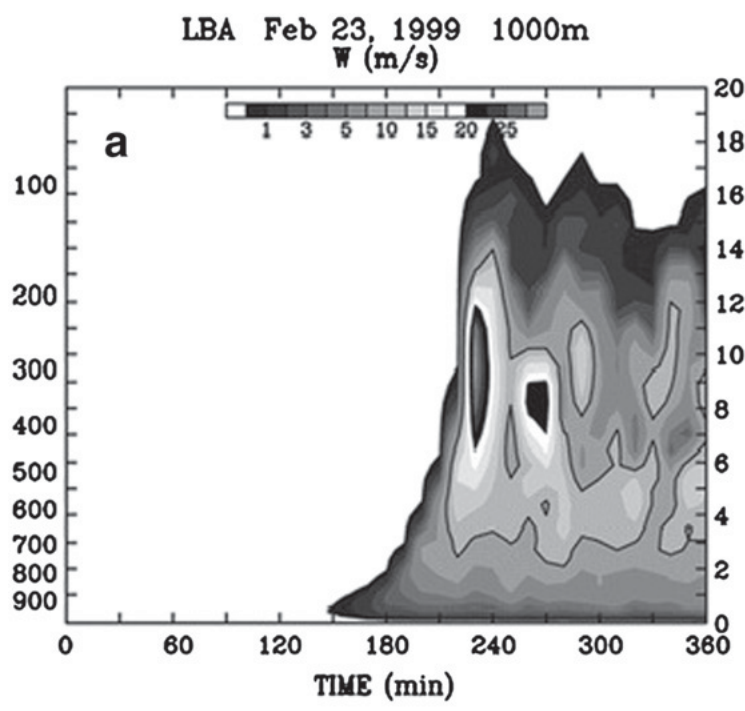

LBA Feb 23, 1999 1000m

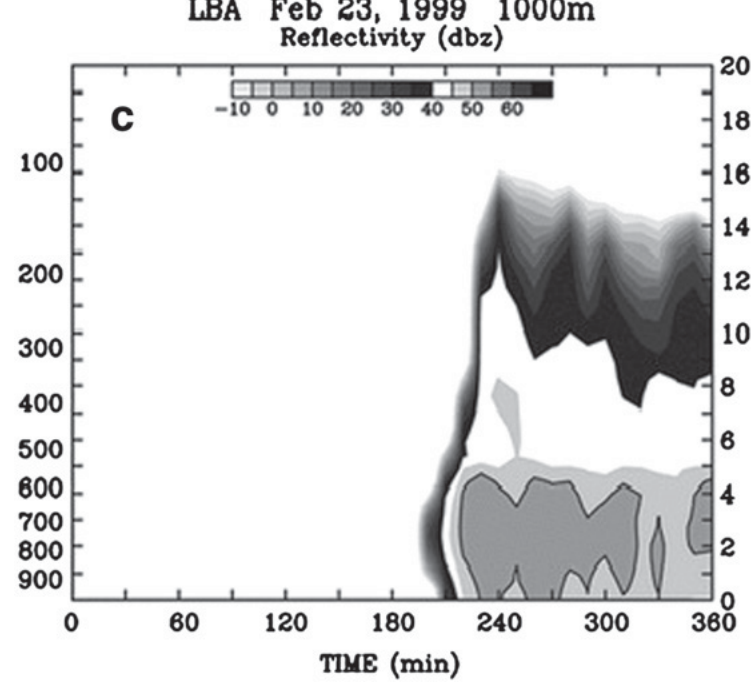

LBA Feb 23, 1999 250m

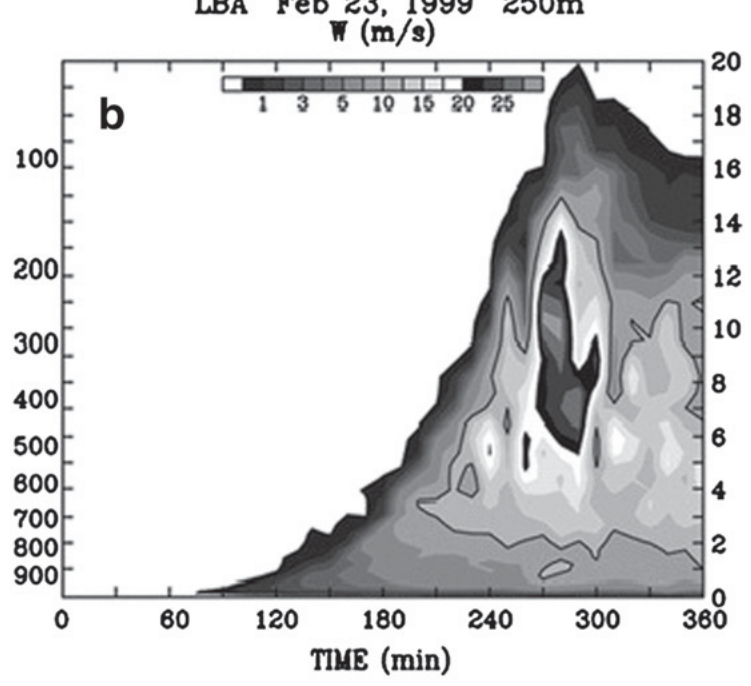

LBA Feb 23, $1999250 \mathrm{~m}$ Reflectivity (dbz)

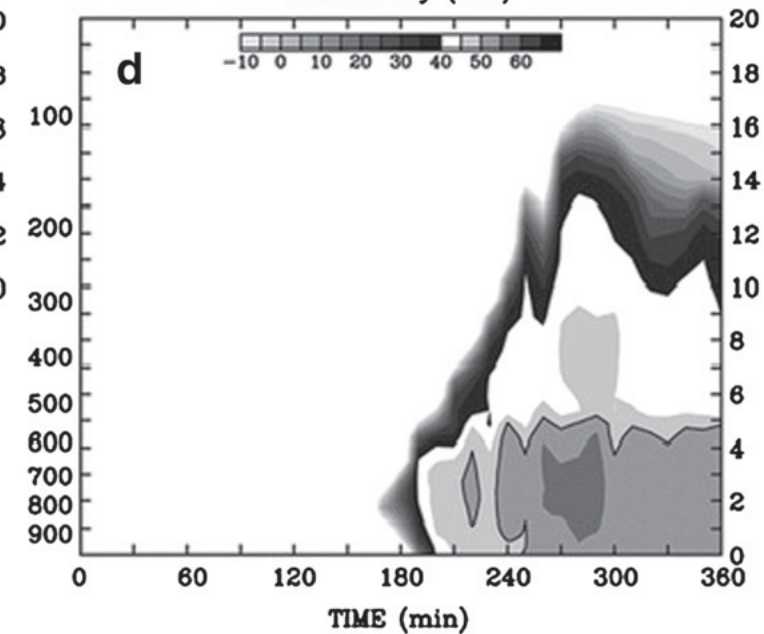

Fig. 2. Time-height cross sections obtained from the 23 Feb 1999 simulations of maximum (a) vertical velocity using 1-km horizontal grid spacing, (b) vertical velocity using 250-m horizontal spacing, (c) reflectivity using 1-km horizontal spacing, and (d) reflectivity using 250-m horizontal spacing.

Figure adapted from Lang et al. (2007).

simulations (Zeng et al., 2008). Lang et al. (2011) further modified the 3ICE scheme to reduce an overabundance of excessively high reflectivity values aloft. Recently, the GCE was adapted to interface with the single and double moment versions of the Colorado State University Regional Atmospheric Modeling System (RAMS) bulk microphysics scheme (Meyers et al., 1997; Saleeby and Cotton, 2004) as well as the spectral bin microphysics (SBM) scheme of the Hebrew University Cloud Model (Khain et al., 2004; Tao et al., 2007; Li et al., 2009a,b). Details of these improvements will be discussed in the following sub-sections.

\subsubsection{Improved 3ICE bulk microphysics scheme}

Lang et al. (2007) showed that more realistic diurnal convective growth was achieved by reducing the horizontal grid spacing from 1000 to $250 \mathrm{~m}$. This produced a gradual transition from shallow to deep convection that occurred over a span of hours as opposed to an abrupt appearance of deep convection in the coarse (i.e., $1000 \mathrm{~m}$ ) resolution simulation
(Fig. 2). In addition, eliminating the dry growth of graupel in the bulk microphysics scheme effectively reduced the unrealistic presence of graupel in the simulated anvil. However, comparisons with radar reflectivity data using contoured-frequencywith-altitude diagrams (CFADs) revealed that the resulting snow contents were too large. The excessive snow was reduced primarily by lowering the collection efficiency of cloud water by snow and resulted in further agreement with the radar observations (Fig. 3). The transfer of cloud-sized particles to precipitation-sized ice appears to be too efficient in the original scheme. Overall, these changes to the microphysics lead to more realistic precipitation ice contents in the model. In addition, the improved precipitation-sized ice signature in the model simulations lead to better latent heating retrievals as a result of both better convective-stratiform separation within the model as well as more physically realistic hydrometeor profiles for radiance calculations for remote sensing applications.

The performance of the GCE bulk microphysics scheme was further improved by reducing the bias in over penetrating 

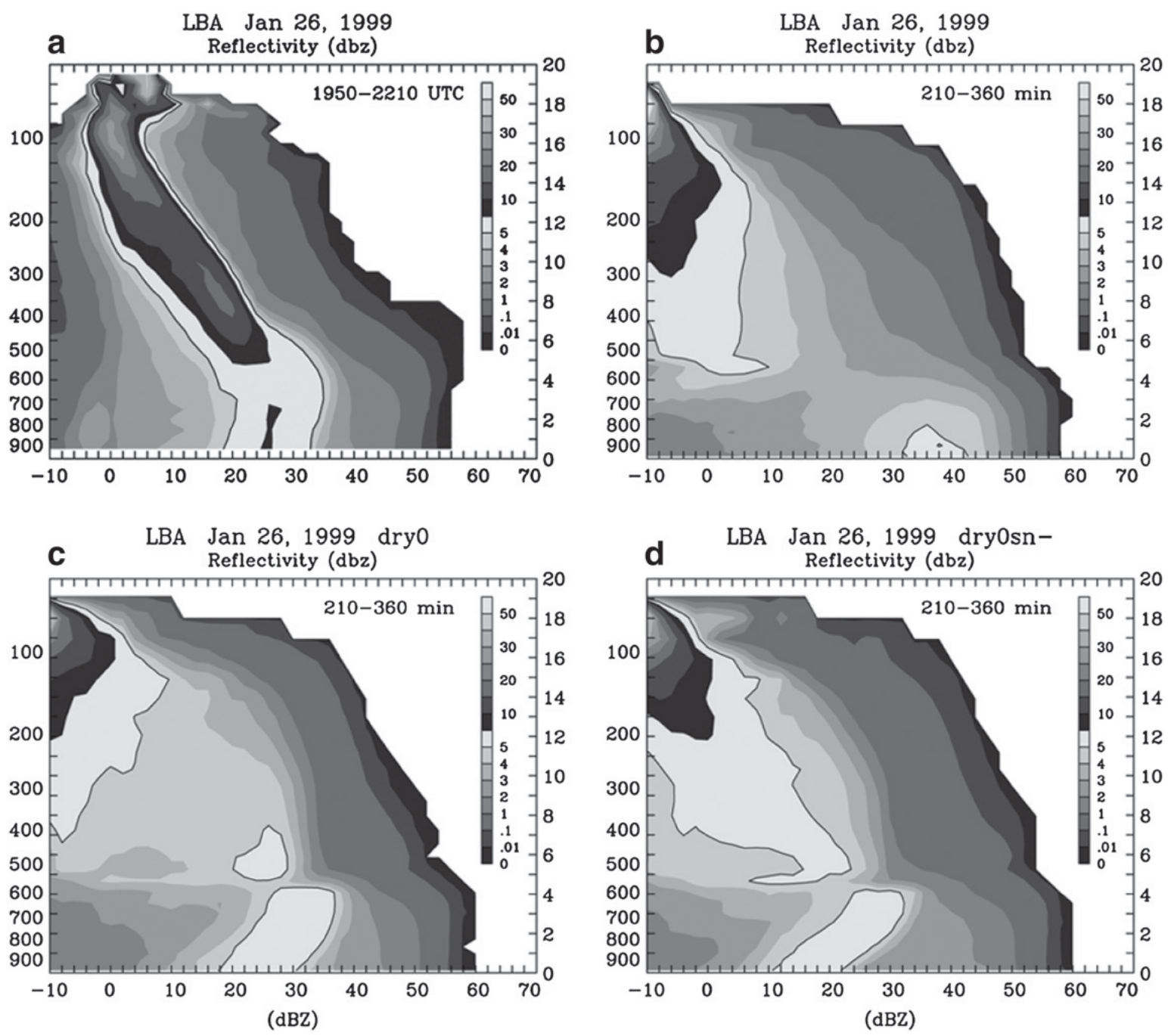

Fig. 3. Contoured-frequency-with-altitude diagrams of radar reflectivity (a) observed from S-pol ground-based radar and simulated with the 3D GCE using (b) the original microphysics, (c) the original microphysics with no dry growth of graupel and (d) the original microphysics with no dry growth of graupel and reduced snow collection efficiencies for the 26 January 1999 LBA case over Amazonia.

Figure adapted from Lang et al. (2007).

40-dBZ echoes at higher altitudes (Fig. 4), which is due mainly to excessively large contents and/or sizes of graupel particles at those altitudes (Lang et al., 2011). This also improved the overall model reflectivity probability distribution (i.e., CFADs). These improvements were achieved by systematically evaluating and improving individual ice processes in the bulk scheme such as: (1) accounting for relative humidity and mean cloud ice mass in the Bergeron process for snow, (2) adding a simple Hallett-Mossop rime splintering parameterization, (3) replacing the Fletcher curve, which determines the number of active ice nuclei (IN) as a function of temperature, with the Meyers et al. (1992) curve, which determines the active IN as a function of ice supersaturation, in the cloud ice nucleation, depositional growth and Bergeron growth parameterizations, (4) relaxing the saturation scheme to allow for ice supersaturation, (5) adding two additional parameterizations for contact nucleation and immersion freezing, (6) including cloud ice fall speeds, (7) allowing graupel and snow to sublimate (the original Rutledge and Hobbs scheme only allows graupel and snow deposition but not sublimation), and (8) mapping the snow and graupel intercepts (effectively the mean snow and graupel particle diameters) as functions of temperature and mass.

The Goddard microphysics schemes have been implemented into the University of Oklahoma Advanced Regional Prediction System (ARPS), Fifth-Generation Penn State/NCAR Mesoscale Model (MM5) and NCAR Advanced Research Weather Research and Forecasting model (ARW). The performance of these schemes has also recently been tested in various types of cloud and precipitation systems with good agreement with observations (Merino et al., 2014; Vich et al., 2011; Van Weverberg et al., 2011; García-Ortega et al., 2012 and others).

\subsubsection{Two-moment bulk microphysics scheme}

The Colorado State University Regional Atmospheric Modeling System (RAMS) two-moment bulk cloud microphysical scheme (Meyers et al., 1997; Cotton et al., 2003; Saleeby and Cotton, 2004, 2008; Lee et al., 2009) has been implemented in the GCE model. The RAMS scheme assumes a gamma-shaped 

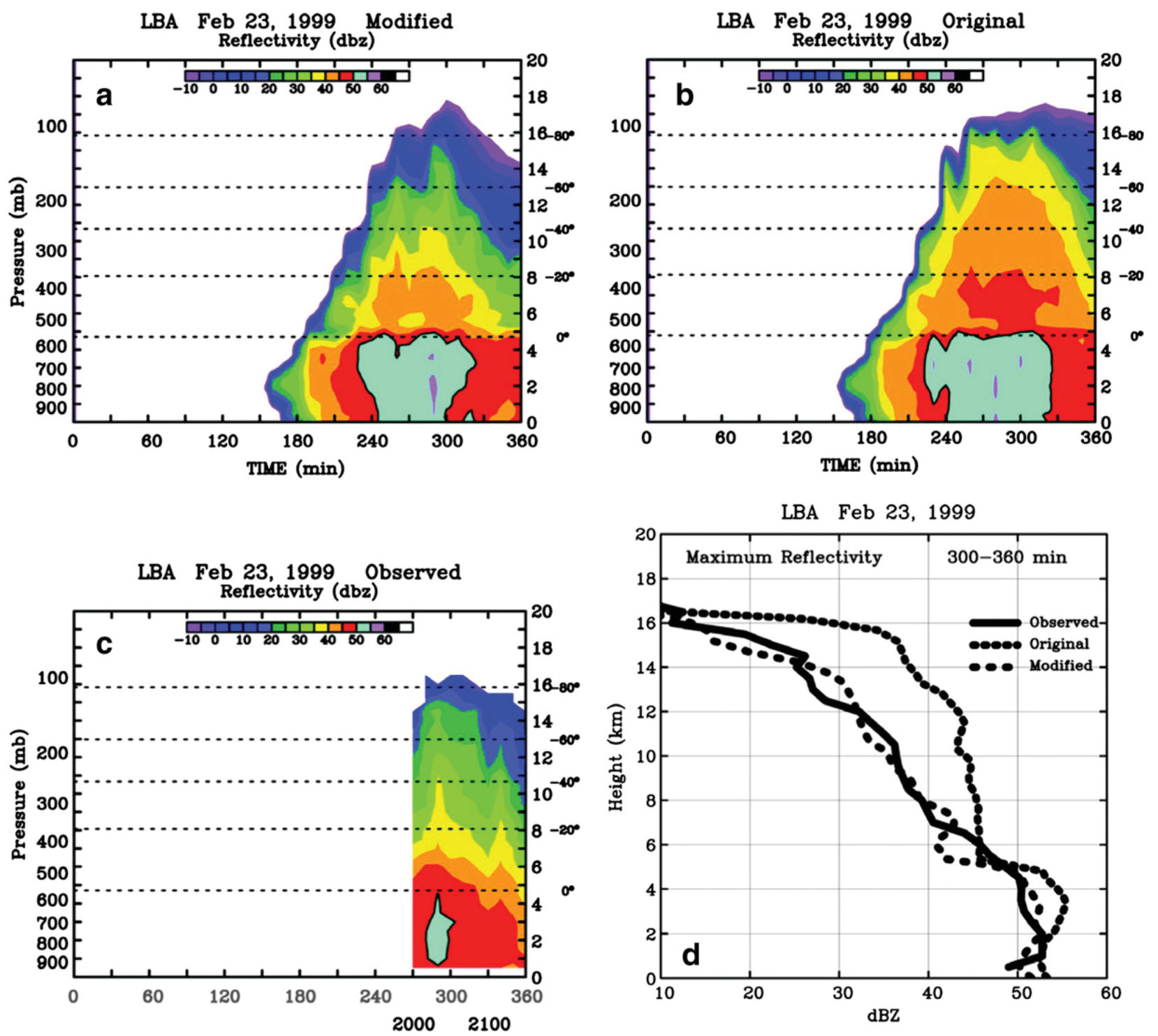

Fig. 4. Time-height cross sections of maximum radar reflectivity for the 23 Feb 1999 case simulated using (a) the modified Goddard microphysics scheme and (b) the original Goddard microphysics scheme, and observed by (c) ground-based radar and (d) vertical profiles of the maximum reflectivities extracted from the observations and the last $60 \mathrm{~min}$ of the simulations. Model data were taken from a $64 \times 64 \mathrm{~km}^{2}$ subdomain. Right axes in (a)-(c) are heights (km), horizontal dashed lines show the level of indicated environmental temperatures $\left({ }^{\circ} \mathrm{C}\right)$. Black labels at the bottom of $(\mathrm{c})$ are UTC times while gray labels indicate approximate matching model time.

Figure adapted from Lang et al. (2011).

particle size distribution for three species of liquid (small and large cloud droplets and rain) and five species of ice (small and large vapor grown crystals, aggregates, graupel, and hail). Ice crystal habit is allowed to vary as a function of temperature and humidity. Consistent with observations of a bimodal cloud droplet size distribution, the cloud droplet spectrum is decomposed into two modes, one for droplets 1 to $40 \mu \mathrm{m}$ in diameter, and the second for droplets 40 to $80 \mu \mathrm{m}$ in diameter. The Goddard radiation scheme (Chou and Suarez, 1999; Chou et al., 2001) fully interacts with all eight-cloud species and accounts for changes in cloud particle size distributions as cloud systems develop and evolve. Collection is simulated using stochastic collection equation solutions, facilitated by bin-emulating look-up tables, rather than by continuous accretion approximations. The philosophy of bin representation of collection is extended to calculations of drop sedimentation and riming. Concentrations of aerosol species serve as prognostic variables in the RAMS microphysics and are used to determine cloud droplet concentration.

Fig. 5 depicts a comparison between observed and GCEsimulated IR and microwave (MW) brightness temperatures for two different assumed background cloud condensation nuclei ( $\mathrm{CCN}$ ) concentrations: pristine and continental following the method outlined in Matsui et al. (2009). In addition to the brightness temperature-echo top height histograms, the cumulative frequency distribution of the $85 \mathrm{GHz}$ brightness temperature is computed for each cloud type. The simulation run in the pristine environment produced a higher fraction of deep clouds relative to the simulation run in the polluted environment. In addition, the fraction of congestus and mid-cold clouds was 


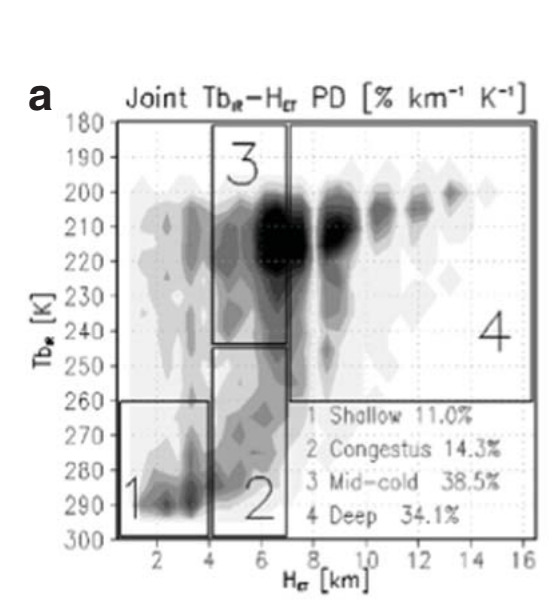

\section{Low CCN}

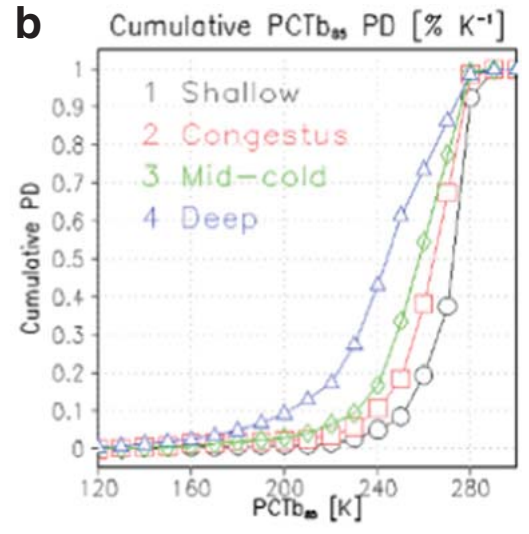

\section{High CCN}
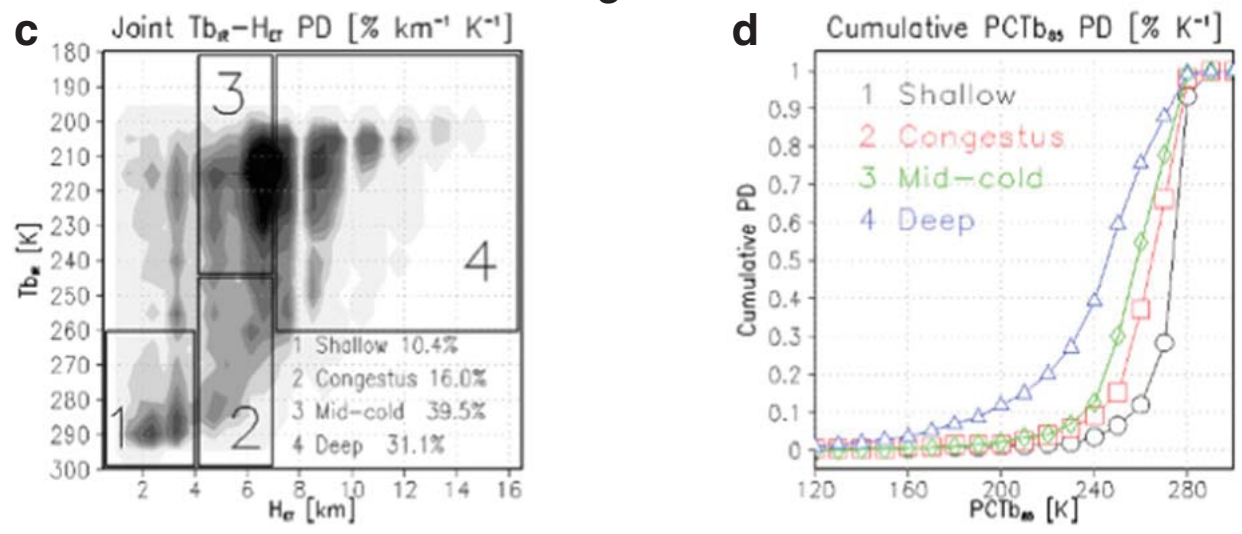

Fig. 5. Output from the TRMM three-step evaluation framework (Matsui et al., 2009) for a GCE simulation with a clean environment (50 cm - 3 CCN, a and b), and a continental environment ( $1000 \mathrm{~cm}-3 \mathrm{CCN}, \mathrm{c}$ and d). The left panels are the two dimensional (joint) frequency distribution of TRMM echo top height (abscissa) and $11 \mu \mathrm{m}$ brightness temperature (ordinate). The right panels are the cumulative frequency distribution of $85 \mathrm{GHz}$ brightness temperature for each of the four cloud types.

slightly higher in the high-CCN simulation than in the low-CCN run. The high-CCN simulation also exhibits a slightly greater frequency of relatively low $85 \mathrm{GHz}$ brightness temperature for congestus, mid-cold, and deep clouds. This implies the presence of a larger concentration of relatively large precipitating ice particles in the high-CCN run than in the low-CCN run - a result consistent with a larger concentration of super-cooled liquid droplets available for riming and vapor growth of ice particles (Wegener-Bergeron-Findeisen process) associate with higher CCN concentration.

\subsubsection{Improved spectral bin microphysics (SBM) scheme}

The SBM includes the following processes: (1) nucleation of droplets and ice particles (Pruppacher and Klett, 1997; Meyers et al., 1992), (2) immersion freezing (Vali, 1994), (3) contact freezing (Meyers et al., 1992), (4) ice multiplication (Hallet and Mossop, 1974; Mossop and Hallet, 1974), (5) detailed melting (Khain et al., 2004), (6) condensation/ evaporation of liquid drops (Pruppacher and Klett, 1997; Khain et al., 2000), (7) deposition/sublimation of ice particles (Pruppacher and Klett, 1997; Khain et al., 2000), (8) drop/drop, drop/ice, and ice/ice collision/coalescence (Pruppacher and Klett, 1997; Pinsky et al., 2001), (9) turbulence effects on liquid drop collisions (Pinsky et al., 2000), and (10) collisional breakup (Seifert and Beheng, 2001; Seifert et al., 2005). In the first process, both condensation-freezing and homogeneous nucleation are considered. The Meyers' formula is applied in a semi-Lagrangian approach (see Khain et al., 2000). The concentration of newly nucleated ice crystals at each time step is calculated by the increase in the value of super-saturation. Sedimentation of liquid and ice particles is also considered. SBM are specially designed to take into account the effect of atmospheric aerosols on cloud development and precipitation formation. The activation of aerosols in each size bin is explicitly calculated in this scheme (Khain et al., 2000). This added level of sophistication will improve our understanding of microphysical processes and positively influence the development of NASA Tropical Rainfall Measurement Mission (TRMM) and Global Precipitation Measurement (GPM) rain/ snowfall retrieval algorithms.

The bulk-microphysics drop size distribution (DSD) assumptions have been evaluated against explicitly-simulated DSDs using the SBM scheme, because SBM simulations yield much more realistic radar echo profiles than the bulk one-moment microphysics (Fig. 6, Li et al., 2009a). The results suggest that SBM-simulated DSDs are more dependent on temperature than mass mixing ratio. In addition, the numerical results are in good agreement with observations, indicating that the microstructure 

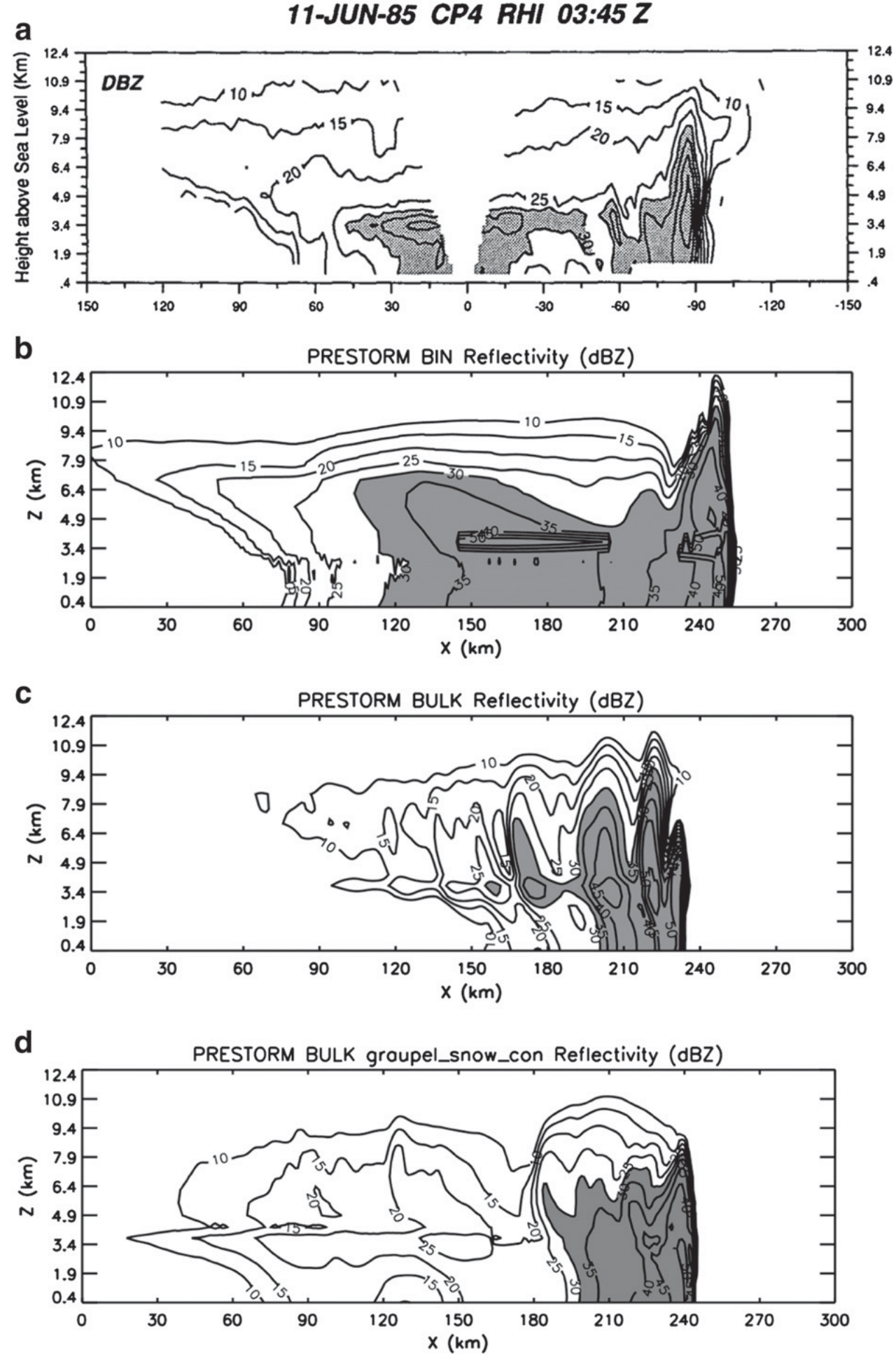

Fig. 6. C-band radar reflectivity observed (a) and simulated (b), (c) and (d) for a PRESTORM case study. The shaded areas indicate radar reflectivity higher than 30 dBZ. (b) Uses the bin microphysical scheme, (c) the original bulk scheme, and (d) the improved bulk scheme where rain evaporation overestimation is corrected according to the bin scheme and the graupel density and fall speed are reduced.

of clouds depends strongly on cloud-aerosol interactions (Tao et al., 2007; Li et al., 2009a,b, 2010).

The SBM have also been used to improved bulk schemes. For example, the raindrop size distribution assumption in the bulk microphysical scheme artificially enhances the rain evaporation rate since smaller raindrops evaporate faster than larger ones. The cooling produced by rain evaporation largely determines the cool pool strength, which is crucial for storm regeneration and propagation (e.g., Rotunno et al., 1988). In the bulk simulation shown in Li et al. (2009a), the 
strong cold pool circulation dominates the near-surface environmental wind shear, producing pulsating updraft cores that tilt rearward and propagate into the stratiform region. This is in contrast to the near-balance between the cold pool and the wind shear simulated in the bin scheme, which results in upright, steady updraft cores and a homogeneous stratiform region. Rain evaporation in the bulk scheme is reduced according to an empirical formula derived from the bin scheme (Li et al., 2009b); the resulting radar reflectivity agrees better with both the observations and the bin simulation.

\subsection{Radiation}

Goddard long- and short-wave radiative transfer processes (Chou and Suarez, 1999; Chou et al., 2001) are used in the GCE model. In the Goddard radiative transfer parameterizations, gaseous absorption is estimated from a k-distribution method in eight bands for solar and eight bands in infrared (IR). Pre-computed Mie tables determine the single-scattering properties of aerosols and hydrometeor species, and a two-stream adding method is used to solve for the radiative transfer in each band. Thus, for a given atmospheric column, profiles of atmospheric radiative heating rate and longwave and shortwave fluxes are obtained to update the atmospheric temperature in the column, diagnose the top-of-the-atmosphere (TOA) energy budget, and provide bottom-of-the-atmosphere (BOA) radiation fluxes to a land-surface model. The code is implemented via a 1-dimensional driver to skip nighttime computation and further developed to add a pre-computed look-up table that accounts for $\mathrm{CO}_{2}$ absorption. Table 2 shows the main characteristics of both the long- and short-wave radiative transfer modules. A comparison with line-by-line radiative code is also shown.

The use of a fully explicit microphysics scheme (with size distributions of liquid and ice) and a fine horizontal resolution can provide relatively realistic cloud optical properties, which are crucial for determining the radiation budgets and diurnal variation of precipitation processes. With high spatial resolution, each atmospheric layer is considered either completely cloudy (overcast) or clear. No partial cloudiness as well as overlap assumption is needed. In addition, the definition of cloud is based on small cloud optical depth (0.0001) to count for thin cloud. The ice cloud effective radius $(25-125 \mu \mathrm{m})$ depends on ambient temperature. Effective radius for precipitation particles (rain, aggregate, graupel) is also considered. Please see Tao et al. (2003a) for details on the cloud optical properties (calculations).

\subsection{Land surface model (LSM)}

Over land, coupled modeling experiments from convectivescale to mesoscale have demonstrated that uncoupled experiments may lead to an inaccurate understanding of the water and energy cycle due to the lack of feedback processes such as entrainment at the top of the boundary layer associated with surface turbulent heat fluxes (Pielke, 2001; Ek and Holtslag, 2004; Santanello et al., 2009). The GCE model has been coupled with the Parameterization for Land-Atmosphere-Cloud Exchange (PLACE). Developed at Goddard by Wetzel and Boone (1995), PLACE is a surface-vegetation-atmosphere transfer scheme (SVATS) that consists of linked process models (e.g., net radiation, evapotranspiration, ground heat storage), emphasizing the vertical transport of moisture and energy through a 5 layer soil moisture and 7 layer soil temperature column to the overlying heterogeneous land surface. The exchange of radiation, heat, momentum, and moisture fluxes between the GCE and PLACE models permits the study of convective-scale land surface-atmosphere feedbacks. GCE-PLACE has been used to study the initiation of landscape-generated (Lynn et al., 1998; Lynn and Tao, 2001) and sea breeze-generated (Baker et al., 2001) deep convection and the sensitivity of West African convective line development to land surface conditions (Mohr et al., 2003; Alonge et al., 2007). The details of the GCE-PLACE coupling can be found in Tao et al. (2003a).

In order to study the sensitivity of various land-surface models (LSMs) and land-surface data assimilation, the GCE model has been coupled with the multi-model Goddard Land Information System (LIS). LIS is a scalable land data assimilation system that integrates a suite of advanced LSMs, high resolution satellite and observational data, data assimilation and parameter optimization techniques, and high performance computing tools (Kumar et al., 2006; Peters-Lidard et al., 2007). LIS can be used in two different modes: (1) an analysis or uncoupled mode and (2) a coupled mode. In the analysis mode, LIS can be used to generate high-resolution land surface initial conditions. Land surface fields typically require long integrations to reach thermodynamic equilibrium with the meteorology and the ability to conduct multiyear "spinup" integrations becomes important in generating accurate initial conditions consistent with the prescribed meteorological conditions. In the coupled mode, LIS directly interacts with the GCE model by acting as the land surface component, encapsulating several community LSMs and the broad set of data and

Table 2

Major characteristics of the Goddard radiation module.

\begin{tabular}{|c|c|c|}
\hline Wavelength & SW (solar) & LW (thermal) \\
\hline Flux solution & Two-stream adding method & Schwarzchild equation \\
\hline \multirow{2}{*}{ Number of bands } & UV\&PAR ( 8 bands) & 10 bands \\
\hline & Solar-IR ( 3 bands) & \\
\hline Optical approximation & $\begin{array}{l}\text { Delta-Eddington approximation (for scattering and } \\
\text { transmission) }\end{array}$ & $\begin{array}{l}\text { Henyen-Greenstein function (for scattering), One/ } \\
\text { two-parameter scaling, modified k-distribution (for absorption) }\end{array}$ \\
\hline Optical parameters & $\begin{array}{l}\mathrm{H}_{2} \mathrm{O}, \mathrm{O}_{2}, \mathrm{O}_{3}, \mathrm{CO}_{2} \text {, condensates (cloud water, cloud ice, snow, } \\
\text { rain, and graupel/hail), aerosols (sulfate and precursors, dust, } \\
\text { black carbon, organic carbon, sea salt) }\end{array}$ & $\begin{array}{l}\mathrm{H}_{2} \mathrm{O}, \mathrm{O}_{3}, \mathrm{CO}_{2} \text {, trace gasses }\left(\mathrm{N}_{2} \mathrm{O}, \mathrm{CH}_{4}, \mathrm{CFC} 11, \mathrm{CFC} 12, \mathrm{CFC} 22\right) \text {, } \\
\text { condensates (cloud water, cloud ice, snow, rain, and graupel/ } \\
\text { hail), aerosols (sulfate and precursors, dust, black carbon, organic } \\
\text { carbon, sea salt), }\end{array}$ \\
\hline Accuracy & $\begin{array}{l}\text { Heating rate error within } 5 \% \text { accuracy in comparison with a } \\
\text { LBL model. }\end{array}$ & Cooling rate error within $0.4 \mathrm{~K} /$ day in comparison with a LBL model. \\
\hline
\end{tabular}


hydrological data assimilation infrastructure. The data handling components in LIS enable the direct use of high-resolution satellite and observational data streams for modeling. Thus, the use of LIS enables the consistent use of the same physical schemes in the generation of initial conditions as in the coupled mode.

Fig. 7 shows an example of the effect of surface fluxes on clouds using GCE-LIS. In that case, CRM simulations were carried out using surface energy/water fluxes from LIS as well as the observed surface fluxes from the Atmospheric Radiation Measurement (ARM) Program's Southern Great Plains (SGP) site over the Great Plains, respectively (Zeng et al., 2007). The results were compared with radar observations to exhibit the effects of surface fluxes on clouds. The values from LIS and the ARM-SGP data were different from days 4 to 9 and led to differing cloud fractions during that period, indicating an effect of surface fluxes on clouds. When the modeled cloud fractions were contrasted against the observations, the coupled LIS run brought about a better cloud simulation than the simulation with the ARM-SGP data because LIS has better temporal resolution than the ARM-SGP data.

\section{Cases}

The GCE model was extensively used to study tropical convection and its relation to the large-scale environment during the past three decades. Typically, the large-scale effects derived from observations are imposed into the model as the main forcing. When the imposed large-scale advective forcing cools and moistens the environment, the model responds by producing clouds through condensation and deposition. The fall out of large precipitation particles produces rainfall at the surface. The larger the advective forcing, the larger the microphysical response (rainfall) the model can produce (Soong and Ogura, 1980; Soong and Tao, 1980; Tao and Soong, 1986; Tao et al., 1987). On the other hand, the model will not produce any cloud or rainfall when the imposed large-scale advective forcing heats and dries the atmosphere. The model, however, needs to use cyclic lateral boundary conditions to ensure that there is no additional heat, moisture or momentum forcing inside the domain apart from the large-scale forcing. The model also requires a large horizontal domain to allow for the existence of an ensemble of clouds/cloud systems of different sizes in various stages of their lifecycles. This approach also allows the GCE model to be used to conduct multi-day up to multi-week integrations (e.g., Zeng et al., 2007, 2013; Lee et al., 2010; Tao et al., 2010). In these longer-term integrations, the model has performed reasonably well in terms of rainfall (Table 3), latent heat and moisture budget structure (Fig. 8) compared to observations when driven by observed large-scale forcing derived from sounding networks. In addition, the model results can provide cloud statistics that represent different types of clouds/cloud systems during their lifetime (life cycle). This type of cloud-resolving modeling was used in many modeling studies to study convective systems during the Global Atmospheric Research Program (GARP) Atlantic Tropical Experiment (GATE), the Tropical Oceans Global Atmosphere (TOGA) - Coupled Ocean Atmosphere Response Experiment
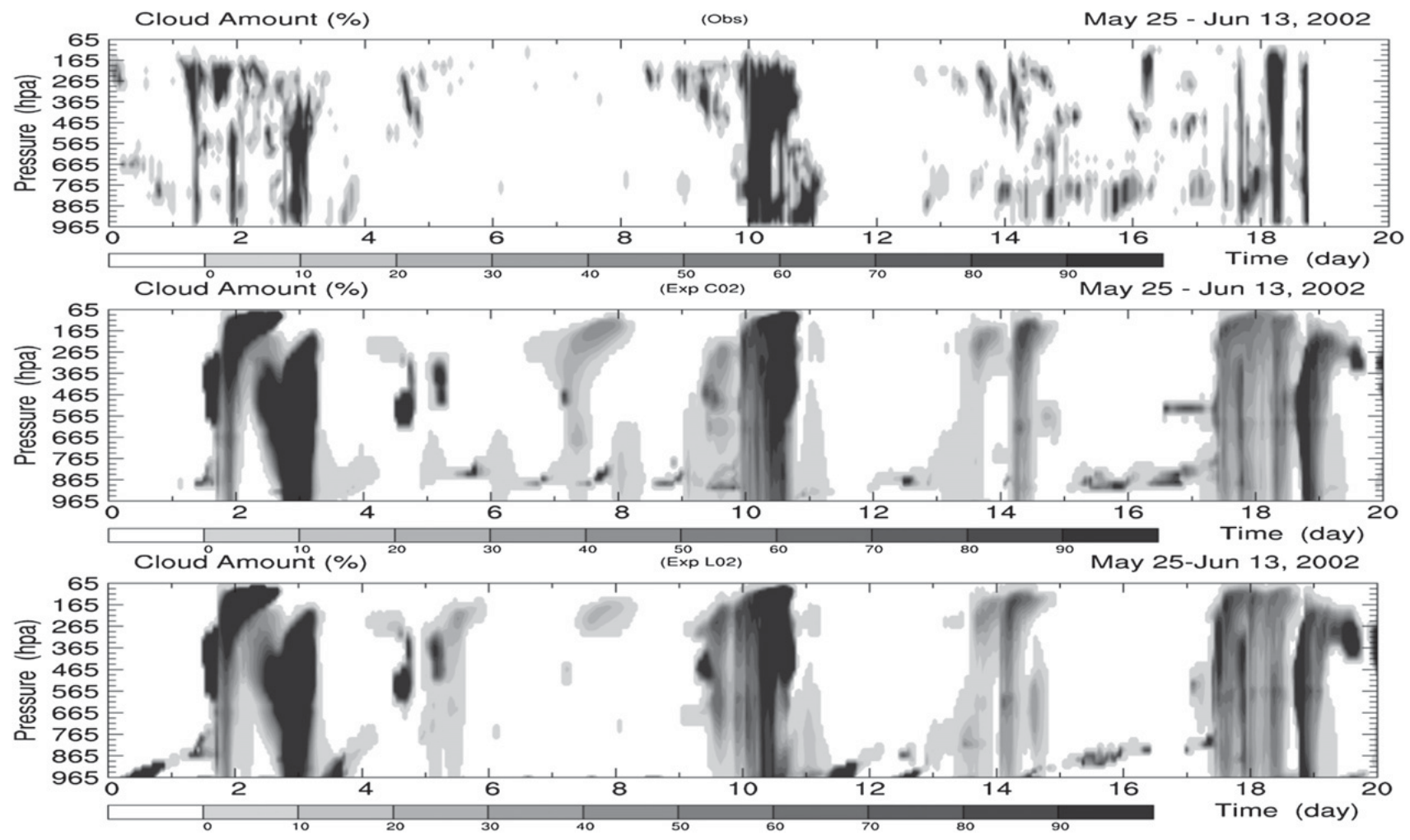

Fig. 7. Time-pressure cross sections of observed (top) and modeled cloud fraction with the surface fluxes from the ARM observations (middle) and LIS land data assimilation system (bottom) starting from 2030 UTC 25 May 2002. 
Table 3

CRM-simulated rainfall amount and stratiform \% for SCSMEX (1998), ARM (1997, 2002), TOGA COARE (1992) and GATE (1974).

\begin{tabular}{lrlr}
\hline & Simulated rainfall amount (mm/day) & Stratiform rain percentage (\%) & Estimated rainfall amount (mm/day) \\
\hline SCSMEX & 12.31 & 42.6 & 11.35 \\
ARM (1997) & 4.31 & 41.3 & 4.32 \\
ARM (2002) & 4.85 & 36.0 & 4.77 \\
TOGA COARE (1992-1993) & 7.72 & 47.6 & 9.32 \\
GATE (1974) & 10.56 & 41.4 & 11.38 \\
\hline
\end{tabular}

(COARE), the South China Sea Monsoon Experiment (SCSMEX), and around the Department of Energy (DOE)/ARM sites and others (see a review by Tao, 2003 and Tao and Moncrieff, 2009; and Fig. 9).

In addition, the GCE model has been used to simulate the evolution of clouds/cloud systems over periods of hours. The initiation (or triggering) of convection is the primary issue with cold pools, surface fluxes or stochastic perturbation used to excite locally-forced convection. Such simulations are very useful for model development especially when conducted in conjunction with field measurements of cloud microphysics (e.g., in-situ surface-based and aircraft observations and ground-, aircraft- and space-based remote sensing) that provide high-resolution data for model validation (e.g., Lang et al., 2003, 2007, 2011; Li et al., 2010 and see previous Section 2.1).

\section{Advanced applications}

\subsection{Diurnal variation}

The diurnal variation of tropical oceanic convection is one of most important components in tropical variability and plays a crucial role in regulating tropical hydrological and energy cycles. The dominant diurnal signal is the nocturnal peak in precipitation that occurs in the early morning (i.e., Kraus, 1963; Gray and Jacobson, 1977; Randall et al., 1991; Sui et al., 1997). The thermodynamic response of clouds to radiative heating (cloud development is reduced by solar heating and enhanced by IR cooling - Kraus, 1963; Randall et al., 1991) and a large-scale dynamic response to the radiational differences between cloudy and clear regions (Gray and Jacobson, 1977) have been suggested as the mechanisms responsible for the diurnal variation of precipitation over tropical oceans. Daytime heating of the boundary layer by solar radiation plays a dominant role in the diurnal variation of convection over tropical continents (see references in Lin et al., 2000). A successful simulation of the diurnal variability of the hydrologic cycle and radiative energy budget provides a robust test of physical processes represented in atmospheric models (e.g., Slingo et al., 1987; Randall et al., 1991; Lin et al., 2000).

The GCE model has been used to examine the mechanisms associated with the diurnal variation of precipitation processes in the Tropics (Tao et al., 1996; Sui et al., 1998; see reviews by Tao, 2003 and Tao and Moncrieff, 2009). Sui et al. (1998) found that modulation of convection by the diurnal change in available water (or relative humidity), which is a function of temperature, was responsible for a rainfall maximum after midnight. This implies that the increase (decrease) in surface precipitation associated with longwave cooling (solar heating) was due to an increase (decrease) in relative humidity (Tao et al., 1996) ${ }^{2}$.

\subsubsection{A midlatitude case}

Recently, Lee et al. (2010) used the 2D GCE model to examine the mechanisms of summertime diurnal precipitation over the Great Plains. The model was constrained by the observed large-scale background state and surface fluxes derived from the DOE ARM Program's Intensive Observing Period (IOP) data at the SGP. The model, when continuously forced by surface fluxes and large-scale advection, captures the observed rainfall events reasonably well with realistic magnitudes (Fig. 10). The observed precipitation amount shows a maximum in the nighttime, whereas the model simulation does not clearly show the nighttime maximum (Fig. 2 in Lee et al., 2010). Sensitivity tests were conducted to determine the mechanisms for the daytime and nighttime convection. Fig. 11 shows the diurnal variation of precipitation driven by the time-mean diurnal variation of the large-scale advection and surface fluxes (EXP1); surface fluxes only (EXP2), large-scale advection only (EXP3), and time invariant large-scale advection and surface fluxes (EXP4). EXP1 is characterized by two peaks in the nighttime and late afternoon. EXP2 shows the daytime convection, which actually happens in late afternoon with the large-scale advection, as shown in EXP1. EXP3 shows predominantly nocturnal precipitation. The results indicate that surface heat and moisture fluxes are primarily responsible for the development of deep convection in the afternoon, whereas the large-scale upward motion and associated moisture advection play an important role in preconditioning nocturnal convection. In the nighttime, high clouds are continuously built up through their interaction and feedback with long-wave radiation, eventually initiating deep convection from the boundary layer (Lee et al., 2010). Without these upper-level destabilization processes, the model tends to produce daytime convection only in response to boundary layer heating.

\subsection{Aerosol effect}

Aerosols and especially their effects on clouds and precipitation are one of the key components of the climate system and the hydrological cycle. Yet, the aerosol effects on clouds remain largely unknown, and the processes involved not well understood. A report published by the United States National

\footnotetext{
${ }^{2}$ Other physical processes (convective organization and its associated ice processes and atmospheric stability) have been proposed by Liu and Moncrieff (1998) and Xu and Randall (1995) as having a role in the diurnal variation of precipitation based on CRM simulations.
} 
a

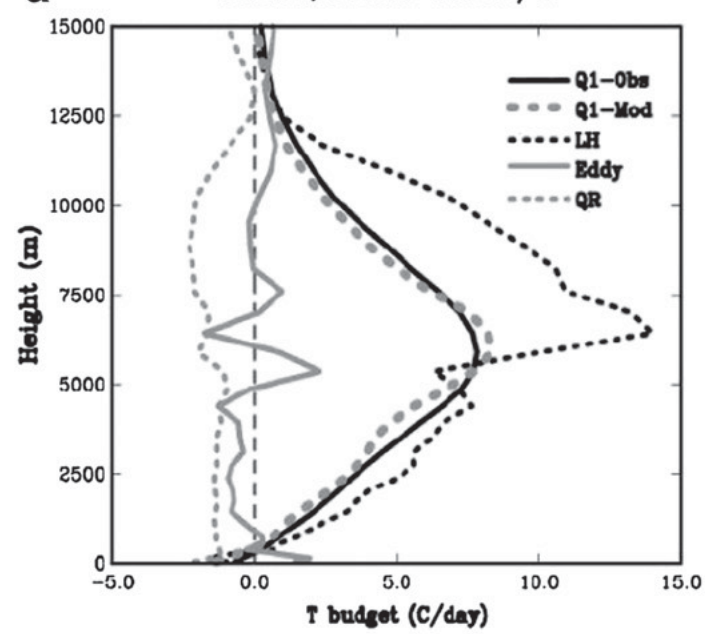

C

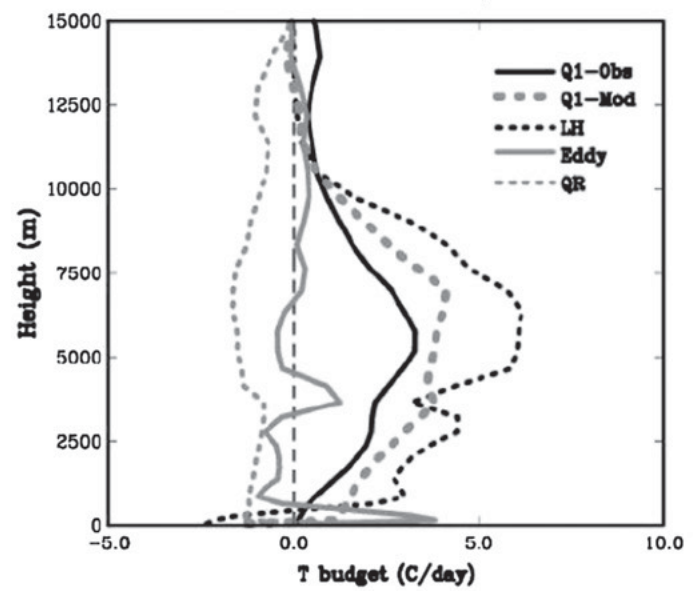

e

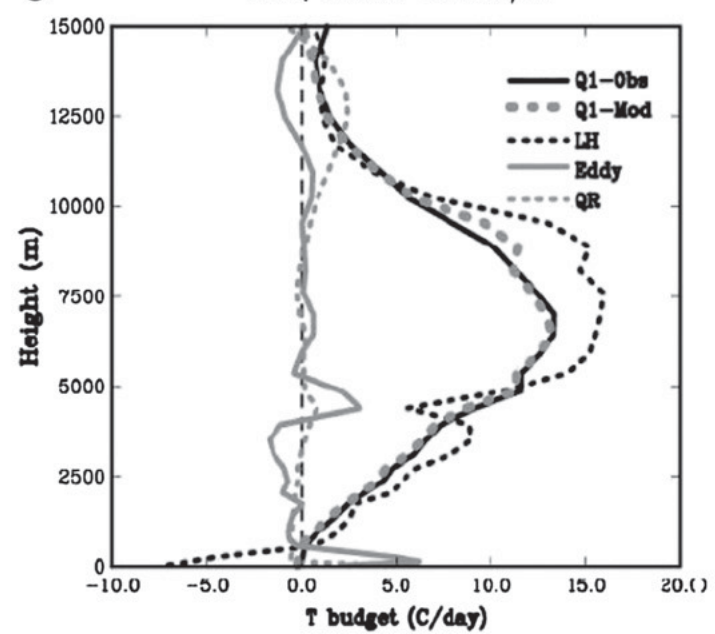

b

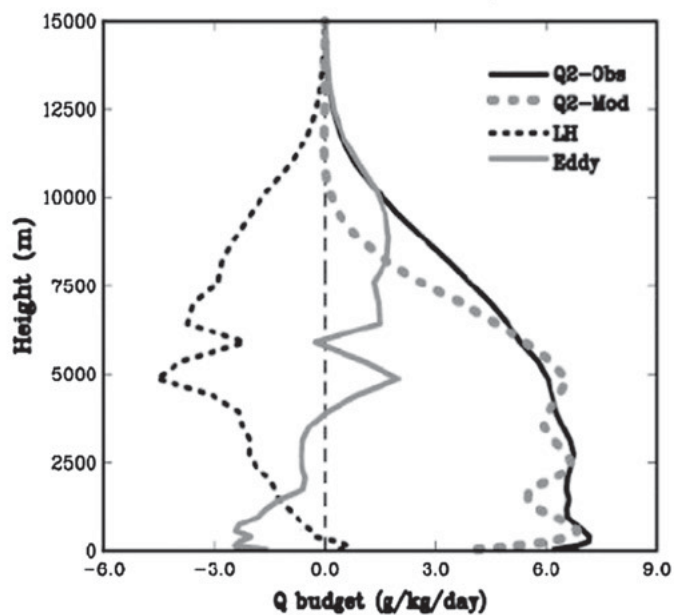

d

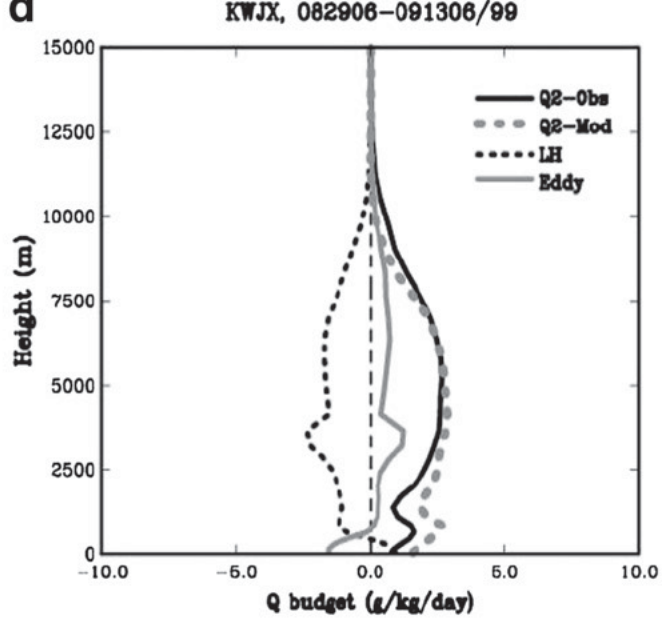

f

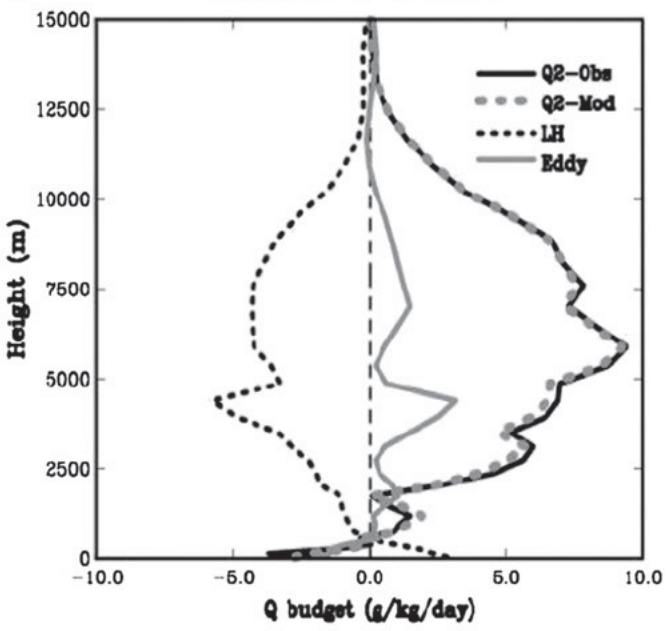

Fig. 8. Heating (a) and moistening (b) budgets for the May SCSMEX case averaged over the 9-day simulation time (thick dashed gray). Contributions from net condensation (condensation + deposition - evaporation - sublimation, dotted black) and the total vertical eddy-flux convergence (solid gray), including both the cloud-scale and sub-grid-scale (turbulence) effects, are shown. The net radiation (dotted gray) and the diagnostically-determined heating and moistening budgets derived from atmospheric sounding data are also shown for comparison (solid black). (c) and (d) are the same as (a) and (b), except for the KWAJEX 14-day simulation. (e) and (f) are the same as (a) and (b), except for the TOGA COARE 8-day simulation.

Academy of Science stated "The greatest uncertainty about the aerosol climate forcing - indeed, the largest of all the uncertainties about global climate forcing - is probably the indirect effect of aerosols on clouds NRC (2001)." This "indirect effect" includes the traditional "indirect" or "Twomey" effect on cloud microphysics (Twomey, 1977; Twomey et al., 1984), the 


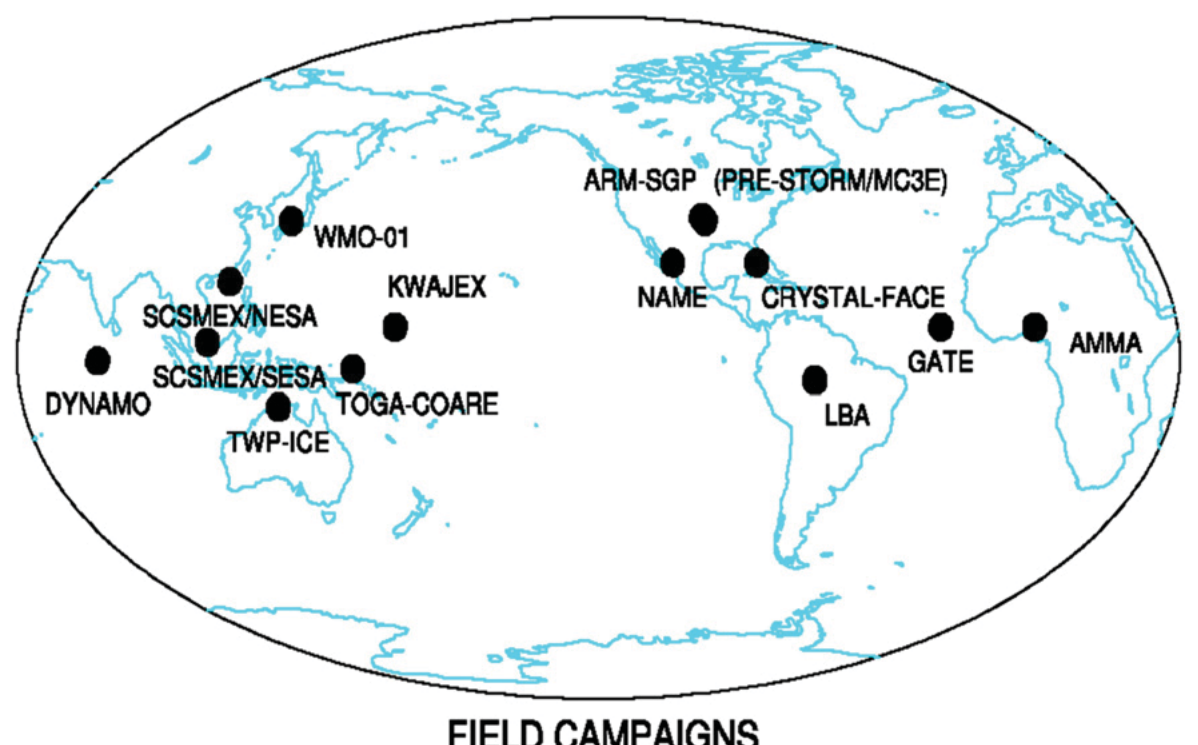

Fig. 9. Geographic locations of twelve field campaigns used to provide data to drive and evaluate CRM simulations. These include: the ARM-SGP (Atmospheric Radiation Measurement Southern Great Plains) campaigns conducted in the summer of 1997, the spring of 2000 and the summer of 2002, GATE (1974, Global Atmospheric Research Program's Atlantic Tropical Experiment), NAME (2004, North American Monsoon Experiment), LBA (1998-1999, Large-Scale Biosphere-Atmosphere Experiment), KWAJEX (1999, the Kwajalein Experiment), TOGA-COARE (the Tropical Ocean Global Atmosphere Program's Coupled Ocean-Atmosphere Response Experiment conducted in 1992 and 1993), CRYSTAL-FACE (2002, Cirrus Regional Study of Tropical Anvils and Cirrus Layers - Florida Area Cirrus Experiment), TWP-ICE (2006, the Tropical Warm Pool - International Cloud Experiment), and SCSMEX/NESA and SESA (1998, the South China Sea Monsoon Experiments over the northern and southern enhanced sounding arrays, respectively), AMMA (2006, the African Monsoon Multidisciplinary Analysis), MC3E (2011, the Midlatitude Continental Convective Clouds Experiment) and AMIE/DYNAMO (2011, the ARM MJO Investigation Experiment/Dynamics of the MJO).

"semi-indirect" effect on cloud extent and lifetime (Hansen et al., 1997; Ackerman et al., 2000), and the effect on precipitation formation (termed the 2nd indirect effect), as observed from TRMM and other satellite studies (Rosenfeld, 1999, 2000). For example, Rosenfeld (2000) found that smoke and air pollution may act to suppress both liquid-phase and ice processes involved in precipitation development, and that this effect can occur over large areas. Rosenfeld and Woodley (2000) used aircraft measurements to infer that suppression of coalescence can reduce areal rainfall by as much as a factor of two. Such pollution effects on precipitation potentially have a regional climatic consequence in terms of feedbacks involving the land surface via rainfall, and its energy budget, and changes in LH in the atmosphere.

CRMs have been used to examine the role of aerosols in precipitation processes (see Table 3 in Tao et al., 2012). These modeling studies had many differences in terms of model configuration (2D or 3D), domain size, grid resolution (150$3000 \mathrm{~m}$ ), microphysics (two-moment bulk scheme, simple or sophisticated SBM), turbulence (1st or 1.5 order TKE), radiation, lateral boundary conditions (closed, open and cyclic), cases (isolated convection to tropical/midlatitude squall lines) and model integration time $(2.5 \mathrm{~h}-48 \mathrm{~h})$. Almost all of the model results indicated that the aerosol concentration had a significant impact on precipitation. However, these CRM simulations differ considerably in terms of the sign and magnitude of the aerosol effect as well as the dominant mechanisms responsible for the effects.

\subsubsection{IN effect}

Since super-cooled cloud droplets are thermodynamically unstable, IN can change their phase status via ice nucleation.
As a result, IN can alter clouds and precipitation significantly (e.g., Vonnegut, 1950). Consequently, their accumulated effects can modify radiative forcing and even climate (Zeng et al., 2009a,b).

The representation of IN in the GCE model (Zeng et al., 2008) was tested using radar and satellite observations from different field campaigns [e.g., the Tropical Warm Pool International Cloud Experiment (TWP-ICE) and the African Monsoon Multidisciplinary Analysis (AMMA)]. Analyzing the variations of CCN and IN concentrations with height can lead to the proper representation of the Bergeron process in CRM simulations. Active IN concentrations (or ice crystal concentrations) increase exponentially with temperature or height (e.g., Fletcher, 1962; DeMott et al., 2010), whereas CCN concentrations (or cloud droplet concentrations) do not and therefore can be treated as a constant approximately (in other words, the variation of CCN concentration with height is much smaller than that of IN concentration). Hence, a mixed-phase layer can be divided into two layers: an upper with excessive IN (with respect to $\mathrm{CCN}$ ) for the Bergeron process and a lower with insufficient active IN (Zeng et al., 2009a,b). Such a two-layer model represents the Bergeron process properly and was supported by the comparisons between CRM simulations and radar/satellite observations over different geographic regions (e.g., Zeng et al., 2009a,b, 2011, 2013; Guy et al., 2013).

Fig. 12 displays the modeled upper-tropospheric (UT) ice water content against the IN concentration at $-10{ }^{\circ} \mathrm{C}$ and shows that UT ice water content increases with increasing IN. This sensitivity of clouds to IN can lead to a sensitivity of radiative forcing to IN concentration, which is shown on the right side of Fig. 12. This sensitivity of radiative forcing to IN 

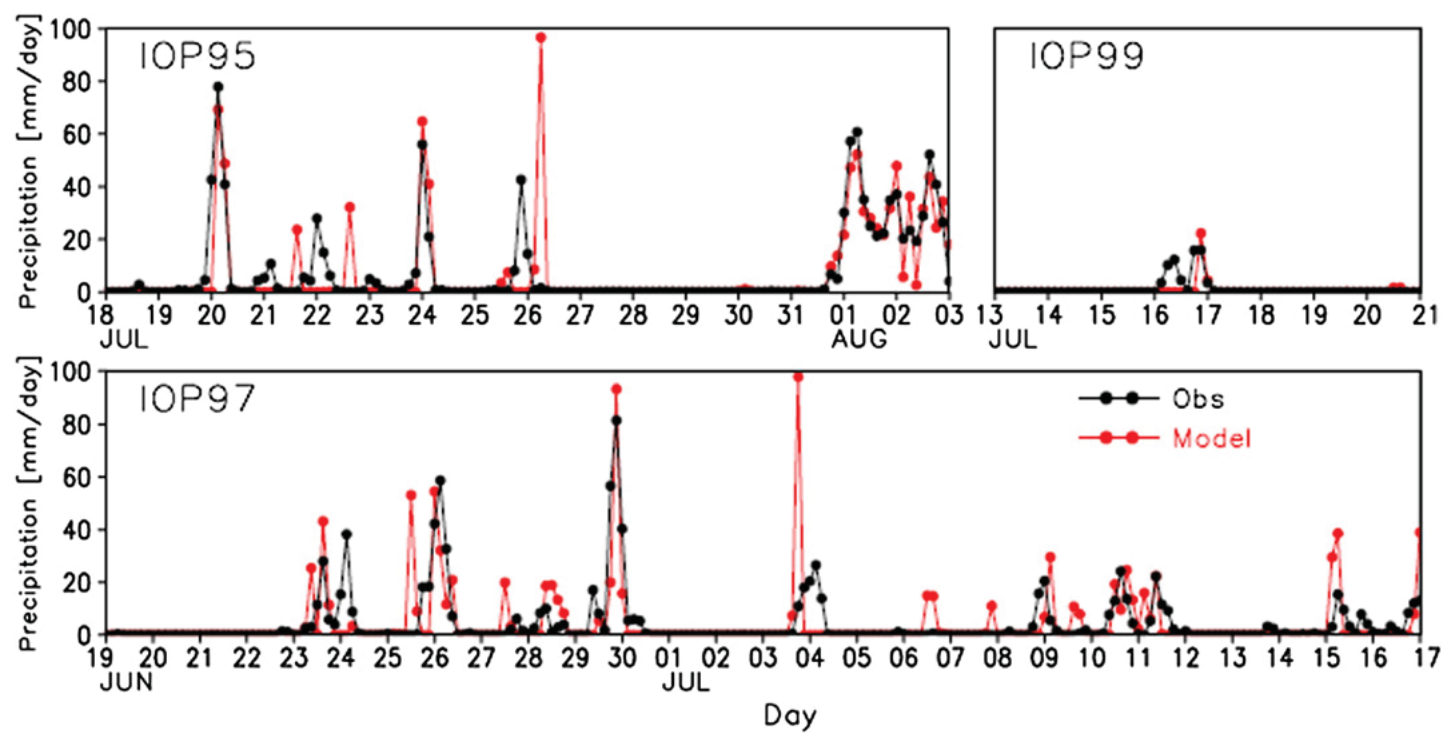

Fig. 10. Time series of three-hourly precipitation $\left(\mathrm{mm} \mathrm{day}^{-1}\right.$ ) from observations (black) and the GCE simulations (red) during three ARM IOPs in 1995, 1997, and 1999. The observations represent the area average precipitation over the ARM SGP ground stations, whereas the model simulation is the average over the whole computational domain.

varies with latitude. Fig. 13 displays the variation of radiative forcing against latitude, which partly explains the observed global warming, namely surface temperatures over land regions

\section{a) EXP1}

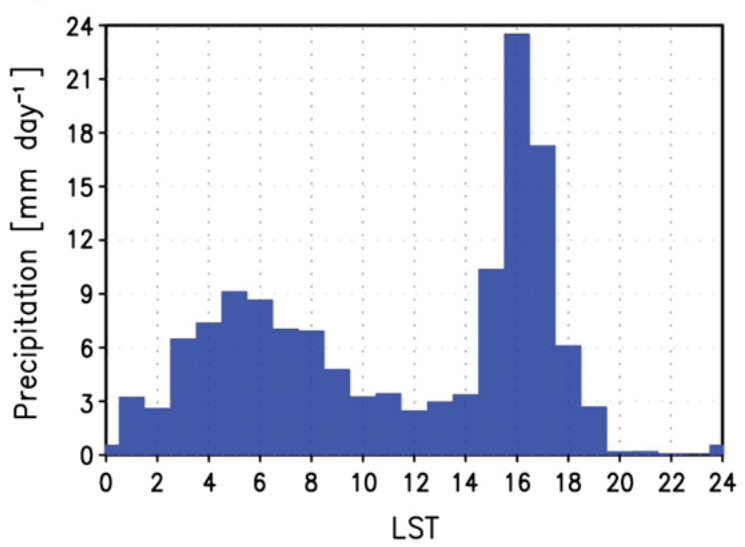

\section{c) EXP3}

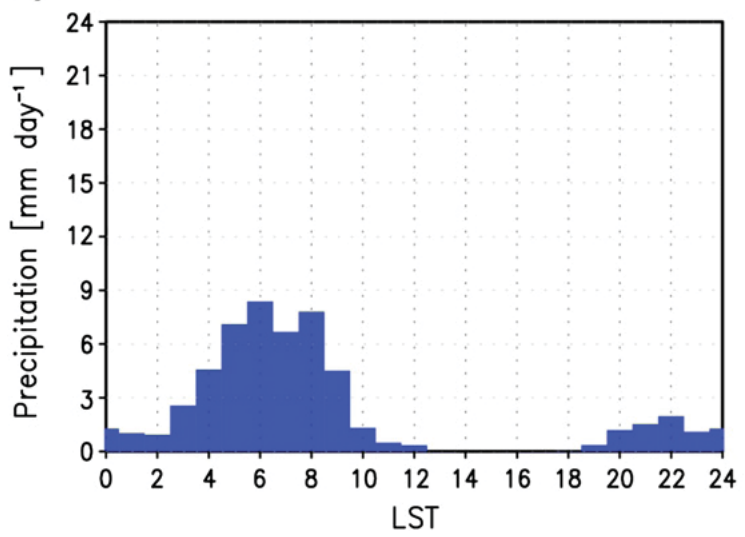

have warmed at a faster rate than over the oceans in both hemispheres with the greatest warming at higher northern latitudes (IPCC, 2007). This effect of IN on warming was

\section{b) EXP2}

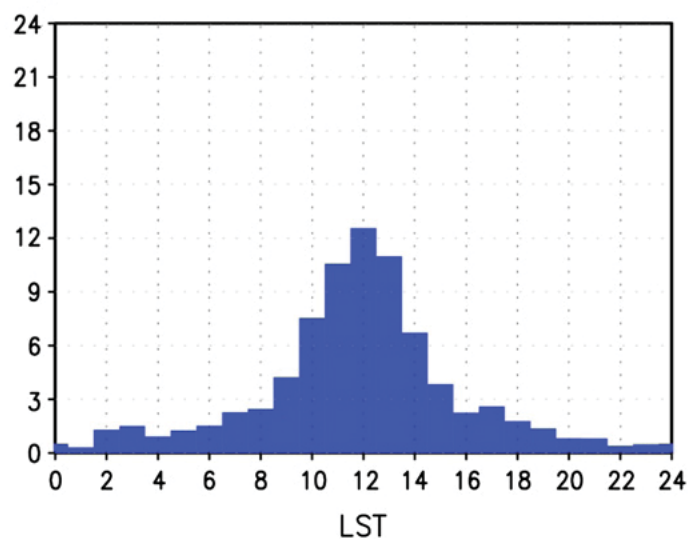

\section{d) EXP4}

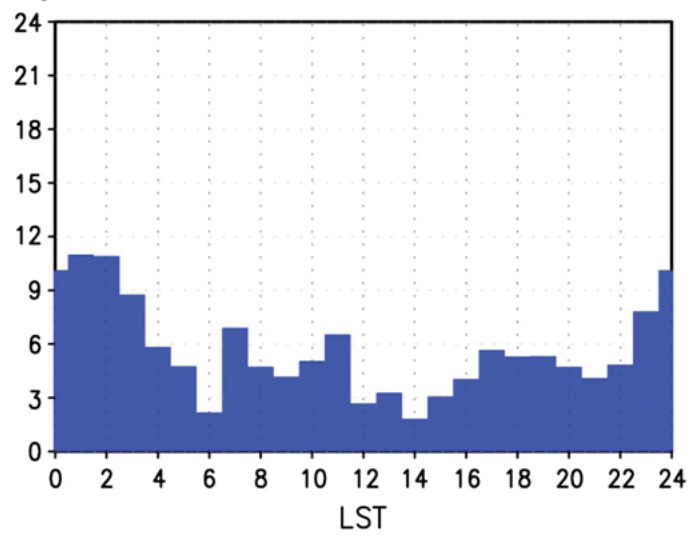

Fig. 11. Diurnal variation of precipitation amount $\left(\mathrm{mm} \mathrm{day}^{-1}\right)$ driven by the time-mean diurnal variations of the large-scale advection and surface fluxes (EXP1), surface fluxes only (EXP2), large-scale advection only (EXP3), and time invariant large-scale advection and surface fluxes (EXP4). 

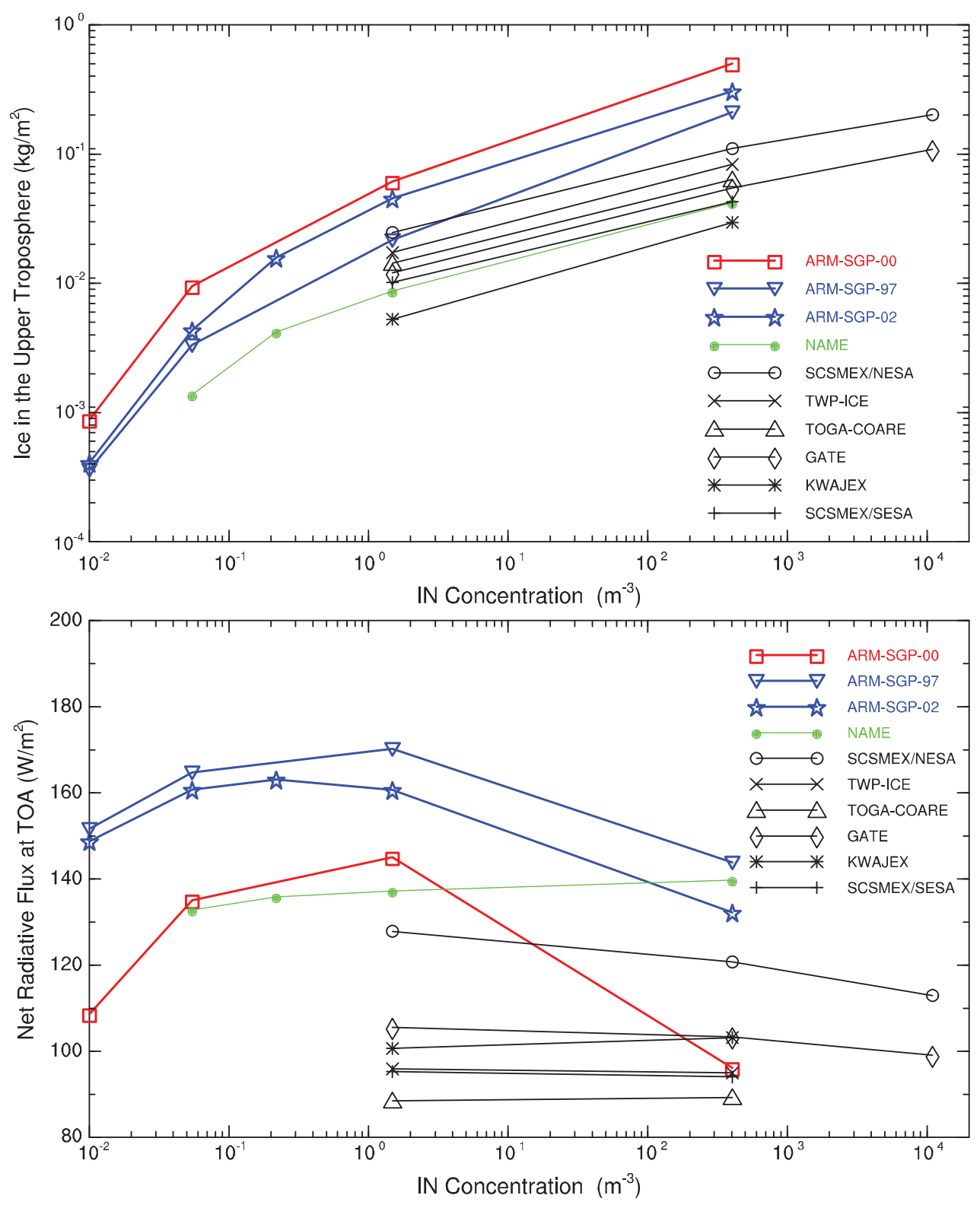

Fig. 12. Upper-tropospheric ice content and TOA radiative flux versus IN concentration over various geographic regions. Modeled cloud ice content above 7.4 km (top) and net downward radiative flux at the TOA (bottom) vary with IN concentration, which are obtained from GCE simulations for ten field campaigns. One line corresponds to one field campaign. Red and blue lines display the mid-latitudinal results in spring and summer, respectively; green and black lines display sub-tropical and tropical results, respectively. The horizontal axis represents the IN concentration calculated with the Fletcher formula at a temperature of $10{ }^{\circ} \mathrm{C}$. Red labels correspond to red lines.

supported by a statistical analysis of satellite data on dust and clouds (Choi et al., 2010).

\subsubsection{CCN effect}

Fig. 14 shows an example of the complexity of $\mathrm{CCN}-$ precipitation interactions using the GCE model with a spectral bin microphysical scheme. Rain is suppressed at a high $\mathrm{CCN}$ concentration (i.e., dirty environment), but only during the first hour of the simulations. Rain reaches the ground early in all the clean cases, in agreement with observations (e.g., Rosenfeld, 1999, 2000). During the mature stage, the effect of increasing the CCN concentration ranges from rain suppression in the Preliminary Regional Experiment for
Storm-Central (PRESTORM) case, to little effect in the Cirrus Regional Study of Tropical Anvils and Cirrus Layers - Florida Area Cirrus Experiment (CRYSTAL-FACE) case, to rain enhancement in the TOGA COARE case. Table 4 summarizes the rainfall statistics for all of the simulations. The precipitation is divided into convective and stratiform components (Tao et al., 1991, 1993; Lang et al., 2003). The convective region includes areas with strong vertical velocities (over 3-5 $\mathrm{m} \mathrm{s}^{-1}$ ) and/or heavy surface rainfall. The stratiform region is non-convective. It is expected that a high CCN concentration allows for more small cloud droplets and ice particles to form. The lower collection coefficient for smaller cloud and ice particles allows for a larger amount of ice 


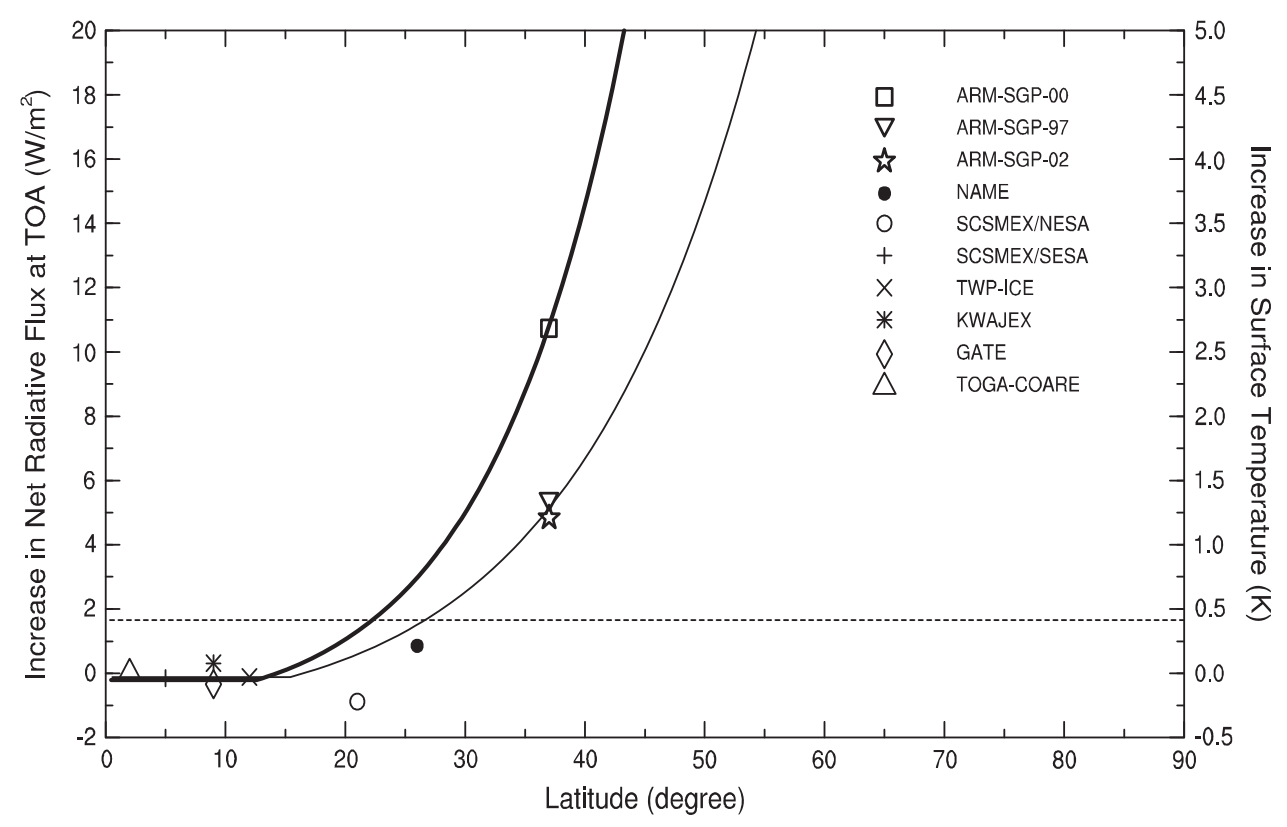

Fig. 13. Increase in the net radiative flux at the TOA from doubling the current IN concentration versus latitude. All of the results are obtained from the GCE simulations for the ten field campaigns. Thick and thin solid lines are introduced to fit the results to spring and summer, respectively. The dashed line represents the increase in the net radiative flux when the atmospheric $\mathrm{CO}_{2}$ concentration is increased from a pre-industrial value of about 280 ppm to 379 ppm in 2005 . The vertical axis also scales to the increase in surface temperature from doubling the IN concentration.

phase particles to be transported into the trailing stratiform region, producing a higher stratiform rain percentage in the dirty case. Aerosols do not have much impact on the stratiform percentage for the CRYSTAL-FACE case because of its short life span. These case studies suggest that simulations of the entire life cycle of convective systems are needed to assess the impact of aerosols on precipitation processes associated with mesoscale convective systems and thunderstorms. It also shows the
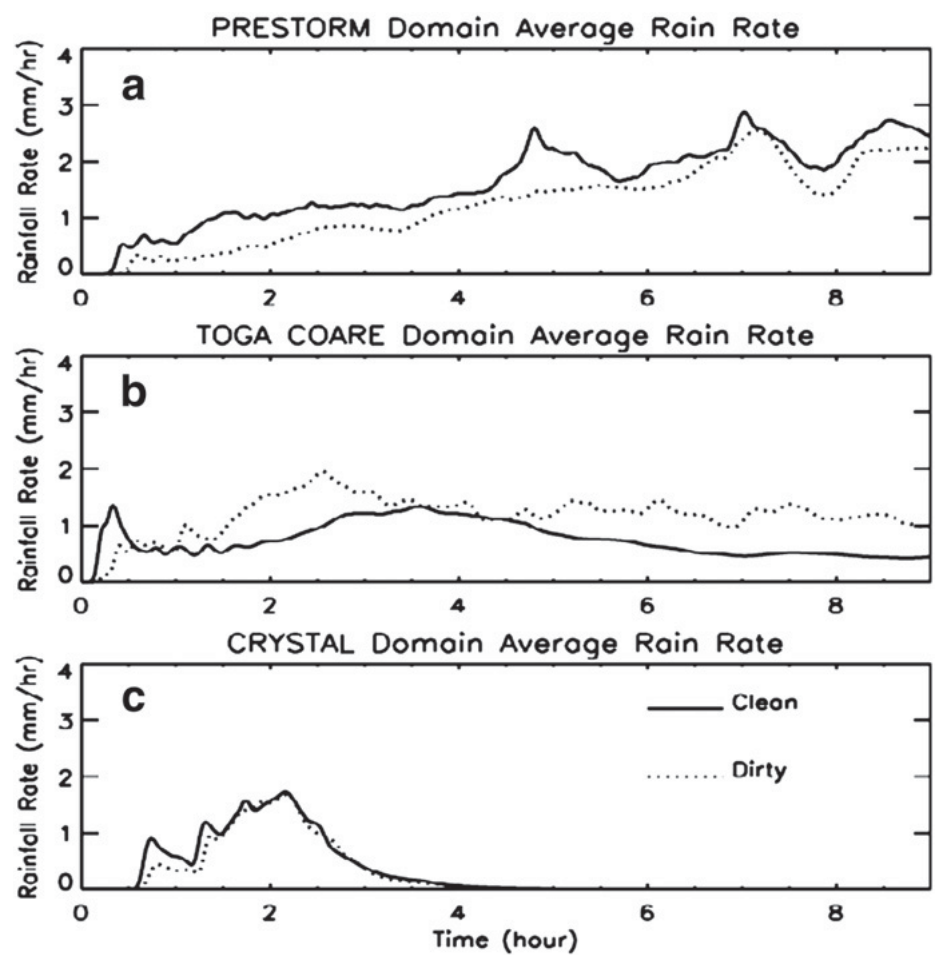

Fig. 14. Time series of GCE estimated domain mean surface rainfall rate $\left(\mathrm{mm} \mathrm{h}^{-1}\right)$ for the (a) PRESTORM, (b) TOGA COARE, and (c) CRYSTAL case. The solid/ dashed line represents clean/dirty conditions.

Adapted from Tao et al. (2007). 


\section{Table 4}

Domain-averaged surface rainfall amount (in $\mathrm{mm} \mathrm{day}^{-1}$ ), stratiform percentage (in \%) for the TOGA COARE, PRESTORM and CRYSTAL-FACE case under dirty and clean conditions. Note there are $9 \mathrm{~h}$ in the PRESTORM and TOGA COARE simulations and $5 \mathrm{~h}$ in the CRYSTAL-FACE simulation.

Adapted from Tao et al. (2007).

\begin{tabular}{|c|c|c|c|c|c|c|}
\hline & TOGA COARE clean & TOGA COARE dirty & PRESTORM clean & PRESTORM dirty & CRYSTAL clean & CRYSTAL dirty \\
\hline Average rain (mm/day/grid) & 18.0 & 28.4 & 38.3 & 29.1 & 12.6 & 11.0 \\
\hline Stratiform (\%) & 50 & 17 & 43 & 70 & 43 & 40 \\
\hline
\end{tabular}

complexity of aerosol-cloud-precipitation interactions within deep convection.

Fan et al. (2007a) also used the GCE model and found that ice microphysics, clouds and precipitation changed considerably with aerosol chemical properties for a convective event in Houston, Texas. In addition, Fan et al. (2007b) found that an increase in precipitation with an increase in aerosol concentration often occurs for clouds forming in a moist environment, such as coastal zones, within cloud ensembles or tropical squall lines. Please see a review paper on the impact of aerosols on precipitation by Tao et al. (2012).

\subsection{Coupling to satellite simulators}

\subsubsection{Satellite simulator}

The NASA Goddard Satellite Data Simulator Unit (G-SDSU) has been developed at NASA GSFC in collaboration with universities (Masunaga et al., 2010) to:

- Formulate a radiance-based evaluation method for clouds and precipitation simulated from numerical atmospheric models,

- Support radiance-based data assimilation for numerical atmospheric models, and

- Support NASA satellite missions [e.g., the A-Train constellation and GPM mission] by providing virtual satellite measurements as well as simulated geophysical parameters to satellite algorithm developers.
The G-SDSU computes satellite-consistent radiances or backscattering signals from simulated atmospheric profiles and condensates consistent with the unified microphysics in the GCE model. It currently has five simulators: passive microwave, radar, visible-infrared, lidar, and broadband (Matsui, 2013; Matsui et al., 2013, see Fig. 15). These simulated radiances and backscattering can be directly compared with satellite observations to evaluate the cloud parameterizations. The G-SDSU has been upgraded for GPM (Matsui et al., submitted for publication) by including (1) a GPM satellite orbit and scanning module that provides accurate representations of satellite and field of view (FOV) geolocations, local sensor-incident angle and antenna gain patterns, (2) an updated particle single scattering database that accounts for non-spherical snow aggregates through T-matrix or discrete dipole approximation for scattering calculations (DDSCAT), (3) surface emissivity modules from the National Environmental Satellite, Data, and Information Service (NESDIS) land-emissivity model (Weng et al., 2001) and A Tool to Estimate Land-Surface Emissivities at Microwave frequencies (TELSEM) land emissivity database (Aires et al., 2011), and (4) slant-path pseudo 3D radiative transfer.

\subsubsection{Statistical analyses}

As it is very difficult for models to predict the exact locations of the cloud and precipitation systems observed by satellites, thus a more systematic approach is preferred wherein ensemble

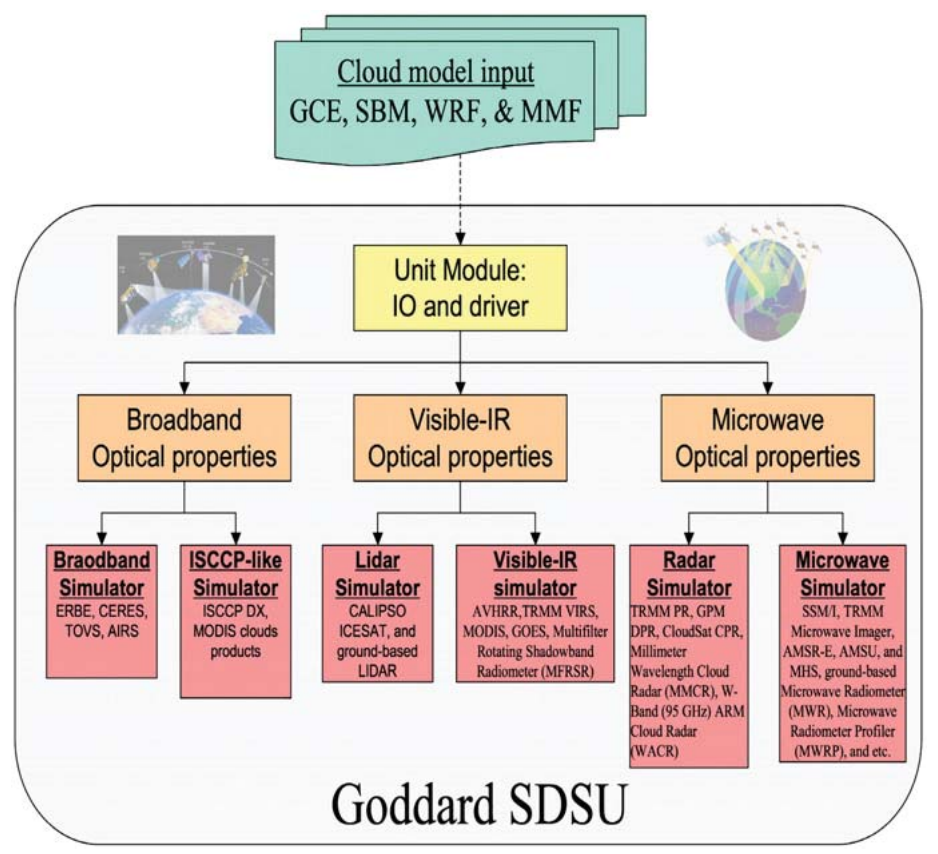

Fig. 15. Schematic diagram showing the major characteristics of the G-SDSU and their respective roles in satellite missions. 

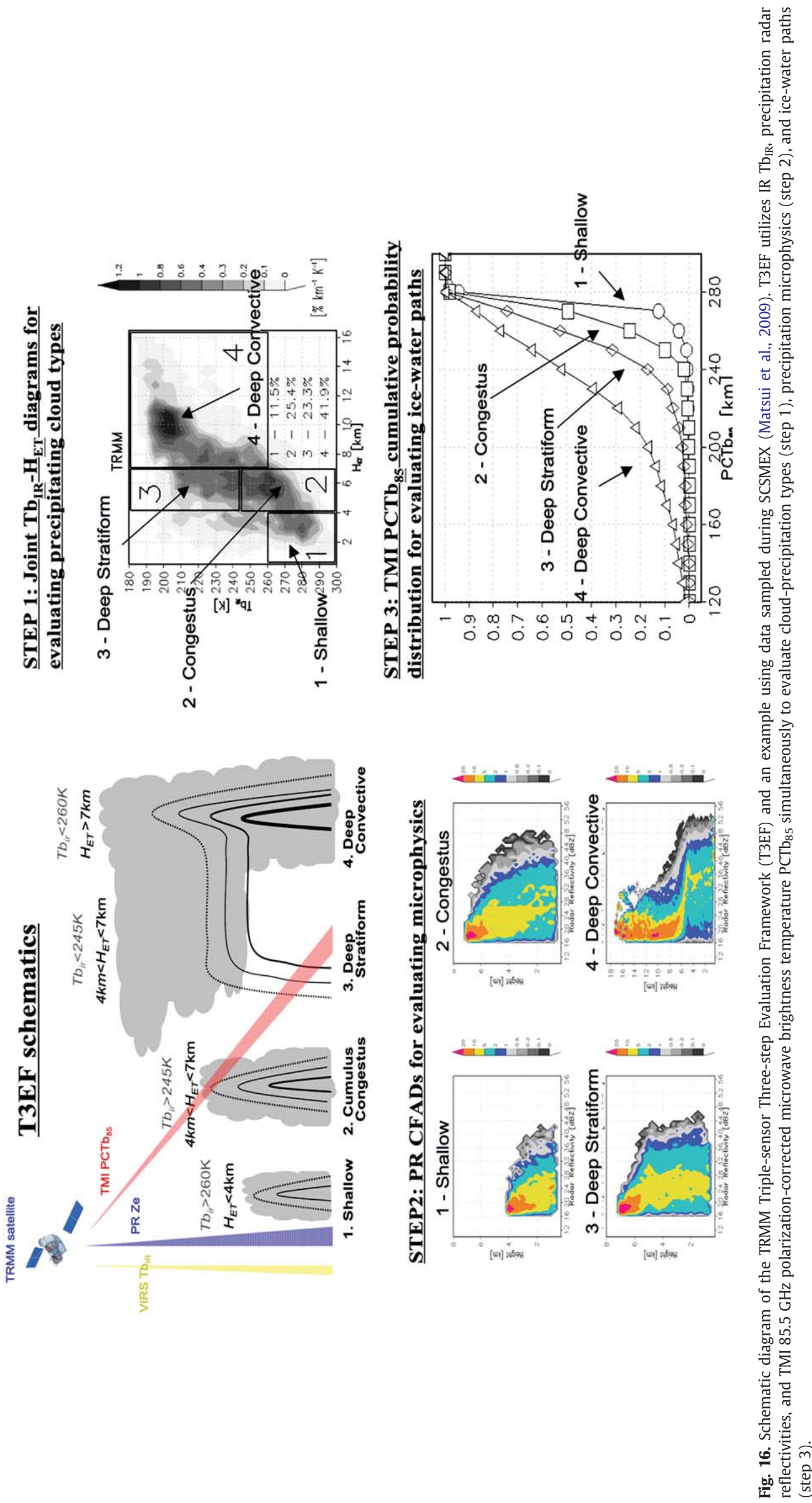

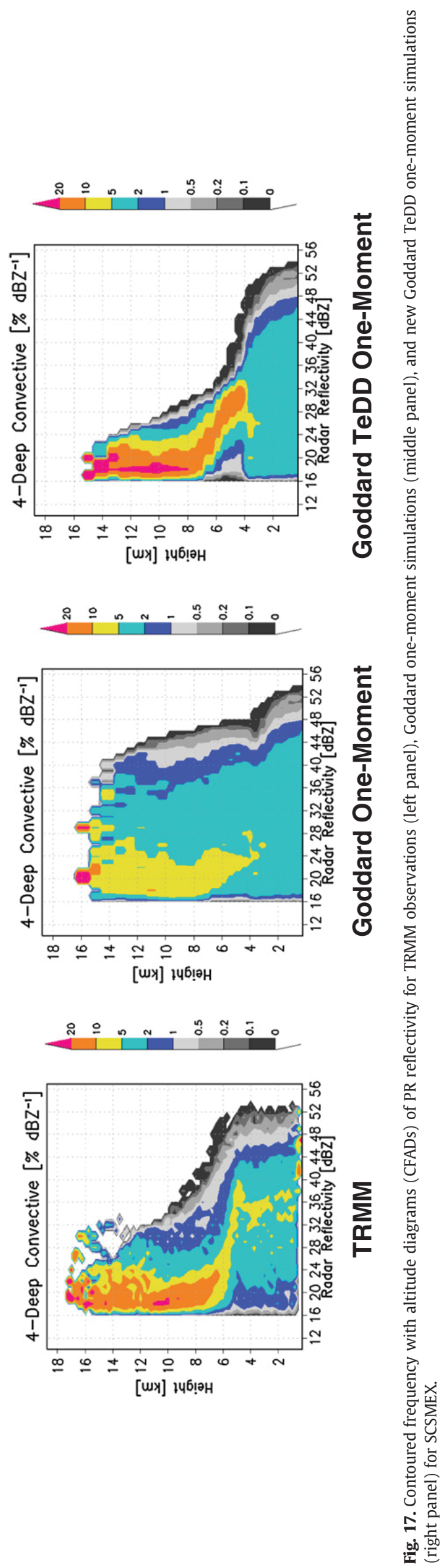


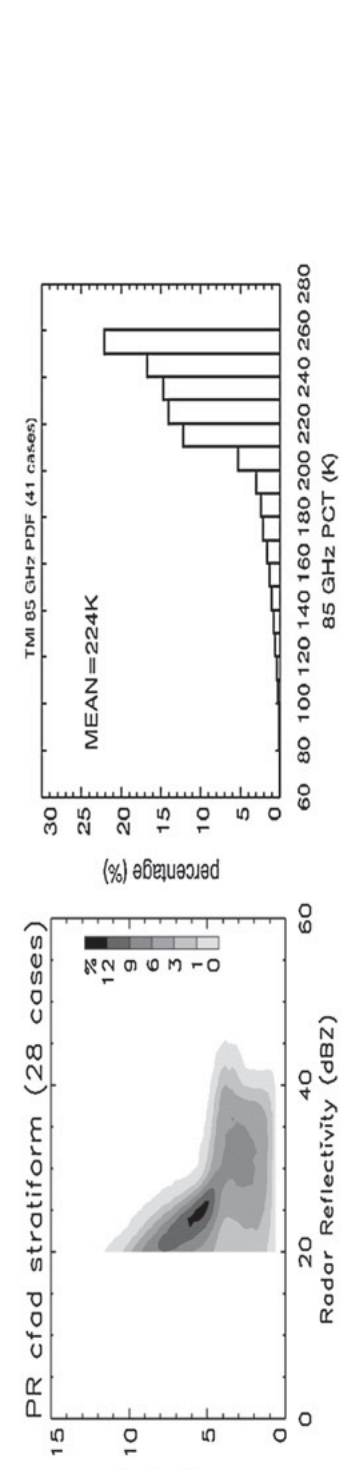

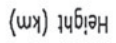

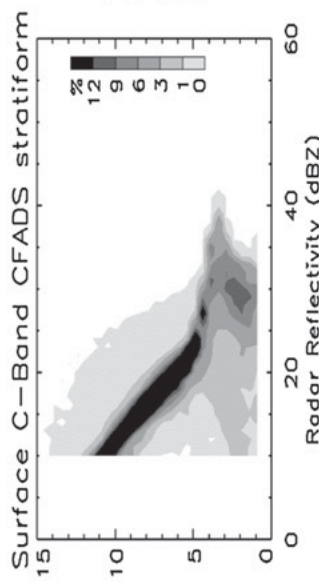

(wx) $146 \div$ 매

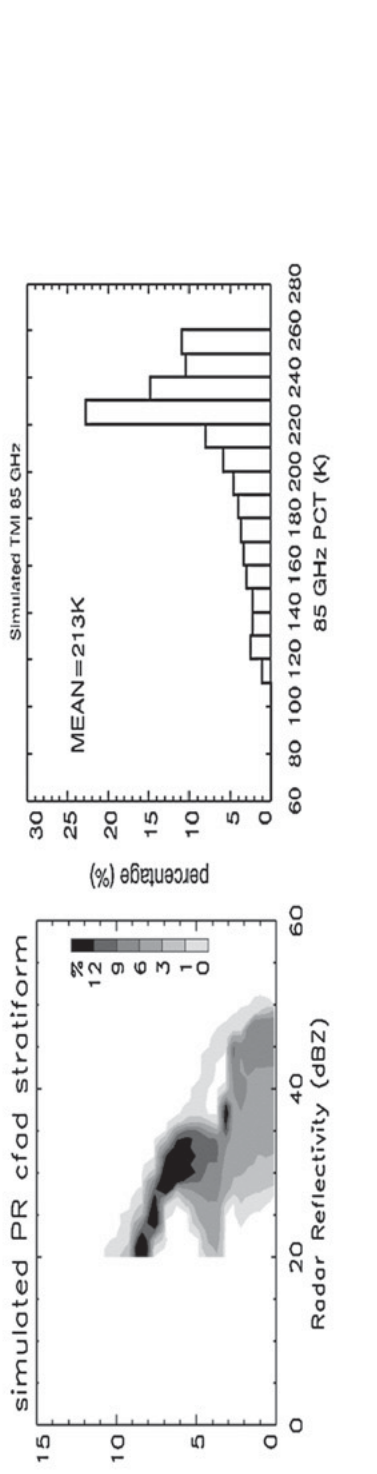

(wx) $146 ! \div 24$

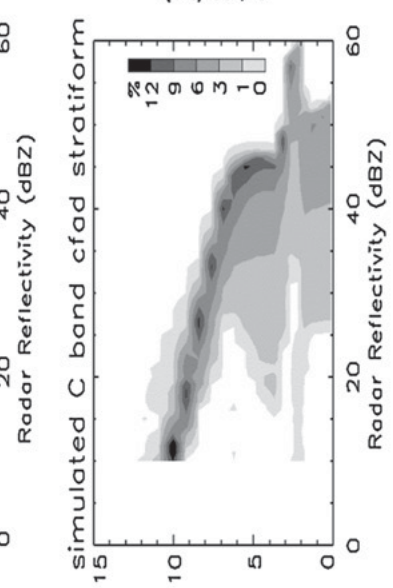

(wx) $746 !$ ə̈

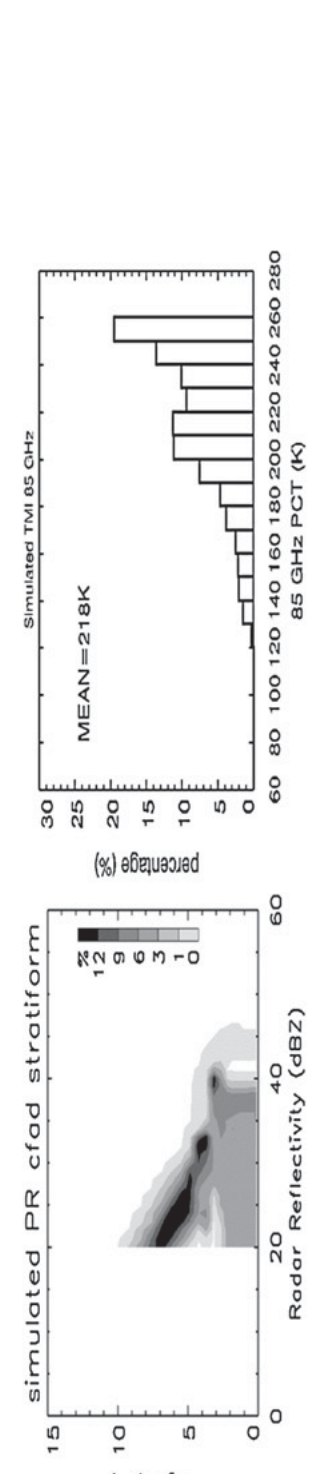

(w) 146!:

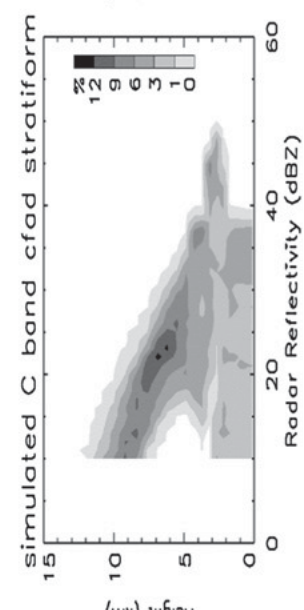

(wx) 346 막 

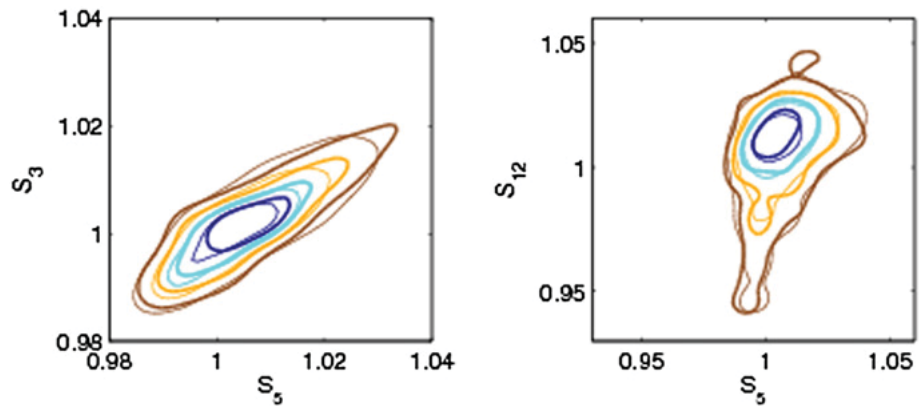

Fig. 19. Contours (brown, orange, cyan, and blue) contain $80,60,40$, and $20 \%$ of the joint inter-layer $\mathrm{S}$ (total moisture saturation ratio) probability, such that the probability densities within each contour are larger than the probability densities outside. Thick contours are for the $128 \times 128$ GCE subcolumns. Thin contours are for $128 \times 128$ subcolumns generated from a Gaussian copula model and GCE layer margins. The left panel is for layers 3 and 5 (separated by 256 m) and the right panel for layers 5 and 12 (separated by $1652 \mathrm{~m}$ ). The panels are consistent with a general reduction in inter-layer correlation with increasing layer separation. The Gaussian copula appears to model the S dependencies well. See Norris et al. (2008) for further explanation.

statistics of brightness temperatures and radar reflectivities from the satellite observations and GCE simulations are compared. To this end, a TRMM Triple-sensor Three-step Evaluation Framework (T3EF) was developed (Matsui et al., 2009, Fig. 16). T3EF uses the following collocated TRMM measurements: TRMM PR 13.8 GHz attenuation-corrected reflectivity, VIRS $12 \mu \mathrm{m}$ infrared brightness temperature $\left(T b_{I R}\right)$, and TMI $85.5 \mathrm{GHz}$ polarizationcorrected microwave brightness temperature $\left(P C T b_{85}\right)$. Using the SDSU, TRMM PR/TMI/VIRS radiances can be constructed from the numerical simulations in an identical manner. The 2nd step in T3EF (PR CFADs) indicated that the Goddard one-moment bulk microphysics simulate probability distributions of radar reflectivity that are too wide at high altitude, indicating the presence of excessively large-sized particles. This is mainly due to the DSD assumptions for frozen particles (i.e., an exponential DSD with a fixed intercept). With this assumption, the effective radius of frozen particles increases as a function of mass mixing ratio.

The bulk-microphysics DSD assumptions have been evaluated against explicitly simulated DSDs using a SBM scheme,
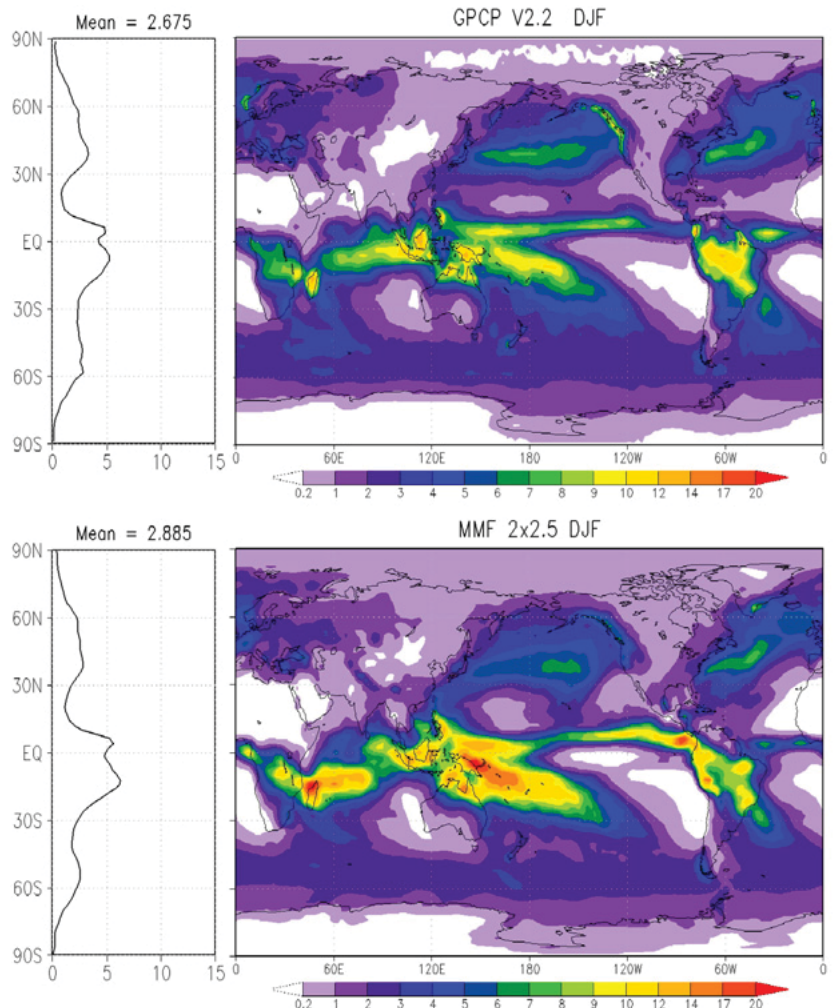

Mean $=2.711$

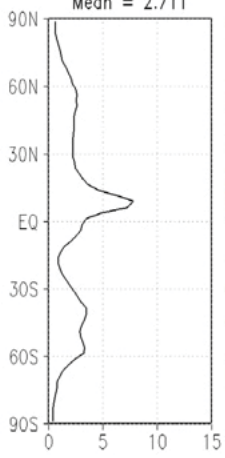

Mean $=2.922$

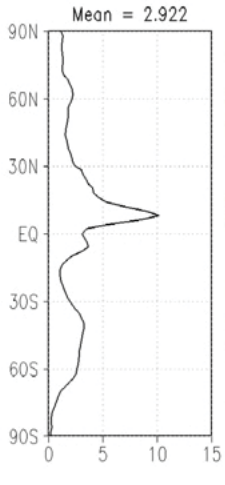

GPCP V2.2 JJA

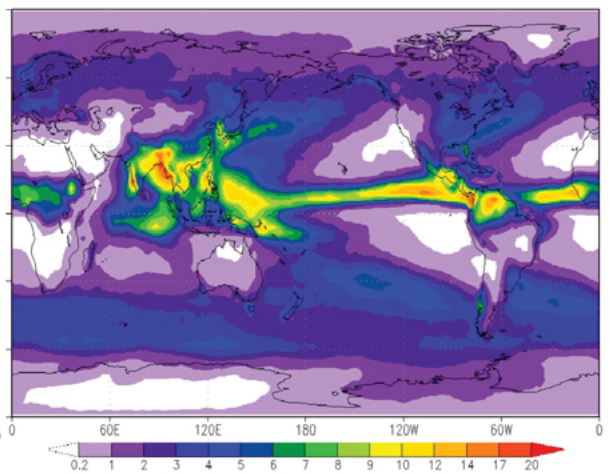

MMF $2 \times 2.5 \mathrm{JJA}$

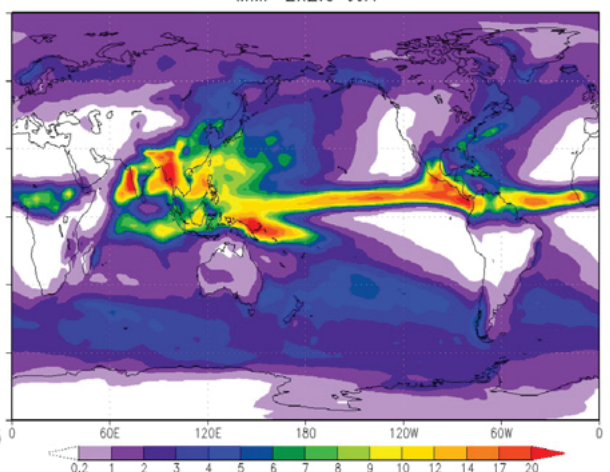

Fig. 20. Geographic distribution of DJF (left column) and JJA (right column) surface precipitation (mm/day) from GPCP observations (top) and G4MMF (AMIP-type) climate simulations (bottom). Both observed and modeled precipitation are averaged over the period 1998-2010. Observed precipitation features are well simulated for both winter and summer. Seasonal changes in precipitation intensity, location and areal coverage over the West Pacific warm pool, Pacific and Atlantic ITCZs, South Pacific Convergence Zone (SPCZ), and Amazon are well captured. But, seasonal changes in rain intensity are too strong, especially in the western and eastern Pacific and Atlantic. Excessive rainfall in JJA remains an issue in MMFs (note this simulation was run with an older Goddard microphysics scheme). 
because SBM simulations yield much more realistic radar echo profiles than the bulk one-moment microphysics (Section 2.1.2 and Fig. 6). The results suggest that SBM-simulated DSDs are more dependent on temperature than mass mixing ratio. A new temperature-dependent DSD (TeDD) was implemented into the one-moment microphysics scheme; it significantly improved the probability distribution of radar echoes in the upper troposphere compared to the original scheme (Fig. 17).

\subsubsection{A case study}

The SBM scheme has helped to improve the bulk scheme (see Section 2) but is itself also not perfect. Nine years of TRMM PR and 85 GHz TMI data during late spring and early summer over the central US were compiled and compared against an SBM simulation of a squall line (PRE-STORM, 1985). Fig. 18 shows the comparisons and the resulting SBM scheme improvements. Comparison against a surface C-band radar (first column) and the TRMM PR radar (second column) shows an over estimation of radar reflectivity in the original scheme (second row). To improve the simulated radar reflectivity profiles, the temperature dependence of the collection efficiency between ice-phase particles, especially plate-type, was modified. This reduced the coalescence of various ice-phase particles and produced smaller aggregates, resulting in better radar CFADs comparisons in the stratiform region as shown in the third row in Fig. 18. The SBM scheme will continue to be tested and improved based on other precipitation events (especially for convective systems and snow events observed at the aforementioned GPM-related GV sites).

\subsection{Role in large-scale modeling}

4.4.1. Application for the development of general circulation model (GCM) cloud parameterizations

Norris et al. (2008) use a GCE simulation of an ARM case study (Zeng et al., 2007) to investigate models for the statistical variability of moisture within a GCM grid-column sized domain $\left(128 \times 128\right.$ at $1 \mathrm{~km}^{2}$ resolution). In particular, they studied the horizontal variability of $S$, the total water saturation ratio (i.e., vapor plus condensate normalized by saturation), within near-surface warm layers (lowest $2 \mathrm{~km}$, $\mathrm{T}>0{ }^{\circ} \mathrm{C}$ ), and the vertical correlation of cloud cover and $S$ between these layers.

The case is a frontally disturbed boundary layer with a warm air mass, having broadly varying cloud cover features, overlying a poorly mixed surface layer containing a field of narrow convective cloud bands. Not surprisingly, the surface layer has positively-skewed temperature and moisture distributions from surface-driven convection, while the upper air mass contains negatively-skewed distributions from top-driven radiatively-induced motions. The probability density functions of intra-layer $S$ within both regions are found to be reasonably well modeled by skewed Generalized Extreme Value (GEV) distributions.

In order to provide a general expression for column cloud fraction in terms of individual layer cloud fractions, Norris et al. (2008) describe the use of so-called Copula functions within this context. These statistical functions model the joint distributions of rank between layers, where the rank is the relative ordering of the $S$ samples within each layer's moisture distribution. They find that the commonly used
Gaussian copula (GCOP) does a good job of modeling inter-layer $S$ rank correlations and gives smaller column cloud fraction errors compared with other common cloud overlap parameterizations (maximum, random, and maximum-random overlap, and a version of the "generalized cloud overlap" of Räisänen et al., 2004). Fig. 19 shows an example of the skill of the GCOP in modeling complex inter-layer moisture correlations. The GCOP approach is also found to yield improved estimates of condensed water path variance and column boundary fluxes of solar and thermal radiation compared with other overlap methods.

\subsubsection{Coupling with a GCM}

With the rapid advancement in computational technology, GCMs and climate models are entering an era of fast development. Because the requirement of a-few-kilometer resolution to resolve convection has been outside of the realm of possible resolutions for global climate models (and will likely still be the case in the near future), representations of convection processes along with aerosol-cloud-precipitation physics in these models have been empirically formulated using parameters resolved at model grid scales. Though still computationally very expensive, global cloud-resolving (or cloud-permitting) models (GCRMs) with high resolutions from 3.5 to $14 \mathrm{~km}$ (i.e., Tomita et al., 2005; Miura et al., 2005; Satoh et al., 2005, 2008; Nasuno et al., 2008) are already being run in an exploratory manner for short-term (i.e., seasonal) simulations and could reach the stage of performing long-term

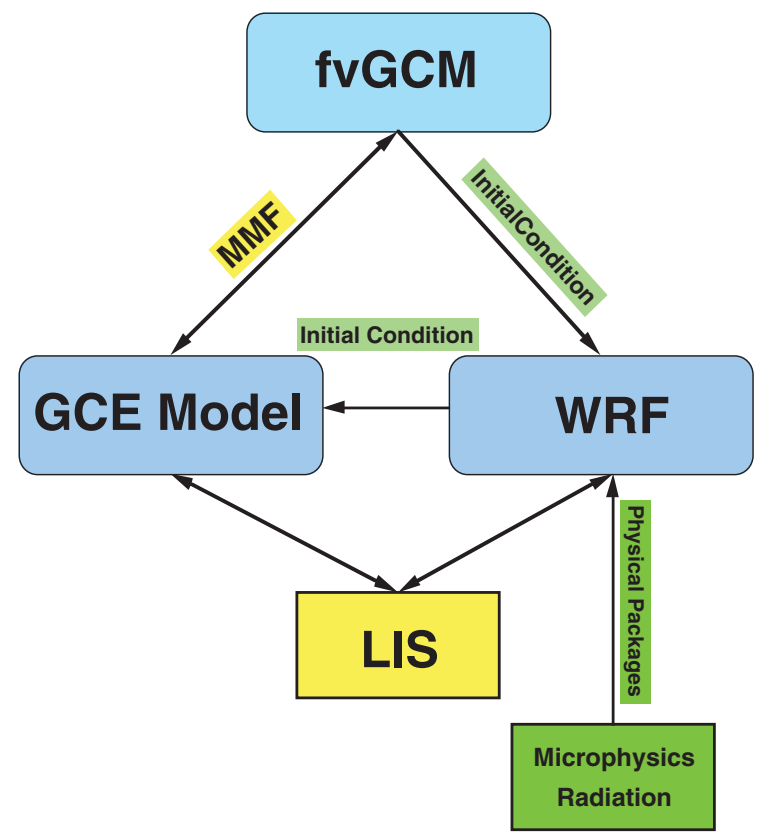

Fig. 21. Schematic diagram of the Goddard Multi-scale Modeling System with unified physics. The coupling between the fvGCM and GCE is two-way, while the coupling between the fVGCM and WRF and WRF and the GCE is only one-way. LIS was developed in the Goddard Hydrological Sciences Branch and has been coupled interactively with both WRF and the GCE. Additionally, WRF has been enhanced by the addition of several of the GCE's physical packages (i.e., microphysical scheme with four different options and short and long-wave radiative transfer processes with explicit cloud-radiation interactive processes). Observations (obtained from satellite and ground-based campaigns) play a very important role in providing data sets for model initialization and validation and consequently improvements. 
integrations as future computational technology advances. Another less computationally demanding way of addressing the issue is the multi-scale modeling framework (MMF) that replaces conventional cloud parameterizations with a CRM in each grid column of a GCM (Grabowski and Smolarkiewicz, 1999; Khairoutdinov and Randall, 2001; Khairoutdinov et al., 2005; Randall et al., 2003; Tao et al., 2009a). The MMF can explicitly simulate deep convection, cloudiness and cloud overlap, cloud-radiation interactions, surface fluxes, and surface hydrology at the resolution of a CRM. The MMF expands traditional CRM modeling to global coverage and enables twoway interactions between the cloud and large scale.
The Goddard MMF is based on a coupling of the GCE model and the Goddard Earth Observing System (GEOS) global atmospheric model versions 4 (GEOS-4) and 5 (GEOS-5). Development and improvement of physical schemes usually require many iterative cycles; it is almost impossible to use GCRMs for this kind of research due to computational resources. The Goddard multi-scale modeling system with unified physics (Tao et al., 2009b) can provide an alternate, computationally feasible tool for parameter optimization.

A 13-year Atmospheric Model Intercomparison Project (AMIP)-type climate simulation was conducted with the Goddard MMF (coupled with GEOS4) to establish the model
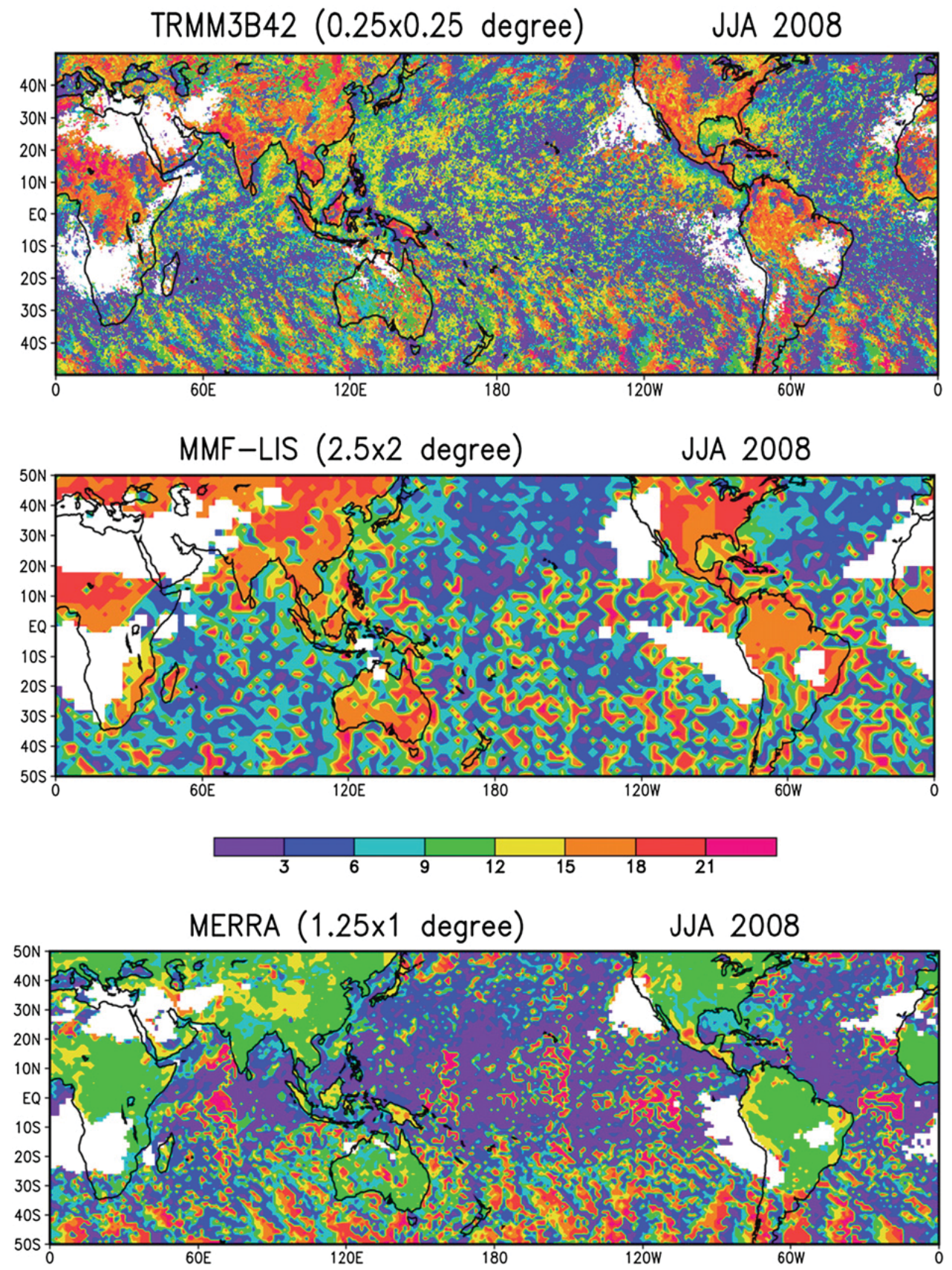

Fig. 22. Geographic distribution of the local solar time (LST) for non-drizzle precipitation intensity maximum in summer 2008 from the TRMM $3 B 42$ product at $0.25^{\circ} \times 0.25^{\circ}$ resolution, MERRA reanalysis at $1^{\circ} \times 1.25^{\circ}$, and an MMF-LIS simulation at $2^{\circ} \times 2.5^{\circ}$. Color bars indicate the LST (hour), and blank regions indicate no or light rain. 
baseline climate of the current model and to evaluate its performance in terms of tropical inter-annual and intraseasonal variability. The simulation was carried out from November 1997 to December 2010 with NOAA weekly OI SSTs. Fig. 20 shows surface as well as zonal mean precipitation from the MMF and Global Precipitation Climatology Project (GPCP) observations. It is encouraging to see that the general pattern of observed precipitation can be reproduced for both the winter (DJF) and summer (JJA) seasons. For example, the changes in the precipitation intensity, location and precipitation areal coverage of the western Pacific warm pool, Pacific ITCZ, South Pacific Convergence Zone (SPCZ), Atlantic ITCZ, Indian ITCZ and the Amazon Basin from DJF to JJA are well captured. The change in the intensity of tropical precipitation from DJF to JJA is, however, too strong, especially in the western and eastern Pacific and Atlantic. The excessive precipitation in JJA is a common feature among MMFs (Khairoutdinov et al., 2005, 2008; Tao et al., 2009a) even those with distinctly different cloud microphysical schemes and global models.

\subsubsection{Multi-scale modeling system with unified physics}

Recently, a multi-scale modeling system with unified physics has been developed at Goddard. One of the key components of this modeling system is the GCE model. The other two components are the NASA unified Weather Research and Forecasting model (NU-WRF) and MMF. The same cloud microphysical processes, long- and short-wave radiative transfer and land-surface processes are applied in all of the models to study explicit cloud-radiation and cloud-surface interactive processes in this multi-scale modeling system. This modeling system has been coupled with the G-SDSU for comparison and validation with NASA high-resolution satellite data (see
Section 4.3). Fig. 21 shows the multi-scale modeling system with unified physics. The GCE model and WRF share the same microphysical and radiative transfer processes (including the cloud-interaction) as well as LIS. The same GCE physics is utilized in the Goddard MMF. The idea behind having a multi-scale modeling system with unified physics is to be able to propagate improvements made to a physical process in one component into other components smoothly and efficiently (Tao et al., 2009b).

Fig. 22 shows an example of MMF-LIS performance in simulating the diurnal variation of precipitation intensity during the summer of 2008 (Mohr et al., 2013). The MMF-LIS simulated timing of maximum diurnal precipitation is in good agreement with TRMM observations over land (in the late afternoon and early evening) and over ocean (in the early morning with large variation). The Modern Era Retrospectiveanalysis for Research and Applications (MERRA) reanalysis has the maximum phase too early over land.

The GCE physical packages (i.e., CRM-based microphysics, radiation and land-surface hydrology processes) have recently been implemented into NU-WRF. The GCE model-based packages have improved forecasts (or simulations) of convective systems [e.g., a linear convective system in Oklahoma (International H2O project, IHOP-2002; Santanello et al., 2009), an Atlantic hurricane (Hurricane Katrina, 2005; Tao et al., 2011a), a Pacific Typhoon (Typhoon Morakot, 2009; Tao et al., 2011b), high latitude snow events (Canadian CloudSat CALIPSO Validation Project, C3VP 2007; Shi et al., 2010; Iguchi et al., 2012a), and mesoscale convective systems in Africa (Shi et al., in press) and Oklahoma (Midlatitude Continental Convective Clouds Experiment, MC3E, Iguchi et al., 2012b; Tao et al., 2013)]. a

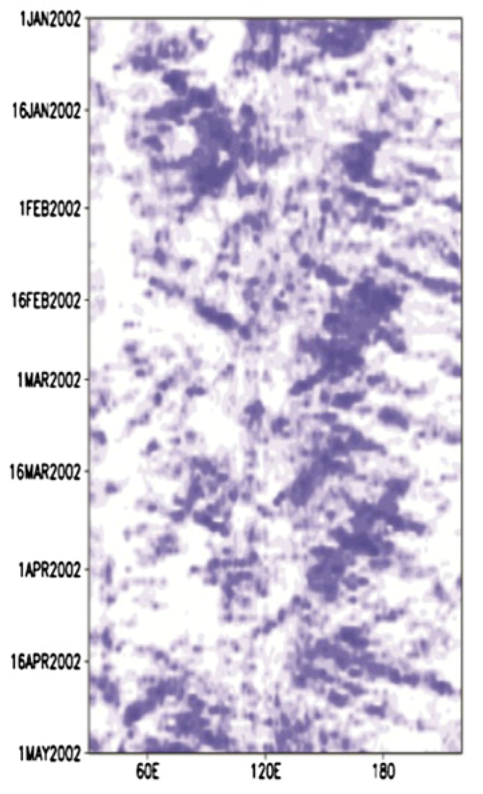

b

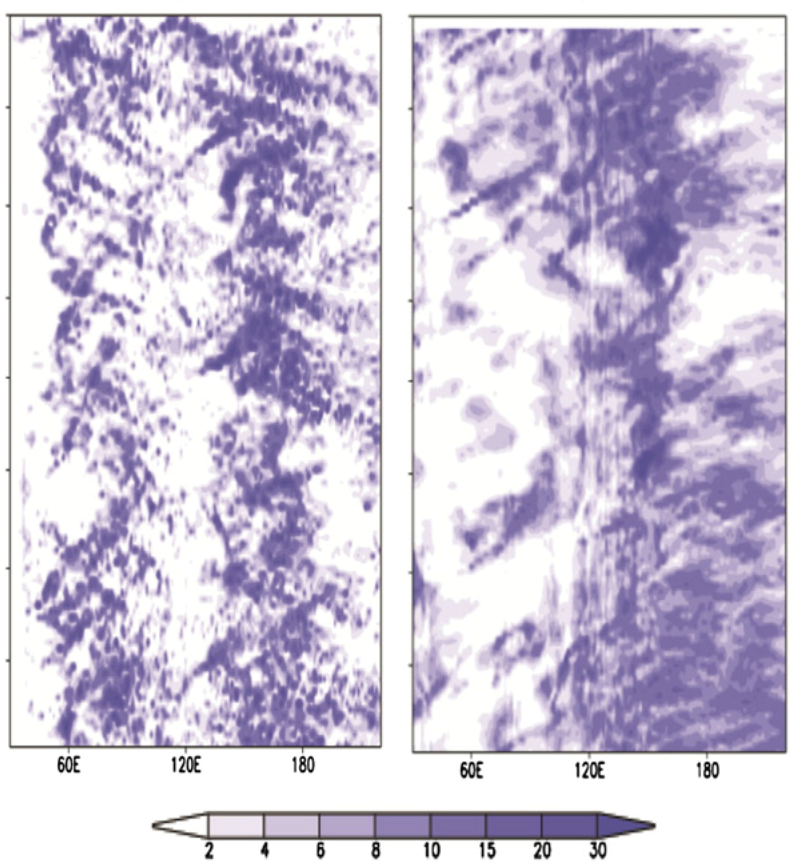

d

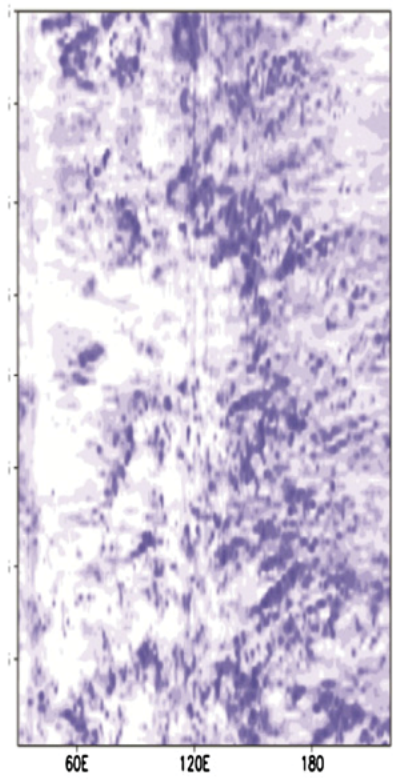

Fig. 23. Hovmoller diagram of daily mean precipitation averaged over $10^{\circ} \mathrm{S}-10^{\circ} \mathrm{N}$ for (a) TRMM and the GCM with the (b) hybrid representation (EXP1), (c) BULK convective parameterization (EXP2) and (d) cloud microphysics only (EXP3). All model simulations have $50 \mathrm{~km}$ horizontal resolution. 

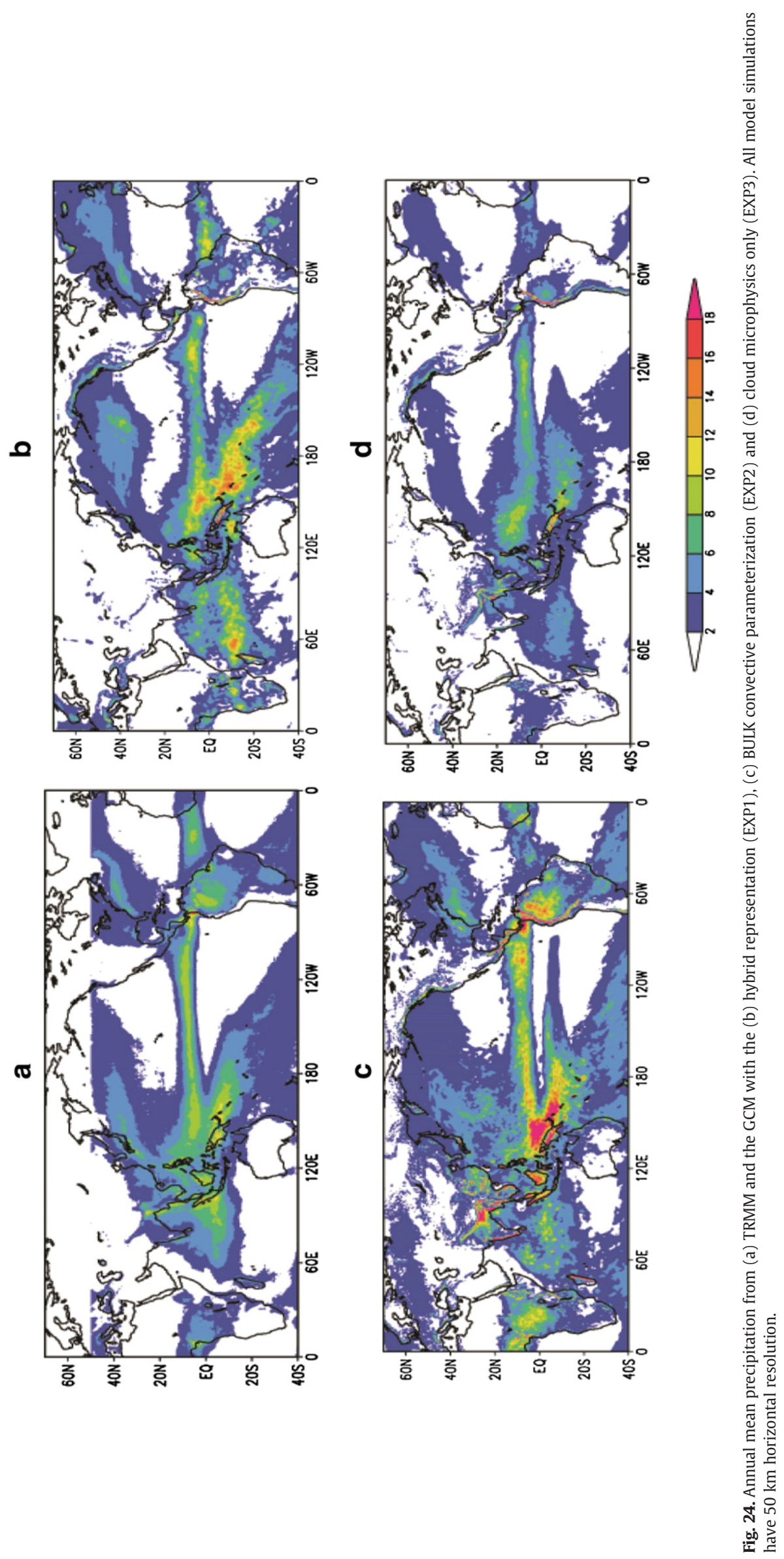
Table 5

Summary of TRMM cloud heating products from the CSH and SLH algorithms. To obtain total $\mathrm{Q}_{1}$ estimates from the CSH algorithm, the three individual heating components (i.e., LH, EHT, and $\mathrm{Q}_{\mathrm{R}}$ ) must be summed together. Also, $\mathrm{Q}_{2}$ estimates from the CSH algorithm are separated into eddy and microphysical components and must be summed to obtain the total $\mathrm{Q}_{2}$. Orbital heating is not a standard TRMM product.

\begin{tabular}{|c|c|c|c|c|}
\hline & Spatial scale & Temporal scale & Algorithm & Products \\
\hline Gridded & $\begin{array}{l}0.5 \times 0.5^{\circ} \\
19 \text { vertical layers }\end{array}$ & Monthly & $\begin{array}{l}\text { SLH-PR } \\
\text { CSH-combined }\end{array}$ & $\begin{array}{l}\mathrm{LH}, \mathrm{Q}_{1}-\mathrm{Q}_{\mathrm{R}}, \mathrm{Q}_{2} \\
\mathrm{LH}, \text { EHT, } \mathrm{Q}_{\mathrm{R}}, \mathrm{Q}_{2}\end{array}$ \\
\hline Orbital* & $\begin{array}{l}\text { Pixel } \\
19 \text { vertical layers }\end{array}$ & Instantaneous & $\begin{array}{l}\text { SLH-PR } \\
\text { CSH-combined }\end{array}$ & $\begin{array}{l}\mathrm{LH}, \mathrm{Q}_{1}-\mathrm{Q}_{\mathrm{R}}, \mathrm{Q}_{2} \\
\mathrm{LH}, \mathrm{EHT}, \mathrm{Q}_{\mathrm{R}}, \mathrm{Q}_{2}\end{array}$ \\
\hline Gridded orbital & $\begin{array}{l}0.5 \times 0.5^{\circ} \\
19 \text { vertical layers }\end{array}$ & Instantaneous $\mathrm{w} /$ time stamps on each grid & $\begin{array}{l}\text { SLH-PR } \\
\text { CSH-combined }\end{array}$ & $\begin{array}{l}\mathrm{LH}, \mathrm{Q}_{1}-\mathrm{Q}_{\mathrm{R}}, \mathrm{Q}_{2} \\
\mathrm{LH}, \mathrm{EHT}, \mathrm{Q}_{\mathrm{R}}, \mathrm{Q}_{2}\end{array}$ \\
\hline
\end{tabular}

\subsection{Application for development of GCM cloud microphysics scheme}

It has been difficult to apply cloud microphysics directly into GCMs mainly due to the limitation of horizontal resolution. However, several attempts have been implemented with the MMF (see Section 4.4.2) and a hybrid method by combining the cloud microphysics and a conventional parameterization (Moncrieff and Liu, 2006). A hybrid representation of precipitation processes in a GCM was developed using cloud microphysics and a vertical diffusion type of convective parameterization for a horizontal resolution on the order of $50 \mathrm{~km}$. The cloud microphysics adapted for this study was from the GCE model (Tao and Simpson, 1993; Tao et al., 2003a). All of the hydrometers within the cloud microphysics are treated as prognostic variables in the GCM. In addition to the cloud microphysics, a diffusion type of convective parameterization based on Tiedtke (1984) was added to improve the vertical sub-grid scale mixing of moisture and temperature. The GCM used in this study was the Seoul National University AGCM (SNUAGCM, Lee et al., 2001, 2003; Kim and Kang, 2012). The GCM with the hybrid representation of cloud physics (EXP1) was integrated for one year with observed sea surface temperatures, and the simulation data were compared with observations (i.e., TRMM). The performance of the model was also compared with simulations of the GCM with the BULK convective parameterization of Kim and Kang (EXP2) and with cloud microphysics only (EXP3).

Fig. 23 compares Hovmöller diagrams of the simulated daily precipitation in the equatorial region (averaged $10^{\circ} \mathrm{S}-$ $10^{\circ} \mathrm{N}$ ). It is clear that EXP1 reproduces organized convective systems and MJO-like eastward propagating events reasonably well when compared to the observations. EXP2, however, produces excessive precipitation in the eastern pacific and too little precipitation in tropical monsoon region. EXP3 produces distinct eastward propagation, but the eastward propagation too fast and the precipitation is mainly light. Fig. 24 compares the annual mean precipitation of the observations and the simulations. EXP1 captures the observed large-scale precipitation pattern reasonably well, although the mean precipitation in the tropics is relatively high. EXP3 (cloud microphysics only) mimics the geographic pattern of precipitation but underestimates the mean precipitation for most of the tropics, particularly over land. At a resolution of $50 \mathrm{~km}$, the model with cloud microphysics (EXP3) appears to produce insufficient vertical mixing due its coarser resolution. This reduced upward transport of moisture, in turn, leads to less precipitation whereas parameterized convection (EXP2) overestimates the precipitation in the tropics, particularly in convectively active regions. The present results indicate that at $50 \mathrm{~km}$ horizontal resolution, the hybrid representation of moist physical processes can be a good and reasonable choice for simulating the mean and transient statistics of global precipitation. However, it is expected that the model with a horizontal resolution on the order of $1 \mathrm{~km}$ will be well adapted to use cloud microphysics only for moist physical processes due to sufficient vertical mixing.

\subsection{TRMM latent heating $(L H)$ retrieval and $L H$ products}

The launch of the TRMM satellite, a joint U.S.-Japan project, in November of 1997 provided a much needed accurate measurement of rainfall as well as the ability to estimate the four-dimensional (4D) structure of latent heating (LH) over the global tropics (Simpson et al., 1988, 1996). Latent heat release is a consequence of phase changes between the vapor, liquid, and frozen states of water, which cannot be measured/detected in present observational instruments. The vertical distribution of LH has a strong influence on the atmosphere, controlling large-scale tropical circulations, exciting and modulating tropical waves, maintaining the intensities of tropical cyclones, and even providing the energetics of midlatitude cyclones and other midlatitude weather systems. The success of TRMM made it possible to have another major NASA precipitation measuring mission, the GPM mission. GPM is considered by NASA to be the centerpiece mission of its Global Water \& Energy Cycle research program. The CRM has been identified as being a valuable tool for GPM-algorithm developers and is considered a key component for one of the major GPM ground validation (GV) sites (GPM GV White Paper). In addition, the CRM is one of the most important tools used to establish quantitative relationships between diabatic heating and rainfall. GCE-simulated data have been used extensively in TRMM for the development of both rainfall and heating retrieval algorithms (Simpson et al., 1996; Tao et al., 2006).

Five different TRMM LH algorithms designed for application with satellite-estimated surface rain rate and precipitation profile inputs have been developed, compared, validated, and applied for over two decades (see reviews by Tao et al. (2001, 2006, in press)). They are the: (1) Goddard ConvectiveStratiform Heating (CSH) algorithm, (2) Spectral Latent Heating (SLH) algorithm, (3) Goddard Trained Radiometer (TRAIN) algorithm, (4) Hydrometeor Heating $(\mathrm{HH})$ algorithm, and (5) Precipitation Radar Heating (PRH) algorithm. The strengths and weaknesses of each algorithm are discussed in Tao et al. (2006). The TRMM-GPM joint science team has decided to 


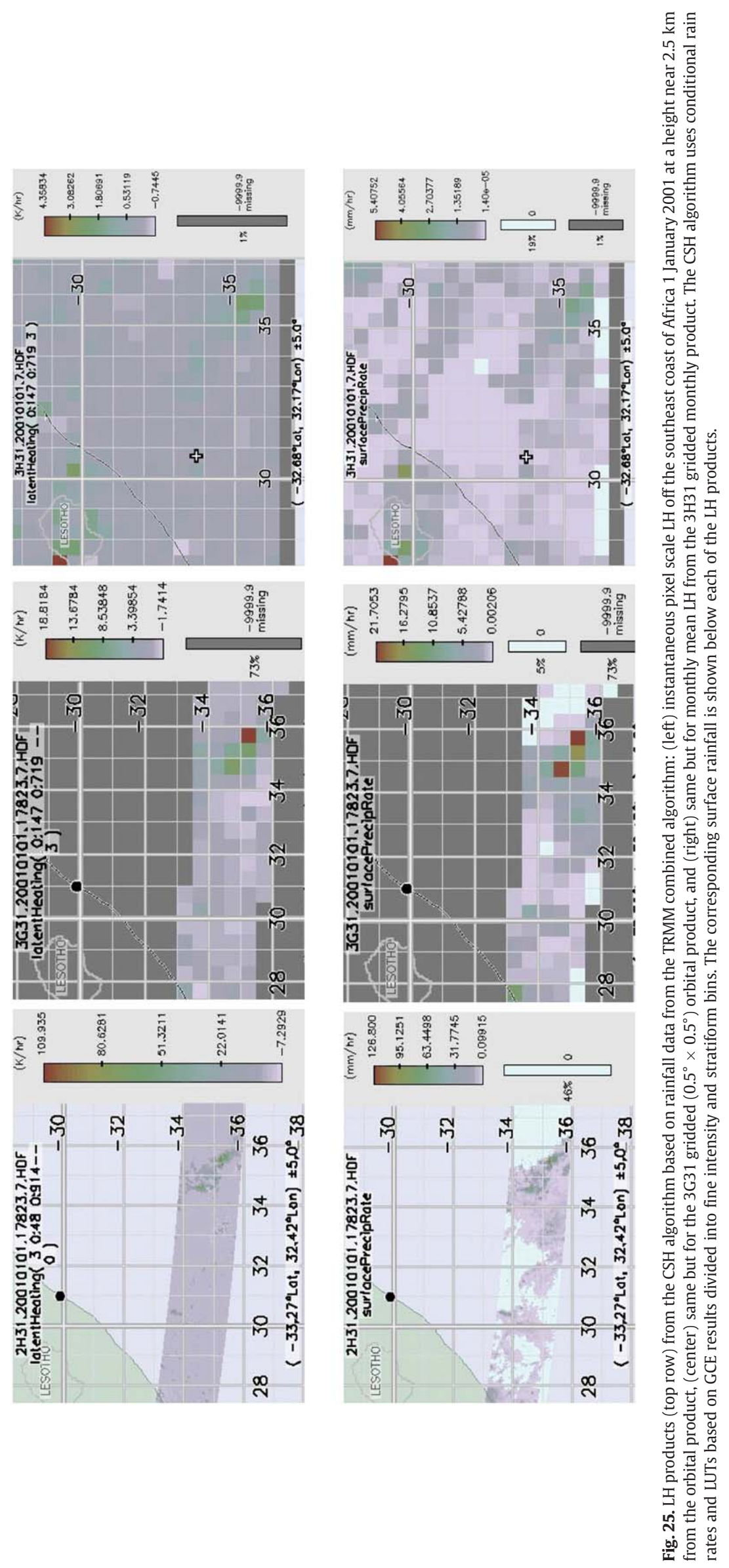



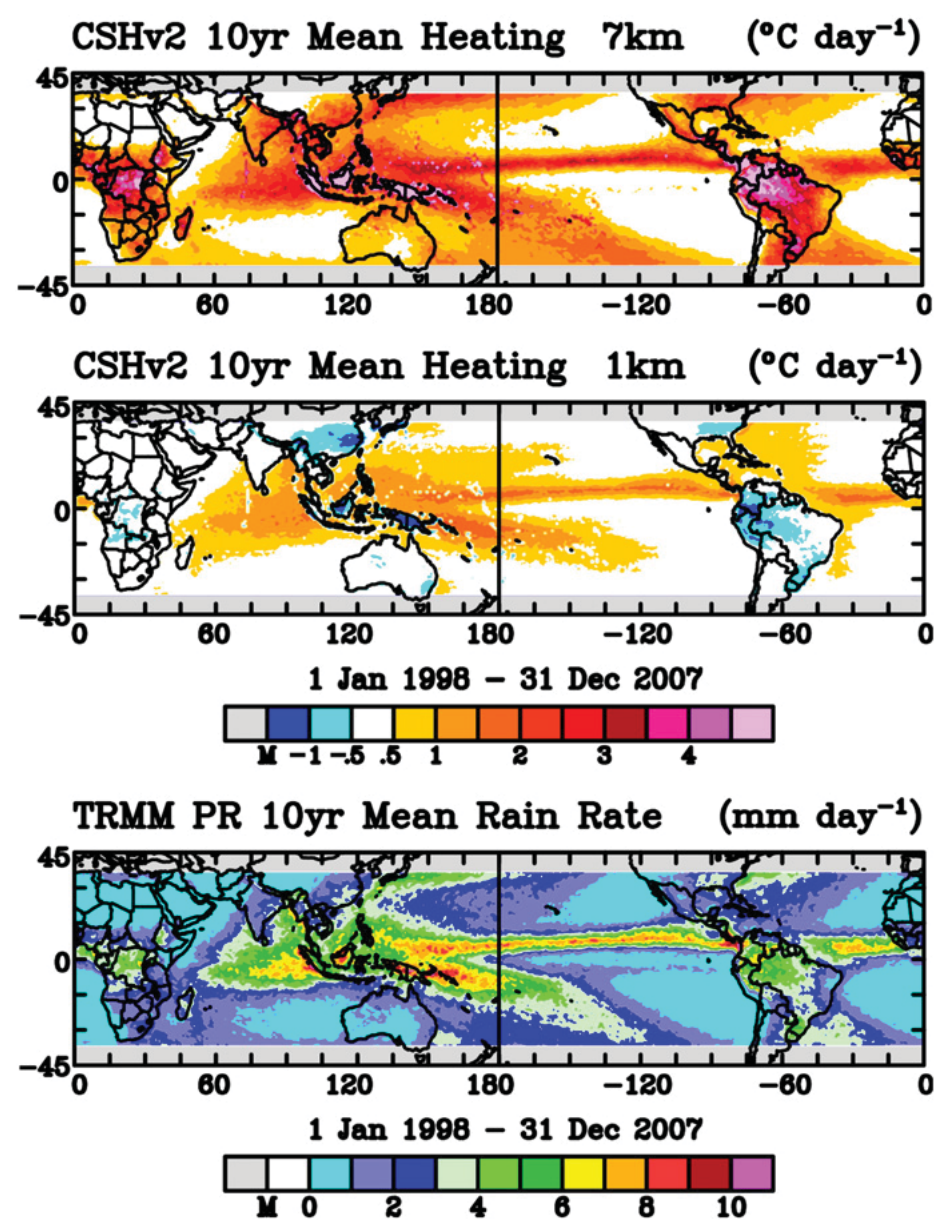

Fig. 26. Ten-year (1998-2007) mean cloud heating rates over the global tropics at 7 and $1 \mathrm{~km}$ AGL (upper 2 panels) obtained from the version 2 CSH algorithm using gridded instantaneous TRMM PR rain rates (bottom panel).

have two standard LH algorithms: the Goddard CSH algorithm and the SLH algorithm. Table 5 lists the required data and type of heating products for these two algorithms and Fig. 25 shows examples of these LH products generated from the current (version 2) CSH (CSHv2) algorithm. Note that one of the major inputs for these standard products is the improved rainfall estimate.

Fig. 26 shows the 10 -year mean $\mathrm{Q}_{1}$ at two different altitudes, 1 and $7 \mathrm{~km}$, over the global Tropics obtained from the new CSHv2 algorithm using the essentially daily gridded PR rainfall product from 3G68. As expected from the design of the $\mathrm{CSH}$ algorithm, the horizontal distribution of the estimated $\mathrm{Q}_{1}$ structure is similar to the surface rainfall pattern (lower panel in Fig. 26). For example, there are well-defined ITCZs across the Pacific, Atlantic, and eastern Indian Ocean, a well-defined South Pacific Convergence Zone (SPCZ) in the south-central Pacific Ocean as well as midlatitude storm tracks over and downwind of the continents. At the lowest levels in $\mathrm{CSH}$, oceanic rain is associated with robust heating, while cooling is prevalent for continental rainfall (Fig. 26, middle panel). At upper levels, heating is intense and stronger over continents than over oceans (Fig. 26, top panel). An interesting feature observed in Fig. 25 is the relatively weaker heating at the $1 \mathrm{~km}$ level (compared to the upper-troposphere) throughout the regions of strongest rain rate. There is a distinct land-sea contrast. Shallow heating occurs almost exclusively over ocean, apart from the Maritime Continent.

\section{Current and future research}

\subsection{Microphysics and aerosols}

The 3-ICE schemes can be deficient in situations where hail and/or high-density graupel forms. The partitioning of ice-phase particles into hail, graupel, or snow and accurately representing their densities and terminal fall speeds (especially for graupel and snow) can significantly impact convective/ stratiform partitioning and anvil formation. Therefore, a 4ICE (cloud ice, snow, graupel and hail; Lang et al., accepted for publication) scheme ${ }^{3}$ was developed for the GCE model. Three different two-moment schemes [CSU RAMS (see Section 2.1.2), Cheng et al. (2010) and Morrison et al. (2005)] have also been

\footnotetext{
${ }^{3}$ The 4ICE scheme is built upon the improvements of Lang et al. (2011), which introduced new parameterizations for rime splintering, immersion freezing, contact nucleation and a size-mapping scheme for snow and graupel. It significantly reduced the overabundance and excessive penetration of strong (e.g., $40 \mathrm{dBZ}$ ) echoes in the middle and upper troposphere. Consequently, more snow and less graupel results in hydrometeors being advected over a larger area, which enhances evaporation aloft and reduces surface rainfall.
} 


\section{Table 6}

Main characteristics of the Goddard 4ICE scheme and three two-moment schemes (RAMS, J.-P. Chen, and Morrison). The similarities and differences between these schemes are also shown. The * means that the bin microphysics is used to drive the parameterization, ${ }^{* *}$ that there is no autoconversion in RAMS. The RAMS model solves the full stochastic collection equations for self-collection among cloud droplets and for rain (drizzle) drop collection of cloud droplets. Lookup tables for collection are computed using realistic collection kernels from Long (1974) and Hall (1980) rather than constant collection efficiencies. The *** means that the CCN and GCCN in the RAMS microphysics have a binned log-normal size distribution with 200 mass bins and activate according to a solution of the Köhler equation. A bin-resolved Lagrangian parcel model is used offline to generate look up tables for computational efficiency and ${ }^{* * * *}$ means that derivation of the auto-conversion rate in Chen's model is based on results from a detailed (binned) microphysical model, which was run for many scenarios and the results analyzed statistically to get a fitting formula for the growth rates. No simplification of the kernels was applied, but some inaccuracy will result from the fitting procedure (error indicated by the R-squared values).

\begin{tabular}{|c|c|c|c|c|}
\hline & $\begin{array}{l}\text { Goddard } \\
\text { 1-moment }\end{array}$ & $\begin{array}{l}\text { RAMS* } \\
\text { 2-moment }\end{array}$ & $\begin{array}{l}\text { JP Chen**** } \\
\text { 2-moment }\end{array}$ & $\begin{array}{l}\text { Morrison } \\
\text { 2-moment }\end{array}$ \\
\hline Cloud water & Mass & $\begin{array}{l}\text { Mass and number concentration } \times 2 \\
{ }^{* *} \text { RAMS has two modes } \\
\text { (small and large) }\end{array}$ & Mass and number concentration & Mass and number concentration \\
\hline Rain & Mass & Mass and number concentration & Mass and number concentration & Mass and number concentration \\
\hline Cloud ice & Mass & $\begin{array}{l}\text { Mass and number concentration } \times 2 \\
{ }^{* *} \text { RAMS has two modes } \\
\text { (small and large) }\end{array}$ & Mass and number concentration & Mass and number concentration \\
\hline Snow aggregates & Mass & Mass and number concentration & Mass and number concentration & Mass and number concentration \\
\hline Graupel & Mass & Mass and number concentration & Mass and number concentration & Mass and number concentration \\
\hline Hail & Mass & Mass and number concentration & None & Option for graupel or hail \\
\hline $\mathrm{CCN}$ & Diagnostic & Diagnostic & $\begin{array}{l}\text { Prognostic } \\
3 \text { species: dry (multi-modes), } \\
\text { cloud, rain }\end{array}$ & Diagnostic \\
\hline GCCN & None & Diagnostic & Prognostic & Diagnostic \\
\hline IN & Diagnostic & Diagnostic & Prognostic (multi-species) & Diagnostic \\
\hline Snow density & Function of Size & Constant (function of size) & Constant & Constant \\
\hline Conversion** & $\begin{array}{l}\text { Autoconversion Kesseler } \\
\text { type or Liu and Daum } \\
\text { (2004) with aerosols }\end{array}$ & LUT-based stochastic solution & Yes & Some \\
\hline $\mathrm{CCN}$ activation & Kohler theory & $\begin{array}{l}\text { T, qv, and w via Köhler theory } \\
\text { (Saleeby and Cotton, 2004)*** }\end{array}$ & Yes $^{* * * *}$ & $\begin{array}{l}\text { Khairoutdinov and } \\
\text { Kogan (2000) or Seifert } \\
\text { and Beheng (2001) }\end{array}$ \\
\hline IN activation & $\begin{array}{l}\text { Meyers et al. (1992) } \\
\text { DeMott et al. (2010) }\end{array}$ & Meyers et al. (1992) & $\begin{array}{l}\text { Köhler theory; supersaturation } \\
\text { calculated with an embedded } \\
\text { Lagrangian parcel }\end{array}$ & $\begin{array}{l}\text { W-velocity, Abdul-Razzak } \\
\text { and Ghan (2000) }\end{array}$ \\
\hline
\end{tabular}

added to the GCE model ${ }^{4}$. Their main characteristics (including similarities and differences) are listed in Table 6.

To compare the performance of these schemes, GCE model simulations will be conducted wherein: (1) all common pre-set cloud properties and parameters (i.e., densities, intercepts, and size distributions) are identified and made identical, (2) the activation of CCN (and/or giant CCN) and IN is determined in each scheme and set as similar as possible, (3) the background aerosols set to be identical, (4) all schemes produce common cloud properties and surface rainfall datasets, and (5) the radiation is coupled explicitly and consistently with the microphysics assumptions and simulated cloud properties (size distributions and optical properties).

\subsection{GPU empowered GCE model}

Current trends in computer technology have recently moved from increasing single-core processor performance to increasing performance through multi-core and many-core (e.g., graphics processing units or GPUs) architectures. The trend toward multiand many-core systems is also being seen in high-end compute clusters. For example, the first petaflop computer, Roadrunner,

\footnotetext{
${ }^{4}$ RAMS has already been implemented into the GCE. The Morrison and JP Chen 2-moment schemes are being implemented and tested currently. In addition, the SBS scheme has been used to improve the performance of the bulk scheme (Li et al., 2010).
}

used the IBM Cell B.E. as a coprocessor in 2008 while the current No. 2 and 4 computers on the TOP500 supercomputing list also use GPUs as coprocessors.

The bin microphysics (see Section 2.1.3) requires significant computations as well as I/O (input/output, Table 7). Tests have shown that computational time is increased by a factor of 226 and I/O time by a factor of 200 as compared to the one-moment microphysics scheme. The GCE radiative transfer module calculates solar and infrared radiation via their emission, absorption and scattering in both cloudy and clear areas (Section 2.2) and also requires significant computations in Table 7. It is typically computed less frequently compared to other physical processes in CRMs and large-scale models ${ }^{5}$. Although massive parallel computing has already improved bin model and radiation performance significantly, additional technology is required to fully apply these schemes to weather and climate studies, especially those involving the effects of aerosols on weather and climate.

Since all of the radiation computations are performed independently of other grid columns, it is suitable for porting to GPUs. It is expected that the GCE's one-, two-moment, and spectral bin microphysics, and radiation should gain significant performance. The accelerated GCE will greatly broaden not only its own scientific application but those of NU-WRF

\footnotetext{
${ }^{5}$ Radiation is computed every ten time steps in WRF and $1-3 \mathrm{~h}$ in GCMs and climate models.
} 
Table 7

CPU times for 3D GCE simulations using one moment bulk and spectral bin microphysics for a TWP-ICE case on the NASA Pleiades computer. The domain size is $256 \times 256 \times 43$, the total integration time $24 \mathrm{~h}$, the time step $3 \mathrm{~s}$, and output occurs every $1 \mathrm{~h}$. Dynamics includes the advection of all variables as well as the pressure solver.

\begin{tabular}{|c|c|c|c|c|c|c|}
\hline & Total CPU hours & Total CPU number & Radiation & Microphysics & Dynamics & Output file size \\
\hline Bulk (radiation every 10 steps) & 198 & 64 & $25.1 \%$ & $10.0 \%$ & $63.9 \%$ & $7.25 \mathrm{~GB}$ \\
\hline Bulk (radiation every step) & 658 & 64 & $77.2 \%$ & $3.0 \%$ & $19.5 \%$ & \\
\hline Bin (radiation every 10 steps) & 44,697 & 1024 & $0.12 \%$ & $45.8 \%$ & $54.1 \%$ & $153.0 \mathrm{~GB}$ \\
\hline Bin (radiation every step) & 47,138 & 1024 & $1.16 \%$ & $45.8 \%$ & $53.0 \%$ & \\
\hline
\end{tabular}

and the Goddard MMF (Tao et al., 2009a) via the shared physical packages, breaking the bottle neck that currently prevents large-domain, long-term integrations. In addition, the proposed compression-enhanced synchronized output tool will be used in other output-intensive applications.

\subsection{Cloud library}

The GCE modeling group has generated and made available a multi-dimensional (space, time, multivariate, and multiple cloud/cloud system type) cloud database representing different geographic locations/climate regimes corresponding to the campaign sites mentioned above to the global modeling community to help improve the representation and performance of moist processes in climate models and to improve our understanding of cloud processes globally. Software tools needed to produce cloud statistics and to identify various types of clouds and cloud systems from both high-resolution satellite and model data will be developed jointly. This database will be available to modelers and other researchers aiming to improve the representation of cloud processes in MMFs, GCMs and climate models. The database will include updraft/downdraft mass fluxes, cloudiness, liquid and ice water contents, evaporation/condensation, long- and short-wave radiative heating/cooling profiles, and the thermodynamic (heat and water vapor) budget. These cloud properties will also be separated into deep convective, stratiform, anvil and cirrus regions. It will also be separated into active/inactive cloud regions based on the method in Tao et al. (1987). Upward and downward long-wave and shortwave radiative fluxes at the TOA, and radiative, latent and sensible heat fluxes at the surface, and surface rainfall will be produced as well.

The cloud dataset is available to the public community via ftp access from a web site created within NASA Goddard (Goddard Cloud Library, http://cloud.gsfc.nasa.gov/). This cloud dataset will be enhanced with the addition of more simulated cases over different geographic locations for different types of cloud systems during their life cycles. Currently, more than 80,000 datasets were downloaded since April 2010 by 150 distinct users.

\section{Acknowledgments}

The first author appreciates the inspiring and enthusiastic support of his mentor, Dr. Joanne Simpson, over a period of 25 years. The author is grateful to Dr. R. Kakar at NASA headquarters for his continuous support of Goddard Cumulus Ensemble model (GCE) improvements and applications. The GCE modeling is mainly supported by the NASA Precipitation
Measurement Mission (PMM). The Goddard MMF, NU-WRF, and GPU work are supported by the NASA Modeling, Analysis, and Prediction (MAP) Program and the NASA Advanced Information Systems Technology (AIST) Program. We would also like to thank one anonymous reviewer for helping to improve the quality of the manuscript.

Acknowledgment is also made to the NASA Ames Research Center and NASA Goddard Space Flight Center for computer time used in this research.

\section{References}

Abdul-Razzak, H., Ghan, S.J., 2000. A parameterization of aerosol activation. Part 2: multiple aerosol types. J. Geophys. Rev. D 105, 6837-6844. http:// dx.doi.org/10.1029/1999JD901161.

Ackerman, A.S., Toon, O.B., Stevens, D.E., Heymsfield, A.J., Ramanathan, V., Welton, E.J., 2000. Reduction of tropical cloudiness by soot. Science 288, 1042-1047.

Aires, F., Prigent, C., Bernardo, F., Jiménez, C., Saunders, R., Brunel, P., 2011. A Tool to Estimate Land-Surface Emissivities at Microwave frequencies (TELSEM) for use in numerical weather prediction. Q. J. R. Meteorol. Soc. 137, 690-699.

Alonge, C.J., Mohr, K.I., Tao, W.-K., 2007. Numerical case studies of wet vs dry regimes in the West African Sahel. J. Hydrometeorol. 8, 102-116.

Baker, R.D., Lynn, B.H., Boone, A., Tao, W.-K., 2001. The influence of soil moisture, coastline curvature, and the land-breeze circulation on seabreeze initiated precipitation. J. Hydrometeorol. 2, 193-211.

Cheng, C.-T., Wang, W.-C., Chen, J.-P., 2010. Simulation of the effects of increasing cloud condensation nuclei on mixed-phase clouds and precipitation of a front system. Atmos. Res. 96, 461-476. http://dx.doi.org/10.1016/ j.atmosres.2010.02.005.

Choi, Y.S., Lindzen, R.S., Ho, C.H., Kim, J., 2010. Space observations of cold cloud phase change. Proc. Natl. Acad. Sci. 107, 11211-11216.

Chou, M.-D., Suarez, M.J., 1999. A solar radiation parameterization for atmospheric studies. NASA Tech. Rep. NASA/TM-1999-10460, vol. 15 (38 pp.).

Chou, M.-D., Suarez, M.J., Liang, X.-Z., Yan, M.-H., 2001. A thermal infrared radiation parameterization for atmospheric studies. NASA Tech. Rep. NASA/TM-2001-104606, vol. 19 (55 pp.).

Cotton, W.R., et al., 2003. RAMS 2001: current status and future directions. Meteorol. Atmos. Phys. 82, 5-29.

DeMott, P.J., Prenni, A.J., Liu, X., Petters, M.D., Twohy, C.H., Richardson, M.S., Eidhammer, T., Kreidenweis, S.M., Rogers, D.C., 2010. Predicting global atmospheric ice nuclei distributions and their impacts on climate. Proc. Natl. Acad. Sci. 107, 11217-11222.

Ek, M.B., Holtslag, A.A.M., 2004. Influence of soil moisture on boundary layer cloud development. J. Hydrometeorol. 5, 86-99.

Fan, J., Zhang, R., Li, G., Tao, W.-K., Li, X., 2007a. Simulations of cumulus clouds using a spectral bin microphysics in a cloud resolving model. J. Geophys. Res. 112, D04201. http://dx.doi.org/10.1029/2006JD007688.

Fan, J., Zhang, R., Li, G., Tao, W.-K., 2007b. Effects of aerosols and relative humidity on cumulus clouds. J. Geophys. Res. 112, D14204. http://dx.doi.org/ 10.1029/2006JD008136.

Fletcher, N.H., 1962. The Physics of Rain Clouds. The Cambridge University Press (386 pp.).

García-Ortega, E., Merino, A., López, L., Sánchez, J.L., 2012. Role of mesoscale factors at the onset of deep convection on hailstorm days and their relation to the synoptic patterns. Atmos. Res. 114-115, 91-106.

Grabowski, W.W., Smolarkiewicz, P.K., 1999. CRCP: a cloud resolving convection parameterization for modeling the tropical convecting atmosphere. Physica D 133, 171-178. 
Gray, W.M., Jacobson, R.W., 1977. Diurnal variation of deep cumulus convection Mon. Weather Rev. 105, 1171-1188.

Guy, N., Zeng, X., Rutledge, S.A., Tao, W.-K., 2013. Comparing the convective structure and microphysics of two Sahelian mesoscale convective systems: radar observations and CRM simulations. Mon. Weather Rev. 141, 582-601.

Hall, W.D., 1980. A detailed microphysical model within a two-dimensiona dynamic framework: model description and preliminary results. J. Atmos. Sci. 37, 2486-2507

Hallet, J., Mossop, S.C., 1974. Production of secondary ice crystals during the riming process. Nature 249, 26-28. http://dx.doi.org/10.1038/249026a0.

Hansen, J., Sato, M., Ruedy, R., 1997. Radiative forcing and climate response. J. Geophys. Res. 102, 6831-6864.

Iguchi, T., Matsui, T., Shi, J.-J., Tao, W.-K., Khain, A.P., Hou, A.Y., Cifelli, A.R., Heymsfield, A., Tokay, A., 2012a. Numerical analysis using WRF-SBM for the cloud microphysical structures of the two distinct snowfall events during the C3VP field campaign. J. Geophys. Res. 117, D23206. http://dx. doi.org/10.1029/2012JD018101.

Iguchi, T., Matsui, T., Tokay, A., Kollias, P., Tao, W.-K., 2012b. Two distinct modes in one-day rainfall event during MC3E field campaign: analysis of disdrometer observations and WRF-SBM simulation. Geophys. Res. Lett. 39, L24805. http://dx.doi.org/10.1029/2012GL053329.

IPCC, 2007. Climate change 2007: the physical science basis. Contribution of Working Group I to the Fourth Assessment Report of the Intergovernmental Panel on Climate ChangeCambridge Univ. Press, Cambridge, United Kingdom and New York, NY, USA (996 pp.).

Johnson, D., Tao, W.-K., Simpson, J., 2007. A study of the response of deep tropical clouds to mesocale processes, part II: Sensitivity tests of radiation, surface fluxes and microphysics. J. Atmos. Sci. 64, 869-886.

Juang, H.M., Tao, W.-K., Zeng, X., Shie, C.-L., Simpson, J., 2007. Parallelization of a cloud-resolving model for massively parallel computing by using message passing interface. Terr. Atmos. Ocean. Sci. 18, 593-622.

Khain, A.P., Ovtchinnikov, M., Pinsky, M., Pokrovsky, A., Krugliak, H., 2000. Notes on the state-of-the-art numerical modeling of cloud microphysics. Atmos. Res. 55, 159-224. http://dx.doi.org/10.1016/S0169-8095(00)00064-8.

Khain, A.P., Pokrovsky, Pinsky, M., Seigert, A., Phillips, V., 2004. Simulation of effects of atmospheric aerosols on deep turbulent convective clouds using a spectral microphysics mixed-phase cumulus cloud model. Part I: model description and possible applications. J. Atmos. Sci. 61, 2983-3001.

Khairoutdinov, M.F., Kogan, Y.L., 2000. A new cloud physics parameterization in a large-eddy simulation model of marine stratocumulus. Mon. Wea. Rev. 128, 229-243.

Khairoutdinov, M.F., Randall, D.A., 2001. A cloud resolving model as cloud parameterization in the NCAR community climate system model: preliminary results. Geophys. Res. Lett. 28, 3617-3620.

Khairoutdinov, M.F., Randall, D.A., DeMott, C., 2005. Simulations of the atmospheric general circulation using a cloud-resolving model as a superparameterization of physical processes. J. Atmos. Sci. 62, 2136-2154

Khairoutdinov, M., DeMott, C., Randall, D.A., 2008. Evaluation of the simulated interannual and subseasonal variability in an AMIP-style simulation using the CSU multiscale modeling framework. J. Clim. 21, 413-431.

Kim, D., Kang, I.S., 2012. A bulk mass flux convection scheme for climate model: description and moisture sensitivity. Clim. Dyn. 38, 411-429.

Kraus, E.B., 1963. The diurnal precipitation change over the sea. J. Atmos. Sci. 20, 546-551.

Kumar, S.V., Peters-Lidard, C.D., Tian, Y., Geiger, J., Houser, P.R., Olden, S. Lighty, L., Eastman, J.L., Dirmeyer, P., Doty, B., Adams, J., Wood, E., Sheffield, J., 2006. LIS - an interoperable framework for high resolution land surface modeling. Environ. Model. Softw. 21, 1402-1415.

Lang, S., Tao, W.-K., Simpson, J., Ferrier, B., 2003. Modeling of convectivestratiform precipitation processes: sensitivity to partitioning methods. J Appl. Meteorol. 42, 505-527.

Lang, S., Tao, W.-K., Cifelli, R., Olson, W., Halverson, J., Rutledge, S., Simpson, J., 2007. Improving simulations of convective system from TRMM LBA: easterly and westerly regimes. J. Atmos. Sci. 64, 1141-1164.

Lang, S., Tao, W.-K., Zeng, X., Li, Y., 2011. Reducing the biases in simulated radar reflectivities from a bulk microphysics scheme: tropical convective systems. J. Atmos. Sci. 68, 2306-2320.

Lang, S., Tao, W.-K., Chern, J.-D., Wu, D., Li, X., 2014. Benefits of a 4th ice class in the simulated radar reflectivities of convective systems using a bulk microphysics scheme. J. Atmos. Sci. (accepted for publication).

Lee, M.I., Kang, I.S., Kim, J.K., Mapes, B.E., 2001. Influence of cloudradiation interaction on simulating tropical intraseasonal oscillation with an atmospheric general circulation model. J. Geophys. Res. 106 (14) 14219-14233.

Lee, M.I., Kang, I.S., Mapes, B.E., 2003. Impacts of cumulus convection parameterization on aqua-planet AGCM simulations of tropical intraseasonal variability. J. Meteorol. Soc. Jpn 81 (5), 963-992.

Lee, S.S., Penner, J.E., Saleeby, S.M., 2009. Aerosol effects on liquid-water path of thin stratocumulus clouds. J. Geophys. Res. 114, D07204. http://dx.doi. org/10.1029/2008JD010513.
Lee, M.-I., Choi, I., Tao, W.-K., Schubert, S.D., Kang, I.S., 2010. Mechanisms of diurnal precipitation over the US Great Plains: a cloud resolving model perspective. Clim. Dyn. 34, 419-437.

Li, X., Tao, W.-K., Khain, A., Simpson, J., Johnson, D.E., 2009a. Sensitivity of a cloud-resolving model to the bulk and explicit bin microphysical schemes. Part I. Comparisons. J. Atmos. Sci. 66, 3-21.

Li, X., Tao, W.-K., Khain, A., Simpson, J., Johnson, D.E., 2009b. Sensitivity of a cloud-resolving model to the bulk and explicit bin microphysical schemes. Part II: cloud microphysics and storm dynamics interactions. J. Atmos. Sci. 66, 22-40.

Li, X., Tao, W.-K., Matsui, T., Liu, C., Masunaga, H., 2010. Improving spectral bin microphysical scheme using TRMM satellite observations. Q. J. R. Meteorol. Soc. 136, 382-399.

Lin, Y.-L., Farley, R.D., Orville, H.D., 1983. Bulk parameterization of the snow field in a cloud model. J. Clim. Appl. Meteorol. 22, 1065-1092.

Lin, X., Randall, D.A., Fowler, L.D., 2000. Diurnal variability of the hydrological cycle and radiative fluxes: comparisons between observations and a GCM. J. Clim. 13, 4159-4179.

Liu, C., Moncrieff, M.W., 1998. A numerical study of the diurnal cycle of tropical oceanic convection. J. Atmos. Sci. 55, 2329-2344.

Liu, Y., Daum, P.H., 2004. Parameterization of the autoconversion process Part I: Analytical formulation of the Kessler-type parameterizations. J. Atmos. Sci. 61, 1539-1548.

Long, A.B., 1974. Solutions to the droplet collection equation for polynomial kernels. J. Atmos. Sci. 31, 1040-1052.

Lynn, B.H., Tao, W.-K., 2001. A parameterization for the triggering of landscape generated moist convection, Part II: zero order and first order closure. J. Atmos. Sci. 58, 593-607.

Lynn, B.H., Tao, W.-K., Wetzel, P., 1998. A study of landscape generated deep moist convection. Mon. Weather Rev. 126, 928-942.

Masunaga, H., Matsui, T., Tao, W.-K., Hou, A.Y., Kummerow, C., Nakajima, T., Bauer, P., Olson, W., Sekiguchi, M., Nakajima, T.Y., 2010. Satellite data simulation unit: multi-sensor and multi-frequency satellite simulator package. Bull. Am. Meteorol. Soc. 91, 1625-1632.

Matsui, T., 2013. Chapter 12 In: Pielke Sr, R.A. (Ed.), Mesoscale Modeling and Satellite Simulator, Mesoscale Meteorological Modeling, 3rd edition. Academic Press. ISBN: 9780123852373, p. 760

Matsui, T., Zeng, X., Tao, W.-K., Masunaga, H., Olson, W., Lang, S., 2009. Evaluation of long-term cloud-resolving model simulations using satellite radiance observations and multifrequency satellite simulators. J. Atmos. Ocean. Technol. 26, 1261-1274.

Matsui, T., Iguchi, T., Li, X., Han, M., Tao, W.-K., Petersen, W., L'Ecuyer, T. Meneghini, R., Olson, W., Kummerow, C.D., Hou, A.Y., Schwaller, M.R. Stocker, E.F., Kwiatkowski, J., 2013. GPM satellite simulator over ground validation sites. Bull. Am. Meteorol. Soc. 94, 1653-1660.

Matsui, T., Shi, J.-J., Wu, D., Tan, Q., Santanero, J., Kemp, E., Tao, W.-K., Chin, Mian, Peters-Lidard, C., 2014. Introducing satellite radiance-based atmospheric model evaluation using the NASA-Unified Weather Research and Forecasting model coupled with the Goddard Satellite Data Simulator Unit. J. Geophys. Res. (submitted for publication).

Merino, A., Wu, X., Gascón, E., Berthet, C., García-Ortega, E., Dessens, J., 2014 Hailstorms in southwestern France: incidence and atmospheric characterization, review article. Atmos. Res. 140-141, 61-75.

Meyers, M.P., DeMott, P.J., Cotton, W.R., 1992. New primary ice-nucleation parameterization in an explicit cloud model. J. Appl. Meteorol. 31 $708-721$.

Meyers, M.P., Walko, R.L., Harrington, J.Y., Cotton, W.R., 1997. New RAMS cloud microphysics. Part II: the two-moment scheme. Atmos. Res. 45, 3-39.

Miura, H., Tomita, H., Nasuno, T., Iga, S., Satoh, M., Matsuno, T., 2005. A climate sensitively test using a global cloud resolving model under an aqua planet condition. Geophys. Res. Lett. 32, L19717 (10.29/2005GL023672).

Mohr, K.I., Baker, R.D., Tao, W.-K., Famiglietti, J.S., 2003. The sensitivity of west African convective lines water budgets to land cover. J. Hydrometeorol. 4, 62-76.

Mohr, K.I., Tao, W.-K., Chern, J., Kumar, S.V., Peters-Lidard, C.D., 2013. The NASA-Goddard Multi-scale Modeling Framework-Land Information System: global land/atmosphere interaction with resolved convection. Environ. Model. Softw. 39, 103-115. http://dx.doi.org/10.1016/j.bbr. 2011.03.031.

Moncrieff, M.W., Liu, C., 2006. Representing convective organization in prediction models by hybrid strategy. J. Atmos. Sci. 63, 3404-3420.

Morrison, H., Curry, J.A., Shure, M.D., Zuidema, P., 2005. A new doublemoment microphysics parameterization for application in cloud and climate models. Part II: single-column modeling of arctic clouds. J. Atmos. Sci. 62, 1678-1692.

Mossop, S.C., Hallet, J., 1974. Ice crystal concentration in cumulus clouds: influence of the drop spectrum. Science 186, 632-634. http://dx.doi.org/ 10.1126/science.186.4164.632.

Nasuno, T., Tomita, H., Iga, S., Miura, H., 2008. Convectively coupled equatorial waves simulated on an aquaplanet in a global nonhydrostatic 
experiment. J. Atmos. Sci. 65, 1246-1265. http://dx.doi.org/10.1175/ 2007JAS2395.1.

Norris, P.M., Oreopoulos, L., Hou, A.Y., Tao, W.-K., Zeng, X., 2008. Representation of 3D heterogeneous cloud fields using copulas: theory for water clouds. Q. J. R. Meteorol. Soc. 134, 1843-1864.

NRC, 2001. Climate Change Science: An Analysis of Some Key Questions. 29.

Peters-Lidard, C.D., Houser, P.R., Tian, Y., Kumar, S.V., Geiger, J., Olden, S., Lighty, L., Doty, B., Dirmeyer, P., Adams, J., Mitchell, K., Wood, E.F., Sheffield, J., 2007. High performance Earth system modeling with NASA/GSFC's Land Information System. Innov. Syst. Softw. Eng. 3 (3), $157-165$.

Pielke, R.A., 2001. Influence of the spatial distribution of vegetation and soils on the prediction of cumulus convective rainfall. Rev. Geophys. 39, 151-177. http://dx.doi.org/10.1029/1999RG000072.

Ping, F., Tang, X., Luo, Z., 2013. Phase differences between rainfall and its sources in the tropical deep convective regime: a partitioning analysis based on the surface rainfall budget. Atmos. Res. 120-121, 325-333.

Pinsky, M., Khain, A.P., Shapiro, M., 2000. Stochastic effect on cloud droplet hydrodynamic interaction in a turbulent flow. Atmos. Res. 53, 131-169. http://dx.doi.org/10.1016/S0169-8095(99)00048-4.

Pinsky, M., Khain, A.P., Shapiro, M., 2001. Collision efficiency of drops in a wide range of Reynolds numbers: effects of pressure on spectrum evolution. J. Atmos. Sci. 58, 742-764.

Pruppacher, H.R., Klett, J.D., 1997. Microphysics of Clouds and Precipitation. Kluwer Academic Publishers, Dordrecht, the Netherlands.

Räisänen, P., Baker, H.W., Khairoutdinov, M.F., Li, J., Randall, D.A., 2004. Stochastic generation of subgrid-scale cloudy columns for large-scale models. Q. J. R. Meteorol. Soc. 130, 2047-2068.

Randall, D.A., Harshvardhan, Dazlich, D.A., 1991. Diurnal variability of the hydrologic cycle in a general circulation model. J. Atmos. Sci. 48, 40-62.

Randall, D.A, Khairoutdinov, M.F. Arakawa, A Grabowski, W, 2003. Breaking the cloud parameterization deadlock. Bull. Am. Meteorol. Soc. $84,1547-1564$.

Rosenfeld, D., 1999. TRMM observed first direct evidence of smoke from forest fires inhibiting rainfall. Geophys. Res. Lett. 26 (20), 3105-3108.

Rosenfeld, D., 2000. Suppression of rain and snow by urban and industrial air pollution. Science 287, 1793-1796.

Rosenfeld, D., Woodley, W.L., 2000. Convective clouds with sustained highly supercooled liquid water down to $-37^{\circ} \mathrm{C}$. Nature $405,440-442$.

Rotunno, R., Klemp, J.B., Weisman, M.L., 1988. A theory for strong, long-lived squall lines. J. Atmos. Sci. 45, 463-485.

Rutledge, S.A., Hobbs, P.V., 1984. The mesoscale and microscale structure and organization of clouds and precipitation in mid-latitude clouds. Part XII: a diagnostic modeling study of precipitation development in narrow cold frontal rainbands. J. Atmos. Sci. 41, 2949-2972.

Saleeby, S.M., Cotton, W.R., 2004. A large droplet mode and prognostic number concentration of cloud droplets in the Colorado State University Regional Atmospheric Modeling System (RAMS). Part I: module descriptions and supercell test simulations. J. Appl. Meteorol. 43, 182-195.

Saleeby, S.M., Cotton, W.R., 2008. A binned approach to cloud-droplet riming implemented in a bulk microphysics model. J. Appl. Meteorol. Climatol. 47, 694-703.

Santanello Jr., J.A., Peters-Lidard, C.D., Kummar, S.V., Alonge, C., Tao, W.-K. 2009. A modeling and observational framework for diagnosing local land-atmosphere coupling on diurnal time scales. J. Hydrometeorol. 10, 577-599.

Satoh, M., Tomita, H., Miura, H., Iga, S., Nasuno, T., 2005. Development of a global cloud resolving model - a multi-scale structure of tropical convections. J. Earth Simul. 3, 1-9.

Satoh, M., Matsuno, T., Tomita, H., Miura, H., Nasuno, T., Iga, S., 2008. Nonhydrostatic icosahedral atmospheric model (NICAM) for global cloud resolving simulations. J. Comput. Phys. 227, 3486-3514.

Seifert, A., Beheng, K.D., 2001. A double-moment parameterization for simulating autoconversion, accretion and selfcollection. Atmos. Res. 59, $265-281$

Seifert, A., Khain, A.P., Blahak, U., Beheng, K.D., 2005. Possible effects of collisional breakup on mixed-phase deep convection simulated by a spectral (bin) cloud model. J. Atmos. Sci. 62, 1917-1931.

Shen, X., Zhang, N., Li, X., 2011. Effects of large-scale forcing and ice clouds on pre-summer heavy rainfall over southern China in June 2008: a partitioning analysis based on surface rainfall budget. Atmos. Res. 101, $155-163$.

Shen, X., Huang, W., Qing, T., Huang, W., Li, X., 2014. A modified scheme that parameterizes depositional growth of ice crystal: a modeling study of pre-summer torrential rainfall case over southern China. Atmos. Res. $138,293-300$

Shi, J.J., Tao, W.-K., Matsui, T., Hou, A.Y., Lang, S., Peters-Lidard, C.D., Jackson, G., Cifelli, R., Rutledge, S., Petersen, W., 2010. Microphysical properties of the January 20-22 2007 snow events over Canada: comparison with in-situ and satellite observations. J. Appl. Meteorol. Climatol. 49, 2246-2266.
Shi, J.J., Matsui, T., Tao, W.-K., Peters-Lidard, C., Chin, M., Tan, Q., Kemp, E., 2013. The impact of aerosol on precipitation processes associated with an NAMMA mesoscale convective system, Quart. J, Royal Meteor. Soc.. http://dx.doi.org/10.1002/qj.2286 (in press).

Simpson, J., Tao, W.-K., 1993. The Goddard Cumulus Ensemble Model. Part II: applications for studying cloud and precipitating processes and for NASA TRMM. Terr. Atmos. Ocean. Sci. 4, 73-116.

Simpson, J., Adler, R.F., North, G.R., 1988. A proposed tropical rainfall measuring mission (TRMM) satellite. Bull. Am. Meteorol. Soc. 69, 278-295.

Simpson, J., Kummerow, C., Tao, W.-K., Adler, R.F., 1996. On the Tropical Rainfall Measuring Mission (TRMM). Meteorol. Atmos. Phys. 60, 19-36.

Slingo, A., Wilderspin, R.C., Brentnall, S.J., 1987. Simulation of the diurnal cycle of outgoing longwave radiation with an atmospheric GCM. Mon. Weather Rev. 115, 1451-1457.

Soong, S.-T., Ogura, Y., 1980. Response of trade wind cumuli to large-scale processes. J. Atmos. Sci. 37, 2035-2050.

Soong, S.-T., Tao, W.-K., 1980. Response of deep tropical clouds to mesoscale processes. J. Atmos. Sci. 37, 2016-2036.

Sui, C.-H., Lau, K.-M., Takayabu, Y., Short, D., 1997. Diurnal variations in tropical oceanic cumulus ensemble during TOGA COARE. J. Atmos. Sci. 54, 639-655.

Sui, C.-H., Li, X., Lau, K.-M., 1998. Radiative-convective processes in simulated diurnal variations of tropical oceanic convection. J. Atmos. Sci. 55, 2345-2359.

Tao, W.-K., 2003. Goddard Cumulus Ensemble (GCE) model: application for understanding precipitation processes. AMS Meteorological Monographs - Cloud Systems, Hurricanes and TRMM 107-138.

Tao, W.-K., 2007. Cloud resolving modeling. J. Meteorol. Soc. Jpn 85, 305-330 (Special Issue of 125th Anniversary of Japan Meteorology Society).

Tao, W.-K., Moncrieff, M.W., 2009. Multi-scale cloud-system modeling. Rev. Geophys. 47, RG4002. http://dx.doi.org/10.1029/2008RG000276.

Tao, W.-K., Simpson, J., 1984. Cloud interactions and merging: numerical simulations. J. Atmos. Sci. 41, 2901-2917.

Tao, W.-K., Simpson, J., 1989. Modeling study of a tropical squall-type convective line. J. Atmos. Sci. 46, 177-202.

Tao, W.-K., Simpson, J., 1993. The Goddard Cumulus Ensemble Model. Part I: model description. Terr. Atmos. Ocean. Sci. 4, 35-72.

Tao, W.-K., Soong, S.-T., 1986. A study of the response of deep tropical clouds to mesoscale processes: three-dimensional numerical experiments. J. Atmos. Sci. 43, 2653-2676.

Tao, W.-K., Simpson, J., Soong, S.-T., 1987. Statistical properties of a cloud ensemble: a numerical study. J. Atmos. Sci. 44, 3175-3187.

Tao, W.-K., Simpson, J., Soong, S.-T., 1991. Numerical simulation of a subtropical squall line over Taiwan Strait. Mon. Weather Rev. 119, 2699-2723.

Tao, W.-K., Simpson, J., Sui, C.-H., Ferrier, B., Lang, S., Scala, J., Chou, M.-D. Pickering, K., 1993. Heating, moisture and water budgets of tropical and mid-latitude squall lines: comparisons and sensitivity to longwave radiation. J. Atmos. Sci. 50, 673-690.

Tao, W.-K., Lang, S., Simpson, J., Sui, C.-H., Ferrier, B., Chou, M.-D., 1996. Mechanisms of cloud-radiation interaction in the tropics and midlatitudes. J. Atmos. Sci. 53, 2624-2651.

Tao, W.-K., Lang, S., Olson, W., Meneghini, R., Yang, Y., Simpson, J., Kummerow, C., Smith, E., Halverson, J., 2001. Retrieved vertical profiles of latent heat release using TRMM rainfall products for February 1998. J. Appl. Meteorol. 40, 957-982.

Tao, W.-K., Simpson, J., Baker, D., Braun, S., Chou, M.-D., Ferrier, B., Johnson, D., Khain, A.P., Lang, S., Lynn, B., Shie, C.-L., Starr, D., Sui, C.-H., Wang, Y., Wetzel, P., 2003a. Microphysics, radiation and surface processes in the Goddard Cumulus Ensemble (GCE) model. A Special Issue on Nonhydrostatic Mesoscale Modeling Meteorol. Atmos. Phys. 82, 97-137.

Tao, W.-K., Shie, C.-L., Johnson, R., Braun, S., Simpson, J., Ciesielski, P.E., 2003b. Convective systems over South China Sea: cloud-resolving model simulations. J. Atmos. Sci. 60, 2929-2956.

Tao, W.-K., Johnson, D., Shie, C.-L., Simpson, J., 2004. Atmospheric energy budget and large-scale precipitation efficiency of convective systems during TOGA COARE, GATE, SCSMEX and ARM: cloud-resolving model simulations. J. Atmos. Sci. 61, 2405-2423.

Tao, W.-K., Smith, E.A., Adler, R.F., Haddad, Z.S., Hou, A.Y., Iguchi, T., Kakar, R., Krishnamurti, T.N., Kummerow, C.D., Lang, S., Meneghini, R., Nakamura, K., Nakazawa, T., Okamoto, K., Olson, W.S., Satoh, S., Shige, S., Simpson, J., Takayabu, Y., Tripoli, G.J., Yang, S., 2006. Retrieval of latent heating from TRMM measurements. Bull. Am. Meteorol. Soc. 87, 1555-1572.

Tao, W.-K., Li, X., Khain, A., Matsui, T., Lang, S., Simpson, J., 2007. The role of atmospheric aerosol concentration on deep convective precipitation: cloud-resolving model simulations. J. Geophys. Res. 112, D24S18. http:// dx.doi.org/10.1029/2007JD008728.

Tao, W.-K., Chern, J., Atlas, R., Randall, D.A., Lin, X., Khairoutdinov, M., Li, J.-L., Waliser, D.E., Hou, A.Y., Peters-Lidard, C.D., Lau, K.-M., Simpson, J., 2009a. Multi-scale modeling system: development, applications and critical issues. Bull. Am. Meteorol. Soc. 90, 515-534. 
Tao, W.-K., Anderson, D., Chern, J., Estin, J., Hou, A.Y., Houser, P., Kakar, R., Lang, S., Lau, K.-M., Peters-Lidard, C.D., Li, X., Matsui, T., Rienecker, M., Schoeberl, M., Shen, B.-W., Shi, J.-J., Zeng, X., 2009b. The Goddard multiscale modeling system with unified physics. Ann. Geophys. 27, 3055-3064.

Tao, W.-K., Lang, S., Zeng, X., Shige, S., Takayabu, Y., 2010. Relating convective and stratiform rain to latent heating. J. Clim. 23, 1874-1893.

Tao, W.-K., Shi, J.-J., Chen, S.S., Lang, S., Lin, P.-L., Hong, S.-Y., Perters-Lidard, C., Hou, A.Y., 2011a. The impact of microphysical schemes on hurricane intensity and track. Special Issue on MCSs and High-Impact Weather/Climate in East Asia, Asia-Pacific Journal of Atmospheric Sciences (APJAS), 47 1-16.

Tao, W.-K., Shi, J.-J., Lin, P.-L., Chen, J., Lang, S., Chang, M.-Y., Yang, M.-J., Wu, C.-C., Peters-Lidard, C.D., Sui, C.-H., Jou, B.J.-D., 2011b. High resolution numerical simulation of the extreme rainfall associated with Typhoon Morakot: Part I: impact of microphysics and PBL. Special Issue on Typhoon Morakot Terr. Atmos. Ocean. Sci. 22, 673-696. http://dx.doi. org/10.3319/TAO2011.08.26.01.

Tao, W.-K., Chen, J.-P., Li, Z.-Q., Wang, C., Zhang, C.-D., 2012. The impact of aerosol on convective cloud and precipitation. Rev. Geophys. 50, RG2001. http://dx.doi.org/10.1029/2011RG000369.

Tao, W.-K., Wu, D., Matsui, T., Lang, S., Peters-Lidard, C.D., Hou, A.Y Rienecker, M., Petersen, W., Jensen, M., 2013. The diurnal variation of precipitation: a numerical modeling study. J. Geophys. Res. 118, 7199-7218. http://dx.doi.org/10.1002/jgrd.50410.

Tao, W.-K., Takayabu, Y., Lang, S., Olson, W., Shige, S., Hou, A.Y., Jiang, X., Lau, K.-M., Krishnamurti, T., Waliser, D., Zhang, C., Johnson, R., Houze, R. Ciesielski, P., Grecu, M., Hagos, S., Kakar, R., Nakamura, N., Braun, S., Bhardwaj, A., 2014. TRMM latent heating retrieval and comparison with field campaigns and large-scale analyses. AMS Meteorologica Monographs - Multi-scale Convection-coupled Systems in the Tropics (in press).

Tiedtke, M., 1984. The effect of penetrative cumulus convection on the largescale flow in a general circulation model. Beitr. Phys. Atmos. 57, 216-239.

Tomita, H., Miura, H., Iga, H., Nasuno, T., Satoh, M., 2005. A global cloudresolving simulation: preliminary results from an aqua planet experiment. Geophys. Res. Lett. 32, L08805. http://dx.doi.org/10.1029/2005GL022459.

Twomey, S.A., 1977. The influence of pollution on the shortwave albedo of clouds. J. Atmos. Sci. 34, 1149-1152.

Twomey, S.A., Piepgrass, M., Wolfe, T.L., 1984. An assessment of the impact of pollution on global cloud albedo. Tellus 36B, 356-366.
Vali, G., 1994. Freezing rate due to heterogeneous nucleation. J. Atmos. Sci. $51,1843-1856$

Van Weverberg, K., van Lipzig, N.P.M., Delobbe, L., 2011. Evaluation of moist processes during intense precipitation in km-scale NWP models using remote sensing and in-situ data: impact of microphysics size distribution assumptions. Atmos. Res. 99, 15-38.

Vich, M., Romero, R., Brooks, H.E., 2011. Ensemble prediction of Mediterranean high-impact events using potential vorticity perturbations. Part I: comparison against the multiphysics approach. Atmos. Res. 102, 227-241.

Vonnegut, B., 1950. Experiments with silver iodide smokes in the natural atmosphere. Bull. Am. Meteorol. Soc. 31, 151-157.

Weng, F., Yan, B., Grody, N.C., 2001. A microwave land emissivity model. J. Geophys. Res. 106 (D17), 20,115-20,123.

Wetzel, P.J., Boone, A., 1995. A parameterization for land-atmosphere-cloud exchange (PLACE): documentation and testing of a detailed process model of the partly cloudy boundary layer over heterogeneous land. J. Clim. 8, 1810-1837.

Xu, K.-M., Randall, D.A., 1995. Impact of interactive radiative transfer on the macroscopic behavior of cumulus ensembles. Part I: radiation parameterization and sensitivity tests. J. Atmos. Sci. 52, 785-799.

Zeng, X., Tao, W.-K., Zhang, M., Lang, S., Peters-Lidard, C.D., Simpson, J., Xie, S., Kumar, S., Geiger, J.V., Shie, C.-L., Eastman, J.L., 2007. Evaluation of longterm cloud-resolving modeling with obserational cloud data. J. Atmos. Sci. 64, 4153-4177.

Zeng, X., Tao, W.-K., Lang, S., Hou, A.Y., Zhang, M., Simpson, J., 2008. On the sensitivity of atmospheric ensembles to cloud microphysics in longterm cloud-resolving model simulations. J. Meteorol. Soc. Jpn 86A, 45-65.

Zeng, X., Tao, W.-K., Zhang, M., Hou, A.Y., Xie, S., Lang, S., Li, X., Starr, D., Li, X. 2009a. A contribution by ice nuclei to global warming. Q. J. R. Meteorol. Soc. $135,1614-1629$.

Zeng, X., Tao, W.-K., Zhang, M., Hou, A.Y., Xie, S., Lang, S., Li, X., Starr, D., Li, X., Simpson, J., 2009b. An indirect effect of ice nuclei on atmospheric radiation. J. Atmos. Sci. 66, 41-61.

Zeng, X., Tao, W.-K., Matsui, T., Xie, S., Lang, S., Zhang, M., Starr, D., Li, X., 2011. Estimating the ice crystal enhancement factor in the tropics. J. Atmos. Sci. 68, 1424-1434.

Zeng, X., Tao, W.-K., Powell, S., Houze Jr., R.A., Ciesielski, P., Guy, N., Pierce, H., Matsui, T., 2013. A comparison of the water budgets between clouds from AMMA and TWP-ICE. J. Atmos. Sci. 70, 487-503. 